UNIVERSIDADE DE SÃO PAULO

INSTITUTO DE ASTRONOMIA, GEOFÍSICA E CIÊNCIAS ATMOSFÉRICAS DEPARTAMENTO DE CIÊNCIAS ATMOSFÉRICAS

\title{
AVALIAÇÃO DO DESEMPENHO DO MODELO BRAMS PARA A PENÍNSULA ANTÁRTICA
}

TATIANE REIS MARTINS

DISSERTAÇÃO DE MESTRADO
ORIENTADOR: PROF. DR. ADILSON WAGNER GANDU

São Paulo

2012 
TATIANE REIS MARTINS

Avaliação do Desempenho do modelo BRAMS para a Península Antártica

Dissertação apresentada ao Instituto de Astronomia, Geofísica e Ciências Atmosféricas da Universidade de São Paulo para obtenção do título de Mestre em Ciências.

Área de concentração: Meteorologia.

Orientador: Prof. Dr. Adilson Wagner Gandu.

São Paulo

2012 


\section{AGRADECIMENTOS}

Ao meu orientador, Adilson W. Gandu, pela oportunidade de trabalho, confiança e, principalmente, paciência.

Aos meus pais Luis e Carla pelo apoio familiar que nunca me faltou.

Aos meus colegas e amigos de laboratório, Camila Carpenedo, Nathalie Boiaski e Fabio Ullman pela amizade e ajuda em muitas etapas de desenvolvimento do trabalho. Ao Bruno Biazeto e ao Demerval Moreira, tanto na disponibilização de dados quanto no auxílio com programação.

Aos amigos pelo companheirismo em todos os momentos.

À Coordenação de Aperfeiçoamento de Pessoal de Nível Superior - CAPES pelo apoio financeiro do projeto e pela bolsa. 
"Não deixe que a saudade sufoque, que a rotina acomode, que o medo impeça de tentar. Desconfie do destino e acredite em você. Gaste mais horas realizando que sonhando, fazendo que planejando, vivendo que esperando, porque, embora quem quase morre esteja vivo, quem quase vive já morreu." 


\section{RESUMO}

\section{MARTINS, T. R. Avaliação do desempenho do modelo BRAMS para a Península}

Antártica. 2012. 99f. Dissertação (Mestrado em Meteorologia) - Instituto de Astronomia, Geofísica e Ciências Atmosféricas, Universidade de São Paulo, São Paulo, 2012.

A Península Antártica (PA) é uma das regiões no planeta que apresentam as mais adversas condições do tempo devido à constante passagem de ciclones. $O$ conhecimento das condições meteorológicas futuras é fundamental para o desenvolvimento de atividades operacionais e de pesquisa na região. Nos últimos anos a implantação e melhoramento dos modelos numéricos, que tem como foco a previsão do tempo na Antártica, têm sido alvo de diversos estudos pela comunidade acadêmica. $O$ objetivo principal deste trabalho foi avaliar o desempenho do modelo BRAMS na simulação de parâmetros meteorológicos durante a passagem de ciclones na Península Antártica. Diversas simulações, que envolveram diferentes configurações estruturais e físicas do modelo foram realizadas para dois casos de passagem de ciclones na PA, um que ocorreu em fevereiro e outro em julho de 2009. A avaliação do desempenho do modelo BRAMS foi feita através de duas análises, uma qualitativa, analisado o comportamento de cada variável simulada pelo modelo em comparação com os dados de estações meteorológicas, e a outra uma análise de sensibilidade baseada em índices estatísticos. O desempenho do modelo BRAMS se mostrou altamente dependente das condições iniciais adotadas. A pressão ao nível médio do mar foi a variável melhor representada, mas o modelo não conseguiu prever adequadamente os aumentos de pressão que ocorrem após a passagem do ciclone pela PA, o que ficou evidente no evento de julho. Por outro lado, o BRAMS se mostrou ineficiente em representar as variações de temperatura que ocorrem durante o período de simulação, principalmente no evento de fevereiro. As temperaturas simuladas pelo BRAMS foram mais elevadas que aquelas observadas nas estações meteorológicas para os dois casos (fevereiro e julho). Além disso, o modelo não conseguiu prever as quedas abruptas de temperatura, observadas durante o avanço do ciclone no mês de julho, devido em grande parte à ausência de gelo marinho nas regiões onde, de fato, as observações mostravam que 
ele estava presente. O modelo BRAMS, de forma geral, não obteve bom desempenho na simulação do vento, principalmente em relação às variações de direção. O modelo capta as principais variações da componente zonal do vento no caso de verão, porém em algumas estações, quando o escoamento tornou-se meridional, o BRAMS simulou um vento de leste, demonstrando uma forte dependência das condições iniciais. Já no caso de inverno, após o ciclone cruzar a $\mathrm{PA}$, os experimentos simulam um vento de oeste que não condiz com o observado nas estações meteorológicas. Já em se tratando do vento meridional notou-se que o BRAMS intensifica os fluxos de sul, principalmente após a passagem do ciclone pela PA.

Palavras-chave: Antártica, modelo BRAMS, ciclones extratropicais. 


\section{ABSTRACT}

\section{MARTINS, T. R. Performance evaluation of BRAMS model for the Antarctic}

Peninsula. São Paulo: Institute of Astronomy, Geophysics and Atmospheric Sciences, University of São Paulo, 2012, 99p. Master Dissertation in Meteorology.

The Antarctic Peninsula is one of the regions of the earth, which have the most adverse weather conditions due to the constant movement of cyclones. The knowledge of future meteorological conditions is essential for the operational activities and research developments on the region. In the last years, implantation and improvement of the numeric models, which focus is the weather forecasting on Antarctic, has been the subject of several studies of academic community. The main objective of this study is evaluating the model BRAMS performance, on the simulation of meteorological parameters in events of cyclones on Antarctic Peninsula. Several simulations with different structural and physics configurations on the model were performed in two events of cyclones on AP. One of them occurred in February e the other one in July of 2009. The evaluation of BRAMS model was performed by means of two analyses. The first analysis was qualitative, which analyzed the behavior of each variable simulated by the model in compared to weather stations data. The second analysis was related with the sensibility based on statistical indexes. The BRAMS model performance seems to be dependent on the initial conditions. The pressure at mean sea level was a well represented variable, however the model did not forecasted properly the pressure increase, which occurred after the cyclone event on the AP and it was more evident on event of July. Otherwise, the BRAMS seems to be inefficient for variations on temperatures during the simulation period, especially on February event. Temperatures simulated by BRAMS were higher than that observed on weather station for both cases (February and July). Furthermore, the model did not predicted the abrupt decrease in temperature, observed during the cyclone in July, due to the absence of ice sea in regions where, in fact, the observations showed that he was present. In general, the BRAMS model did not achieved good performance simulating winds, especially on changes of direction. The model captures the major variations of zonal wind during summer, however, in some stations, when the flow direction was changed to meridional, the BRAMS simulated an easterly wind, showing a strong dependence on 
initial conditions. During winter events, after the cyclone cross the AP, the experiments simulated a west wind, which is not consistent with that observed at meteorological stations. In the case of meridional wind, BRAMS intensified the south flows, especially after the cyclone on AP.

Keywords: Antarctica, BRAMS model, extratropical cyclones, 


\section{SUMÁRIO}

1 INTRODUÇÃO ............................................................1

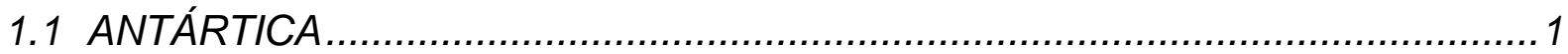

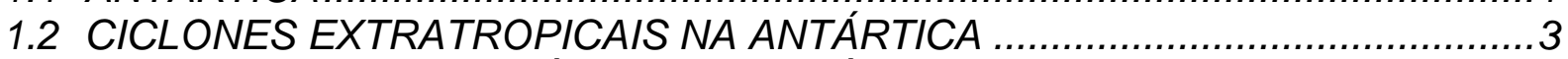

1.3 MODELAGEM ATMOSFÉRICA NA ANTÁRTICA .....................................

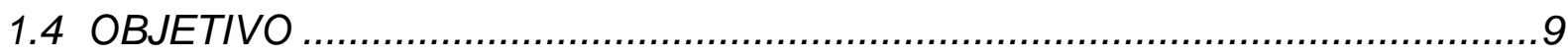

2 MATERIAL E MÉTODOS..............................................10

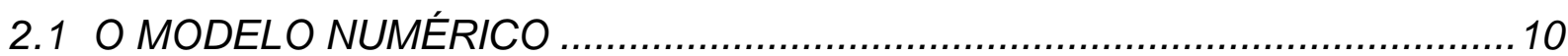

2.2 A CONFIGURAÇÃO DAS SIMULAÇÕES ............................................... 11

2.3 DADOS E ESTAÇÕES METEOROLÓGICAS ........................................ 15

2.4 AVALIAÇÃO DO DESEMPENHO DO MODELO ....................................... 16

3 RESULTADOS E DISCUSSÕES .....................................19

3.1 ANÁLISE SINÓTICA DOS EVENTOS CICLÔNICOS ................................... 19

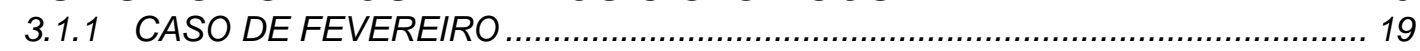

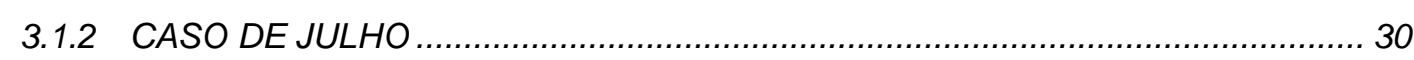

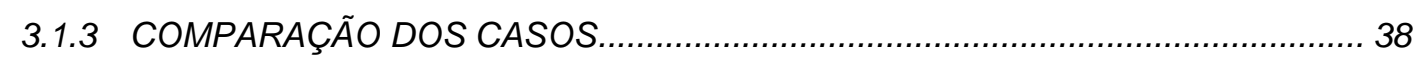

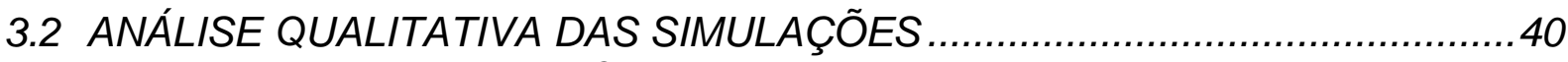

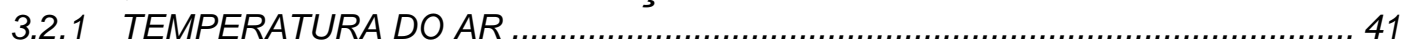

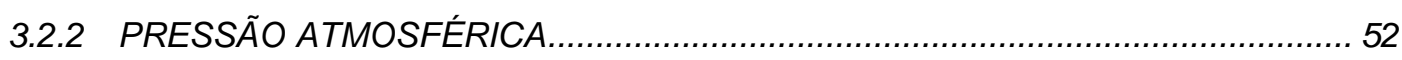

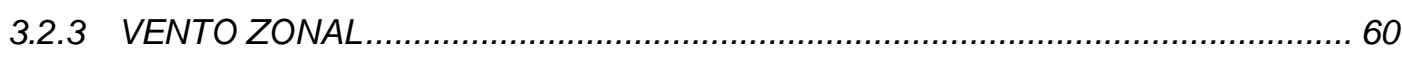

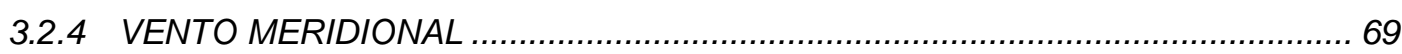

3.3 ANÁLISE DE SENSIBILIDADE DAS SIMULAÇÕES ................................. 77

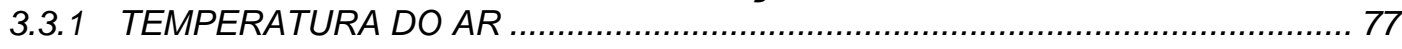

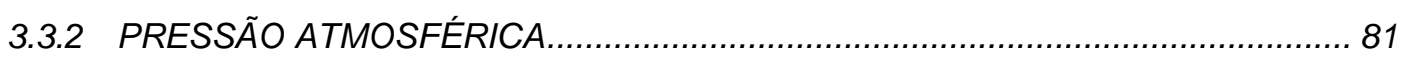

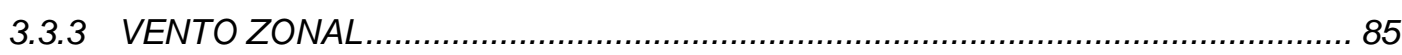

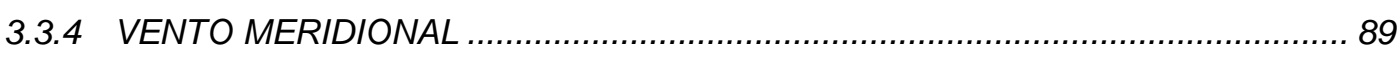

4 CONCLUSÕES E SUGESTÕES.......................................93

5 REFERÊNCIAS BIBLIOGRÁFICAS ..............................96 


\section{LISTA DE FIGURAS}

Figura 1.1-1: Localização geográfica da Antártica e seus principais mares (modificado de Cavalieri e Parkinson, 2008).

Figura 1.1-2: Esquema conceitual do escoamento de ar sobre a Antártica. (a) A convergência em altos níveis entra em equilíbrio com a superfície através da subsidência sobre o platô Antártico. (b) A consequente divergência em superfície gera os ventos catabáticos, que adquirem forte componente de leste próximo à costa devido à forçante de Corilis. (Fonte: King \& Turner, 1997)

Figura 1.2-1: Classificação de Streten e Troup para categorias de ciclones extratropicais. (Fonte: King \&Turner, 1997)

Figura 2.2-1: Domínio das grades simuladas (Fonte: modificado de Carvalho et al., 2008) 13

Figura 2.3-1: Localização das estações meteorológicas na PA utilizadas neste estudo; 15

Figura 3.1-1: (a) Pressão ao nível médio do mar (hPa); (b) temperatura potencial (sombreado, em K) e geopotencial (linha contínua, em m) em 500 hPa; (c) advecção de temperatura (sombreado, em Kdia ${ }^{-1}$ ) e geopotencial (linha contínua, em m) em $850 \mathrm{hPa}$; (d) advecção de vorticidade relativa (sombreado, em $10^{-8} \mathrm{~s}^{-1}$ ) e geopotencial (linha contínua, em m) em 500hPa; (e) magnitude do vento horizontal (sombreado, em ms- ${ }^{1}$ ) e geopotencial (linha contínua, em m) em 250 hPa, todas para o dia 15 de fevereiro de 2009 as 00 UTC; (f) imagem do satélite GOES-10, no canal infravermelho, do dia 14 de fevereiro as 23:45 UTC

Figura 3.1-2: De (a) a (e) idem à figura 3.1-1, porém para o dia 16 de fevereiro de 2009 as 00 UTC; (f) imagem do satélite GOES-10, no canal infravermelho, do dia 15 de fevereiro as 23:45 UTC 23

Figura 3.1-3: De (a) a (e) idem à figura 3.1-1, porém para o dia 17 de fevereiro de 2009 as 00 UTC; (f) imagem do satélite GOES-10, no canal infravermelho, do dia 17 de fevereiro as 02:45 UTC

Figura 3.1-4: De (a) a (e) idem à figura 3.1-1, porém para o dia 18 de fevereiro de 2009 as 00 UTC; (f) imagem do satélite GOES-10, no canal infravermelho, do dia 17 de fevereiro as 20:45 UTC 28

Figura 3.1-5: De (a) a (e) idem à figura 3.1-1, porém para o dia 10 por de julho de 
2009 as 00 UTC; (f) imagem do satélite GOES-10, no canal infravermelho, do dia 10 de julho as 23:45 UTC

Figura 3.1-6: De (a) a (e) idem à figura 3.1-1, porém para o dia 11 de julho de 2009 as 00 UTC; (f) imagem do satélite GOES-10, no canal infravermelho, do dia 10 de julho as 23:45 UTC.

Figura 3.1-7 De (a) a (e) idem à figura 3.1-1, porém para o dia 12 de julho de 2009 as 00 UTC; (f) imagem de satélite do canal infravermelho do dia 11 de julho as 23:45 UTC 36

Figura 3.1-9: Observação da temperatura e pressão na EACF. As linhas cheias representam a temperatura do $\operatorname{ar}\left({ }^{\circ} \mathrm{C}\right)$ e as linhas tracejadas a pressão ao nível médio do mar ( $\mathrm{hPa}$ ), para os casos de fevereiro (laranja) e julho (azul) de 2009. A hora "zero" no gráfico representa o horário de 00 UTC do dia 15 no caso de fevereiro e 00 UTC do dia 09 no caso de julho de 2009 38

Figura 3.1-10: Temperatura do ar a 2 metros $\left[{ }^{\circ} \mathrm{C}\right]$ em sombreado e Linhas de corrente em $925 \mathrm{hPa}$, nos dias e horários indicados na figura. 39

Figura 3.2-1: Série temporal da temperatura do ar para a EACF no evento de fevereiro 42

Figura 3.2-2: Série temporal da temperatura do ar para a estação Jubany no evento de fevereiro 43

Figura 3.2-3: Série temporal da temperatura do ar para a estação Marambio no evento de fevereiro. 44

Figura 3.2-4: Série temporal da temperatura do ar para a estação Pratt no evento de fevereiro 45

Figura 3.2-5: Série temporal da temperatura do ar para a estação Frei no evento de fevereiro 46

Figura 3.2-6: Série temporal da temperatura do ar para a estação O'higgins no evento de fevereiro. 47

Figura 3.2-7: Série temporal da temperatura do ar para EACF no evento de julho... 48 Figura 3.2-8: Série temporal da temperatura do ar para Jubany no evento de julho. 49 Figura 3.2-9: Série temporal da temperatura do ar para Marambio no evento de julho

Figura 3.2-10: Cobertura de gelo no modelo BRAMS durante o mês de julho de 2009; a) apenas gelo continental e plataformas de gelo; b) gelo continental, plataformas de gelo e gelo marinho (experimento GEL) 
Figura 3.2-11: Extensão de gelo marinho para o mês de julho de 2009. (Fonte: National Snow and Ice Center). 52

Figura 3.2-12: Série temporal da pressão ao nível médio do mar para Jubany no evento de fevereiro. 53

Figura 3.2-13: Série temporal da pressão ao nível médio do mar para Marambio no evento de fevereiro 54

Figura 3.2-14: Série temporal da pressão ao nível médio do mar para Pratt no evento de fevereiro .55

Figura 3.2-15: Série temporal da pressão ao nível médio do mar para Frei no evento de fevereiro 56

Figura 3.2-16: Série temporal da pressão ao nível médio do mar para O’higgins no evento de fevereiro 56

Figura 3.2-17: Série temporal da pressão ao nível médio do mar para EACF no evento de julho 58

Figura 3.2-18: Série temporal da pressão ao nível médio do mar para Jubany no evento de julho 58

Figura 3.2-19: Série temporal da pressão ao nível médio do mar para Marambio no evento de julho. 59

Figura 3.2-20: Vorticidade em $850 \mathrm{hPa}\left(10^{-5} \mathrm{~s}^{-1}\right)$ em sombreado; pressão ao nível médio do mar $(\mathrm{hPa})$ nas linhas pretas cheias e temperatura a 2 metros $\left({ }^{\circ} \mathrm{C}\right)$ nas linhas tracejadas rosa às 22 UTC do dia 11 de julho de 2009 para o experimento CTR 60

Figura 3.2-21: Série temporal da componente zonal do vento para a EACF no evento de fevereiro 61

Figura 3.2-22: Série temporal da componente zonal do vento para Jubany no evento de fevereiro 62

Figura 3.2-23: Série temporal da componente zonal do vento para Marambio no evento de fevereiro 63

Figura 3.2-24: Série temporal da componente zonal do vento para Pratt no evento de fevereiro 64

Figura 3.2-25: Série temporal da componente zonal do vento para Frei no evento de fevereiro .65

Figura 3.2-26: Série temporal da componente zonal do vento para O'higgins no evento de fevereiro. 
Figura 3.2-27: Série temporal da componente zonal do vento para EACF no evento de julho.

Figura 3.2-28: Série temporal da componente zonal do vento para Jubany no evento de julho. 68

Figura 3.2-29: Série temporal da componente zonal do vento para Marambio no evento de julho..... 69

Figura 3.2-30: Série temporal da componente meridional do vento para EACF no evento de fevereiro. .70

Figura 3.2-31: Série temporal da componente meridional para Jubany no evento de fevereiro 71

Figura 3.2-32: Série temporal da componente meridional para Marambio no evento de fevereiro 72

Figura 3.2-33: Série temporal da componente meridional para Pratt no evento de fevereiro .72

Figura 3.2-34: Série temporal da componente meridional para Frei no evento de fevereiro .73

Figura 3.2-35: Série temporal da componente meridional para O'higgins no evento de fevereiro 74

Figura 3.2-36: Série temporal da componente meridional do vento para EACF no evento de julho 75 Figura 3.2-37: Série temporal da componente meridional do vento para Jubany no evento de julho..... 76

Figura 3.2-38: Série temporal da componente meridional do vento para Marambio no evento de julho 76 


\section{LISTA DE TABELAS}

Tabela 1.2-1: Classificação de Streten e Troup (1973) para categorias de vórtices ...5 Tabela 2.2-1: Características dos Experimentos Numéricos ...................................14

Tabela 2.3-1: Estações Meteorológicas utilizadas ….............................................15

Tabela 3.3-1: Análise de skill para a temperatura do ar para a EACF. .....................78

Tabela 3.3-2: Análise de skill para a temperatura do ar para Jubany .......................78

Tabela 3.3-3: Análise de skill para a temperatura do ar para Marambio .................... 79

Tabela 3.3-4: Análise de skill para a temperatura do ar para Pratt ........................... 80

Tabela 3.3-5: Análise de skill para a temperatura do ar para Frei............................. 80

Tabela 3.3-6: Análise de skill para a temperatura do ar para O'higgins ..................... 80

Tabela 3.3-7: Análise de skill para a pressão ao nível médio do mar para EACF.....81

Tabela 3.3-8: Análise de skill para a pressão ao nível médio do mar para Jubany... 82 Tabela 3.3-9: Análise de skill para a pressão ao nível médio do mar para

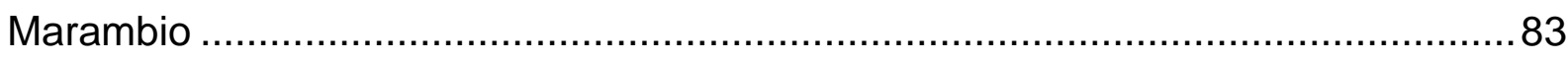

Tabela 3.3-10: Análise de skill para a pressão ao nível médio do mar Pratt.............. 84

Tabela 3.3-11: Análise de skill para a pressão ao nível médio do mar para Frei ......84 Tabela 3.3-12: Análise de skill para a pressão ao nível médio do mar para

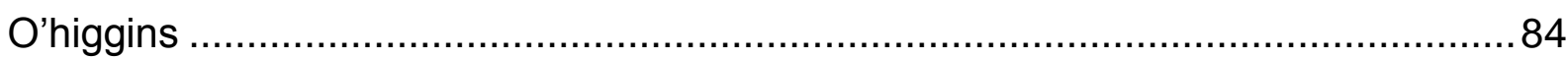

Tabela 3.3-13: Análise de skill para a componente zonal do vento para EACF .........85

Tabela 3.3-14: Análise de skill para a componente zonal do vento para Jubany .......86

Tabela 3.3-15: de skill para a componente zonal do vento para Marambio ...............86

Tabela 3.3-16: Análise de skill para a componente zonal do vento para Pratt..........87

Tabela 3.3-17: Análise de skill para a componente zonal do vento para Frei ............88

Tabela 3.3-18: Análise de skill para a componente zonal do vento para

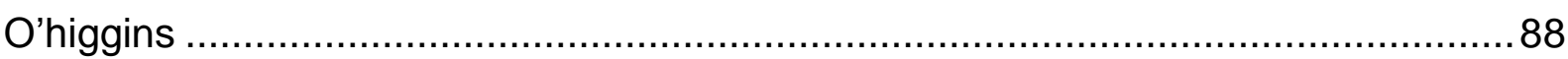

Tabela 3.3-19: Análise de skill para a componente meridional do vento para EACF .89

Tabela 3.3-20: Análise de skill para a componente meridional do vento para Jubany. .90

Tabela 3.3-21: Análise de skill para a componente meridional do vento para Marambio 91

Tabela 3.3-22: Análise de skill para a componente meridional do vento para Pratt..91 
Tabela 3.3-23: Análise de skill para componente meridional do vento para Frei ......92 Tabela 3.3-24: Análise de skill para componente meridional do vento para O’higgins ..... .92 


\section{LISTA DE SIGLAS}

AS

AMPS

AVHRR

BIAS

BRAMS

CE

CSU

EACF

ECMWF

GFS

HS

INPE

LEAF - 3

NCAR

NDC

$\bar{o}$

$\mathrm{O}_{\mathrm{i}}$

PA

$\bar{p}$

$\mathrm{p}_{\mathrm{i}}$

PROANTAR

RAMS
América do Sul

Antartic Mesoscale Prediction System

Advanced Very High Resolution Radiometer

Erro Médio

Brazilian Developments on Regional Atmospheric Modeling System

Ciclone extratropical

Colorado State University

Estação Antártica Comandante Ferraz

European Centre for Medium-Range Weather Forecasts

Global Forecast System

Hemisfério Sul

Instituto Nacional de Pesquisas Espaciais

Land Ecosystem - Atmosphere Feedback, versão 3

National Center for Atmospheric Research

Nudging central

Média das observações

Valor observado no instante "i"

Península Antártica

Média dos valores previstos pelo modelo

Valor previsto pelo modelo no instante "i"

Programa Antártico Brasileiro

Regional Atmospheric Modeling System 
RMSE

Raiz quadrada do erro médio quadrático

RMSE $_{U B} \quad$ Raiz quadrada do erro médio quadrático normalizado

USGS US Geological Survey

$z_{0} \quad$ Comprimento de rugosidade

$\sigma_{i} \quad$ Desvio padrão da simulação

$\sigma_{0} \quad$ Desvio padrão das observações

$\sigma_{z} \quad$ Sistema de coordenadas sigma-z 


\section{Introdução}

\subsection{ANTÁRTICA}

A Antártica é um dos menores continentes do planeta com apenas 14 milhões de quilômetros quadrados, sendo cerca de $65 \%$ maior que o território brasileiro. Situado completamente no Hemisfério Sul (Fig. 1.1-1), o continente é circundado pelo Oceano Austral e coberto em quase sua totalidade por imensas calotas de gelo. A altitude média do continente fica em torno de $2500 \mathrm{~m}$, sendo que em seu interior se eleva um platô que ultrapassa os 4400 metros de altitude.

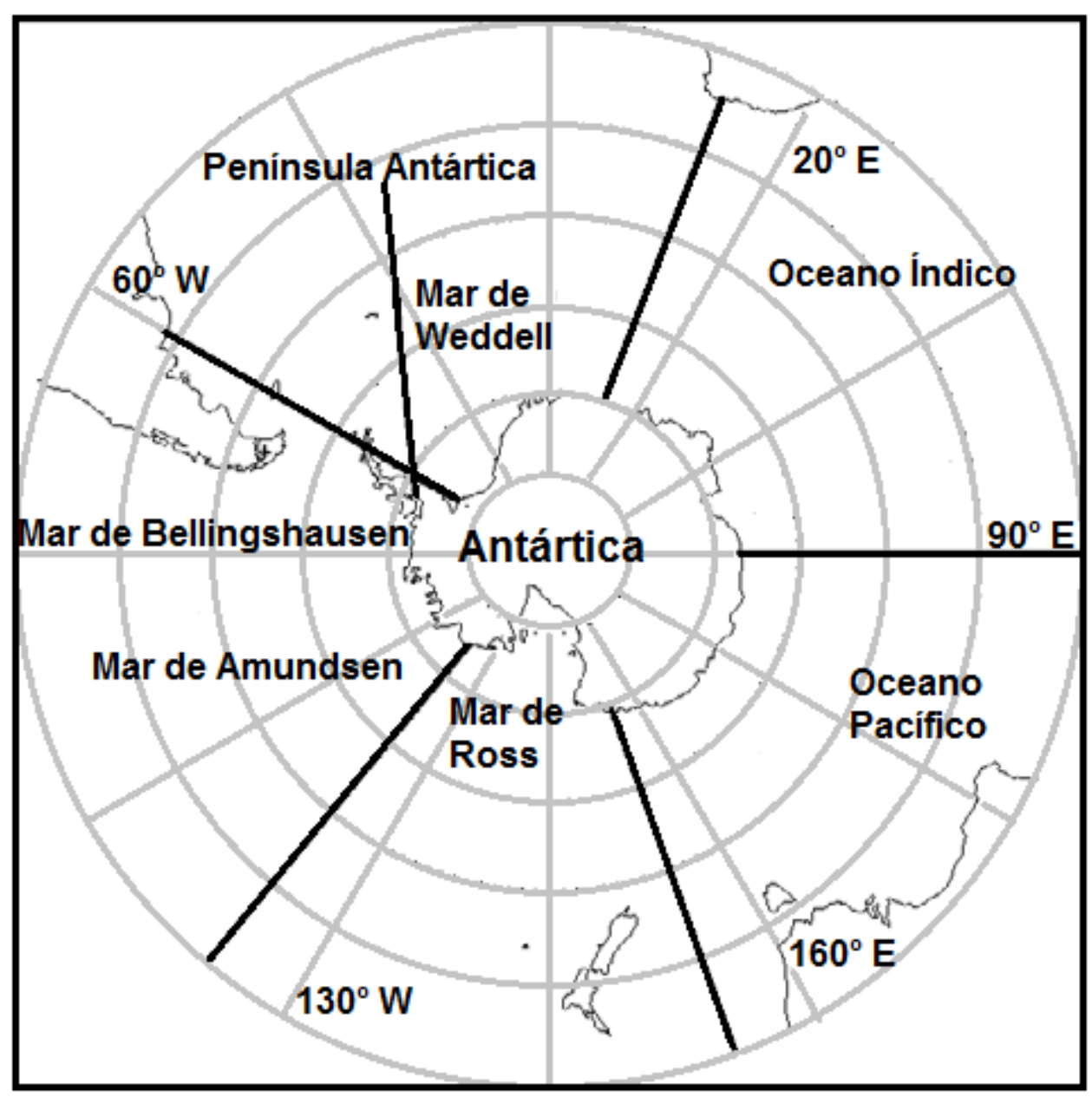

Figura 1.1-1: Localização geográfica da Antártica e seus principais mares (modificado de Cavalieri e Parkinson, 2008) 
No interior da Antártica as temperaturas podem variar entre $-30^{\circ} \mathrm{C}$ e $-70^{\circ} \mathrm{C}$, de forma que um sistema de alta pressão se mantém praticamente estacionário sobre o centro do continente, formado devido ao ramo descendente da célula Polar da circulação geral da atmosfera.

O ar que subside sobre o platô antártico tende a escoar para menores altitudes, dando origem aos conhecidos e, praticamente constante ventos catabáticos que dominam a circulação em baixos níveis sobre o continente e, ainda, são responsáveis pelo transporte de ar frio em direção à região costeira, conforme ilustra a figura 1.2. Ao chegar à região costeira do continente estes ventos catabáticos adquirem uma componente de leste devido à deflexão de Coriolis.

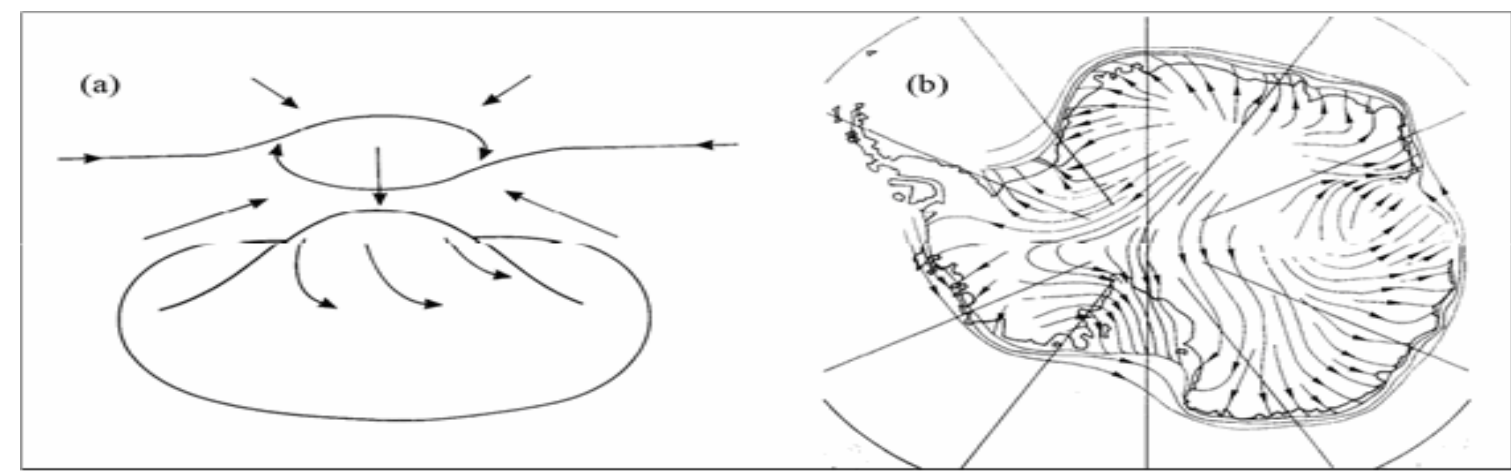

Figura 1.1-2: Esquema conceitual do escoamento de ar sobre a Antártica. (a) A convergência em altos níveis entra em equilíbrio com a superfície através da subsidência sobre o platô Antártico. (b) A consequente divergência em superfície gera os ventos catabáticos, que adquirem forte componente de leste próximo à costa devido à forçante de Corilis. (Fonte: King \& Turner, 1997)

A circulação oceânica no oceano Austral governada pelos ventos de oeste em superfície, chamada de Corrente Circumpolar Antártica (localizada ao longo de $\left.55^{\circ} \mathrm{S}\right)$, modera as temperaturas nas regiões costeiras em altas latitudes do HS. Os ventos catabaticos ao chegarem na região costeira encontram massas de ar mais quentes e úmidas, criando uma região muito instável, favorável ao desenvolvimento e intensificação dos ciclones extratropicais que atuam nesta região.

Além disso, o centro de alta pressão semi-permanente no interior do continente antártico e também a topografia do platô configuram uma barreira que impede os ciclones de adentram muito no continente, de forma que estes sistemas acabam se deslocando para leste ao redor da Antártica sobre o oceano Austral entre $60^{\circ}$ e $70^{\circ}$ $\mathrm{S}$, região conhecida como Baixa Pressão Circumpolar devido a grande quantidade 
de sistema presentes nesta faixa de latitudes e em diferentes fases de desenvolvimento.

Estes ciclones afetam diretamente as condições meteorológicas da região costeira e estão relacionados ao transporte de ar relativamente mais quente e úmido em direção às altas latitudes, ventos intensos e precipitação na região da Península Antártica (PA). A adversidade das condições meteorológicas causas pela passagem destes ciclones extratropicais pela PA acaba prejudicando as tarefas diárias desenvolvidas pelas equipes operacionais que ali desenvolvem suas atividades, como é o caso do Programa Antártico Brasileiro (PROANTAR).

Portanto, previsões acuradas das condições meteorológicas, fornecidas por modelos numéricos bem ajustados ao ambiente polar, são de fundamental importância para o planejamento operacional das atividades, tais como, voos, navegação, instalação e manutenção de instrumentos e estações meteorológicas e realização de tarefas externas.

\subsection{CICLONES EXTRATROPICAIS NA ANTÁRTICA}

Os ciclones extratropicais são um dos principais sistemas meteorológicos encontrados na região costeira da Antártica. Tipicamente possuem um comprimento horizontal que varia entre $1000 \mathrm{~km}$ e $6000 \mathrm{~km}$ e uma duração que vai de um dia a uma semana (King e Turner, 1997). O principal papel destes sistemas ciclônicos é o transporte de umidade e energia em direção ao continente antártico por meio de fluxos de calor sensível e latente que, por sua vez, visam reduzir o gradiente de temperatura existente entre o Equador e o pólo (Radok et al., 1975; Physick,1981; apud King e Turner, 1997)

O contraste térmico na região costeira da Antártica, gerado pelo encontro de massas de ar frio, provenientes do interior do continente antártico e massas de ar mais aquecido que se deslocam sobre o oceano Austral, é um dos principais fatores para o desenvolvimento dos sistemas de escala sinótica (Turner e Thomas, 1994; Felício, 2007). Segundo Carpenedo (2012), outro local favorável ao desenvolvimento de ciclones extratropicais é a região da Frente Polar Oceânica, onde se observa uma zona de forte baroclínia e um intenso gradiente meridional de temperatura. 
Uma vez sobre o Oceano Austral, o ar relativamente mais frio associa-se a intensos fluxos de calor ascendente (Irving, 2010). Estes fluxos de calor sensível e latente do oceano para a camada inferior da atmosfera podem induzir convecção na massa de ar frio, desenvolvendo e intensificando perturbações ciclônicas (Boiaski, 2009). Além disso, segundo Astapenko (apud Felício, 2007), uma vez que os gradientes meridionais de temperatura são mais intensos no HS, os ventos gerados pela passagem dos ciclones extratropicais são mais fortes e as precipitações mais volumosas se comparado às que ocorrem nas latitudes correspondentes no hemisfério norte. Estes ciclones, seguindo as correntes oceânicas, rumam em direção à passagem de Drake levando condições de tempo severo à PA.

As forçantes topográficas também desempenham um papel importante no desenvolvimento e intensificação de ciclones na Antártica. Quando o escoamento de oeste é forçado a transpor a barreira topográfica, que neste caso é a Península Antártica, ocorre um aumento da vorticidade que contribui para o desenvolvimento de ciclones a sotavento da PA. Muitas vezes estes sistemas se desenvolvem, no oeste do mar de Weddell, dentro de um ciclone principal. Este tipo de ciclogênese é semelhante àquela que ocorre a leste da Cordilheira dos Andes.

Na década de 1960, com o surgimento de imagens de satélite de órbita polar, diversos estudos científicos passaram a ser realizados com o intuito de associar padrões de nebulosidade a sistemas meteorológicos. Um dos pioneiros foi o trabalho realizado por Streten e Troup (1973), no qual utilizaram imagens de satélite do comprimento de onda visível, de um período de 1966 a 1969, para mapear e classificar ciclones extratropicais e associar as características de nebulosidade com os estágios de desenvolvimento dos vórtices. O resultado deste trabalho foi um esquema de classificação de vórtices ciclônicos de acordo com seu estado de desenvolvimento como mostram a tabela 1.2-1 e a figura 1.2-1. 
Tabela 1.2-1: Classificação de Streten e Troup (1973) para categorias de vórtices

\begin{tabular}{|c|c|}
\hline Vórtice & Características \\
\hline $\bar{W}$ & Onda desenvolvida a partir de uma banda frontal \\
\hline $\boldsymbol{A}$ & $\begin{array}{l}\text { Desenvolvimento de vórtice jovem, isolado ou misturado em uma banda de } \\
\text { nebulosidade }\end{array}$ \\
\hline$B$ & $\begin{array}{l}\text { Amadurecimento do vórtice. A banda nebulosa começa a marcar o formado do } \\
\text { ar claro }\end{array}$ \\
\hline$C$ & $\begin{array}{l}\text { Maduro. Vórtice apresenta alternância entre bandas nebulosas e ar claro } \\
\text { espiralando ao redor de um centro bem definido }\end{array}$ \\
\hline$D$ & $\begin{array}{l}\text { Decaimento, com considerável nebulosidade ao redor do centro }\left(D_{x}\right) \text { ou com } \\
\text { nebulosidade fragmentada próximo ao centro }\left(D_{y}\right)\end{array}$ \\
\hline$F / G$ & $\begin{array}{l}\text { Vórtices de Frontólise. Correspondem aos vórtices } D_{x} \text { e } D_{y} \text {, porém sem a banda } \\
\text { de nuvens }\end{array}$ \\
\hline
\end{tabular}

Este esquema assume que o vórtice se desenvolve a partir de onda em uma banda frontal (tipo W) ou como uma nuvem em forma de vírgula invertida isolada ou mergulhada em uma banda de nebulosidade maior (tipo A). Conforme o vórtice vai se desenvolvendo passa por um estágio do tipo $B$ até atingir a maturidade completa (tipo C). A partir de então entra em fase de dissipação, passando ao estágio D. Este decaimento pode ser identificado de duas formas, quando há uma grande quantidade de nuvens no centro do sistema e já não existem áreas de ar claro $\left(D_{x}\right)$ ou quando a nebulosidade do centro do vórtice começa a se fragmentar $\left(D_{y}\right)$.

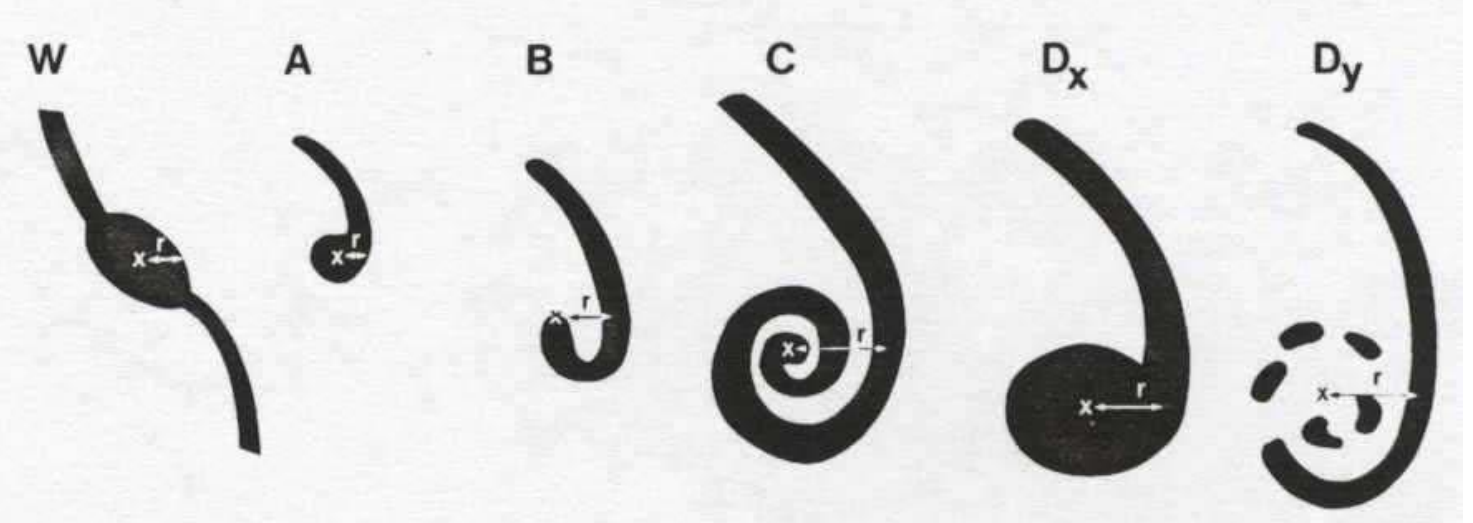

Figura 1.2-1: Classificação de Streten e Troup para categorias de ciclones extratropicais. (Fonte: King \&Turner, 1997)

Nesse trabalho, Streten e Troup (1973) classificaram, ainda, as principais áreas de formação de ciclones durante as estações de verão, inverno e em alguns meses 
intermediários e descobriram que muitos vórtices se formam em latitudes médias, mas poucas na região das Baixas Circumpolares.

Já Simmonds et al. (2003), utilizando algoritmos para rastreio de ciclones extratropicais a partir de dados da reanálise NCEP-2, observaram que durante o inverno há uma maior densidade de ciclones, em torno ou a sul da latitude de $60^{\circ} \mathrm{S}$, em comparação ao verão. Embora o número de ciclones no verão exceda aos valores de inverno em algumas regiões específicas como, por exemplo, no mar de Bellingshausen. Ainda nesse trabalho, os autores perceberam que durante o inverno as principais áreas ciclogenéticas são a região do oceano Índico (tanto abaixo de $45^{\circ} \mathrm{S}$ como ao sul de 60ㅇ), a Península Antártica e partes sul dos mares de Weddell e Ross. Já durante o verão a principal área de formação de ciclones é a Península Antártica. Os padrões de inverno e verão para a ciclólise são bastante parecidos, mostrando uma alta taxa de decaimento dos ciclones ao sul de $60^{\circ} \mathrm{S}$ no setor do oceano Índico e no mar de Bellingshausen.

Desta forma, fica evidente a importância da região da Península Antártica tanto no desenvolvimento quanto decaimento dos vórtices ciclônicos. Sendo, assim, necessário um estudo mais detalhado das características sinóticas desses sistemas meteorológicos, uma vez que são os principais responsáveis por condições extremas de tempo observadas na região da PA, onde está localizada a estação brasileira Comandante Ferraz.

\subsection{MODELAGEM ATMOSFÉRICA NA ANTÁRTICA}

Desde a década de 80 a comunidade científica brasileira vem atuando de forma significativa ao Programa Antártico Nacional (ProAntar). Essa atuação se dá de diversas formas, tais como o apoio na previsão do tempo na região da PA, montagem, instalação e manutenção de estações meteorológicas remotas automáticas e desenvolvimento de pesquisas na área de meteorologia antártica. Uma importante área de pesquisa, que também tem uma forte componente operacional, é a implantação e verificação de modelos de previsão regional de tempo sobre a região da PA.

Um trabalho de Carvalho et al. (2008), utilizando o modelo regional BRAMS (Brazilian developments on Regional Atmospheric Modeling System), mostrou que esse modelo apresentou um bom desempenho em simular variações de temperatura 
devido ao ciclo diurno e a sistemas sinóticos embebidos em trens de onda de escala intra-sazonal, conforme indicado nos registros da estação Arturo Pratt.

Trabalho semelhante foi feito por Bromwich et al. (2005) em relação ao Sistema de Previsão de Mesoescala na Antártica (AMPS - Antartic Mesoscale Prediction System), baseado na versão Polar do modelo MM5 ( $5^{\text {th }}$ generation of the Pennsylvania State University-NCAR Mesoscale Model), para um período de 2 anos (2001-2003). Nesse trabalho foram analisadas as grades com espaçamento de $10 \mathrm{e}$ 3,3 Km, a primeira cobrindo todo o continente Antártico e a segunda sobre a região de terreno complexo sobre McMurdo. As correlações entre variáveis simuladas e observadas se mostraram mais altas para a pressão e temperatura próxima a superfície e mais baixas para os ventos. As maiores correlações foram encontradas para as variáveis na atmosfera livre, analisadas através de radiossondagens de algumas estações antárticas. Mostram também que a grade de $3,3 \mathrm{~km}$ era mais sensível às mudanças espaciais e temporais no vento, o que representou uma melhora no desempenho do modelo, especialmente a barlavento da llha Ross e também a sotavento dessa ilha, região esta favorável à ciclogênesis de mesoescala.

Analisando o desempenho do AMPS com uma grade de $10 \mathrm{~km}$ durante um evento que combinava mesoescala e escala sinótica ocorrido em janeiro de 2001, Bromwich et al. (2003) observaram que o modelo reproduziu a evolução das condições atmosféricas em altos níveis, e ainda que resolveu as características de mesoescala próximo a superfície, como por exemplo, vórtices ciclônicos/anticiclônicos topograficamente induzidos. Além disto, eles notaram que a acurácia das simulações depende diretamente da qualidade das condições iniciais apesar da resolução da grade relativamente alta.

Monaghan et al. (2003) compararam o desempenho do AMPS com o de outros modelos por um período de aproximadamente uma semana para o pólo Sul em abril de 2001. Eles descobriram que, em geral, cada um dos quatro modelos (o AMPS, o modelo do NCEP, o espectral do ECMWF e uma versão global do MM5) reproduziu as condições na atmosfera livre com boa habilidade. Além disto, a simulação do ECMWF foi a melhor dentre todos os modelos, e os autores atribuem isto a sua resolução relativamente alta próximo ao polo e a qualidade de suas condições iniciais. Já próximo à superfície as simulações não tiveram tão bom desempenho e apresentaram uma maior variabilidade entre os modelos, sendo que aqueles de maior resolução obtiveram melhor desempenho. Os autores sugeriram 
que as parametrizações da camada limite planetária não representam adequadamente a atmosfera polar próximo à superfície, e a isto se atribuiu o baixo desempenho das simulações.

Guo et al. (2003) avaliaram, para o período de um ano completo, as simulações não-hidrostáticas com resolução horizontal de $60 \mathrm{~km}$ do MM5 Polar. Eles verificaram que o modelo representou fielmente as circulações tanto as de grande escala, quanto as de mesoescala. Mostraram ainda, que a variabilidade das observações sinóticas de temperatura do ar, pressão próxima à superfície, magnitude e direção do vento e razão de mistura de vapor, e também o ciclo diurno destas mesmas variáveis foram reproduzidas pelo MM5 Polar com razoável acurácia.

Turner et al (1997), fizeram uma verificação dos resultados de previsão obtidos do modelo do Reino Unido também para a região antártica. Foi visto que há uma razoável representação da circulação atmosférica da região, porém com algumas deficiências. Os ventos catabáticos costeiros das saídas do modelo foram bem representados, comparando com o vento real medido pelas estações num prazo de até três dias de prognóstico. Entretanto, a estimativa de temperatura apresentou erros, acusando valores mais baixos que os observados, devido à influência dos ventos frios catabáticos modelados provindos do escoamento descendente sobre o continente na região costeira. Quanto ao cinturão de baixas pressões, o modelo acertou bem, em média, as posições dos grandes centros, desde que fossem distúrbios sob a influência de anomalias de baixa frequência, como uma grande baixa que se propaga por alguns dias. O parâmetro que teve maior índice de acerto pelos modelos, em comparações com valores in situ, foi a cobertura de nuvens. Os acertos foram muito bons no verão, entretanto, para julho, o modelo aumentou em demasia a nebulosidade.

Simmonds e Budd (apud Cunnningham, 2001) estudaram o impacto que as áreas de mar aberto têm na atmosfera. Seus resultados mostraram que quanto maior o numero de fraturas em uma determinada área maior a temperatura próxima à superfície. Os aumentos variam da ordem de 2,0 graus no caso de apenas $5 \%$ de mar aberto, até 17,5 graus no caso da remoção total do gelo marinho. Na ausência do gelo marinho, que normalmente atua como um isolante térmico, os fluxos de calor sensível entre o oceano e o ar da baixa troposfera tende a aumentar, refletindo na elevação da temperatura do ar. 


\subsection{OBJETIVO}

Em novembro de 2008, com base no trabalho de Carvalho et at. (2008), iniciou-se no Laboratório MASTER do IAG-USP, uma rodada operacional diária com o BRAMS, cobrindo a PA. Entretanto, esse modelo não teve nenhuma adaptação especial para o ambiente antártico e necessitava, portanto, que fosse feito um trabalho de verificação de seus resultados. A verificação dessa corrida operacional do BRAMS, comparado com observações de superfície, é o motivo desta proposta de trabalho.

O objetivo deste estudo é avaliar o desempenho do modelo BRAMS que está sendo utilizado na previsão de tempo na Península Antártica. Especificamente, pretende-se:

1. Comparar as previsões de pressão ao nível do mar, temperatura, umidade específica e vento do modelo BRAMS com observações em superfície na Península Antártica;

2. Avaliar objetivamente, através de índices estatísticos, a acurácia do modelo BRAMS ao simular sistemas significativos de tempo, principalmente os ciclones, que ocorrem na região da Península Antártica;

3. Analisar os efeitos decorrentes do aumento da resolução horizontal na grade do modelo e também da inserção de gelo marinho nas simulações.

4. Indicar sugestões de alteração no modelo BRAMS, a partir dos resultados obtidos com os experimentos realizados no intuito de melhorar as simulações do modelo, dando assim uma ferramenta mais confiável para o desenvolvimento das previsões de tempo; 


\section{Material e Métodos}

\subsection{O MODELO NUMÉRICO}

O BRAMS é uma versão brasileira do modelo numérico RAMS (Regional Atmospheric Modeling System) e é distribuído pelo Centro de Previsão do Tempo e Estudos Climáticos (CPTEC) do Instituto Nacional de Pesquisas Espaciais (INPE) ${ }^{1}$. Devido à sua versatilidade e das diversas opções físicas, o BRAMS é bem difundido no meio acadêmico, sendo bastante utilizado para a previsão do tempo, em estudos de brisa marítima, na simulação de sistemas convectivos de mesoescala, simulações climáticas e aplicado na modelagem de dispersão atmosférica, dentre outros.

O RAMS, no qual está fundamentado o BRAMS, foi desenvolvido pela Universidade do Colorado (CSU - Colorado State University) e é o resultado da combinação de dois modelos existentes inicialmente na CSU: o modelo de nuvem/mesoescala (Tripoli e Cotton, 1982) e o modelo de brisa marítima descrito por Marher e Pielke (1977).

O BRAMS utiliza uma grade computacional alternada do tipo $\mathrm{C}$ de Arakawa (Messinger e Arakawa, 1976), onde as variáveis termodinâmicas e de umidade são definidas nos mesmos pontos da grade, enquanto as componentes $u, v$ e $w$ do vento são intercaladas em $\Delta x / 2, \Delta y / 2$ e $\Delta z / 2$, respectivamente (Biazeto, 2007). A projeção horizontal estereográfica é usada para a definição das coordenadas da grade, uma vez que diminuem as distorções da projeção na área de interesse, de maneira que o polo da projeção fica o mais próximo possível do centro da grade. Já na vertical é utilizado o sistema de coordenadas sigma- $z\left(\sigma_{z}\right)$, descrito em Tripoli e Cotton (1982), onde os níveis verticais não interceptam a topografia. Ressalta-se ainda que a espessura de cada camada atmosférica é variável, e além disso, o espaçamento entre os níveis pode aumentar com a altura, obtendo maior resolução espacial próximo a superfície e menor no topo do modelo.

\footnotetext{
${ }^{1}$ http://brams.cptec.inpe.br
} 
No RAMS está disponível a opção de trabalhar com aninhamento múltiplo de grades, de forma que as equações podem ser resolvidas simultaneamente em diferentes resoluções espaciais. A interação entre grades dá-se em duplo sentido (two way interaction) de maneira que os processos que ocorrem na grade de menor resolução ocorram também na grade mais refinada (o contrário também é válido) conforme os esquemas de Clark e Farley (1984) e Clark e Hall (1991) (apud Walko e Tremback, 2001).

As equações usadas pelo modelo são aquelas para uma atmosfera nãohidrostática, descritas em Tripoli e Cotton (1982). Existem equações prognósticas para todas as variáveis de estado incluindo as componentes zonal, meridional e vertical do vento $(u, v, w)$, temperatura potencial, razão de mistura e função de Exner (Freitas, 2003). Além disso, é usada a formulação de diferenças finas de segunda ordem no tempo e espaço para resolver essas equações.

O BRAMS resolve numericamente as equações utilizando o método de Reynolds, onde cada variável é decomposta em uma parte média e outra perturbada, de modo que é definido um novo conjunto de equações que apresentam termos médios e turbulentos. O modelo apresenta, ainda, um esquema de divisão de passos de tempo (time-split), onde passos de tempo menores que o utilizado em termos como advecção são usados para calcular os termos responsáveis pelas ondas sonoras e de gravidade.

\subsection{A CONFIGURAÇÃO DAS SIMULAÇÕES}

Neste trabalho o domínio simulado e as configurações são os mesmo utilizados por Carvalho et al. (2008), constituído de duas grades aninhadas com interação mútua. A primeira grade (G1) apresenta menor resolução horizontal e cobre a Península Antártica e parte dos oceanos adjacentes, conforme pode ser visto na Figura 2.2-1. Já na segunda grade (G2) é adotada maior resolução horizontal e varre uma área que compreende as Ilhas Shetland Sul e parte da PA. Nestas simulações são adotados 42 níveis sigma-z na vertical, iniciando com espaçamento de $70 \mathrm{~m}$ e aumentando progressivamente a uma taxa de estiramento de 1,2 até atingir $1000 \mathrm{~m}$, que são mantidas com esta espessura até o topo do modelo, que está a aproximadamente $25 \mathrm{~km}$ de altura. O primeiro nível representativo da atmosfera está a 33,4 m acima da superfície. 
As condições iniciais e das fronteiras laterais ao longo da simulação são determinadas a partir das previsões do modelo global GFS. O arquivo de tipo e uso do solo para essa região, atualmente utilizado, é baseado nos dados de espaçamento de $1 \mathrm{~km}$ obtidos entre abril de 1992 e março de 1993 pelo Advanced Very High Resolution Radiometer (AVHRR), e fornecido pelo US Geological Survey (USGS), onde o gelo da superfície é representado apenas pelo gelo permanente e não pelo gelo oceânico que tem variação ao longo do ano. Dentre os diversos submodelos que compõe o RAMS, deve-se destacar o Land Ecosystem-Atmosphere Feedback, versão 3 (LEAF-3) que representa as características da superfície, tais como solo, oceanos, vegetação e cobertura de neve e suas influencias recíprocas e sobre a atmosfera (Walko et al., 2000). O solo e a cobertura de neve são divididos em múltiplas camadas verticais e a vegetação é representada por uma única camada. Na configuração adotada é usado quatro camadas de neve e nove camadas de solo. A superfície de uma dada célula da grade é dividida horizontalmente em múltiplos patches, cada um com seu próprio ar de dossel, solo e camadas de neve, ou corpo de água permanente (neste caso não há camadas de solo). Nesta configuração as células das grades próximas à PA contem um ou dois patches representando gelo, oceano, ou ambos.

Para este trabalho foram escolhidos dois eventos sinóticos observados no ano de 2009 para realizar as simulações e análises. O primeiro evento ocorreu entre $16 \mathrm{e}$ 18 de fevereiro, onde foi observado uma abrupta queda de pressão em cerca de 20 horas na Estação Antártica Comandante Ferraz (EACF). O segundo evento ocorreu no dia 11 de julho e foi observado, também, uma forte diminuição de pressão atmosférica, porém acompanhada de uma intensa queda na temperatura do ar na EACF. No capítulo 3 será apresentada uma análise sinótica para cada um dos casos. 


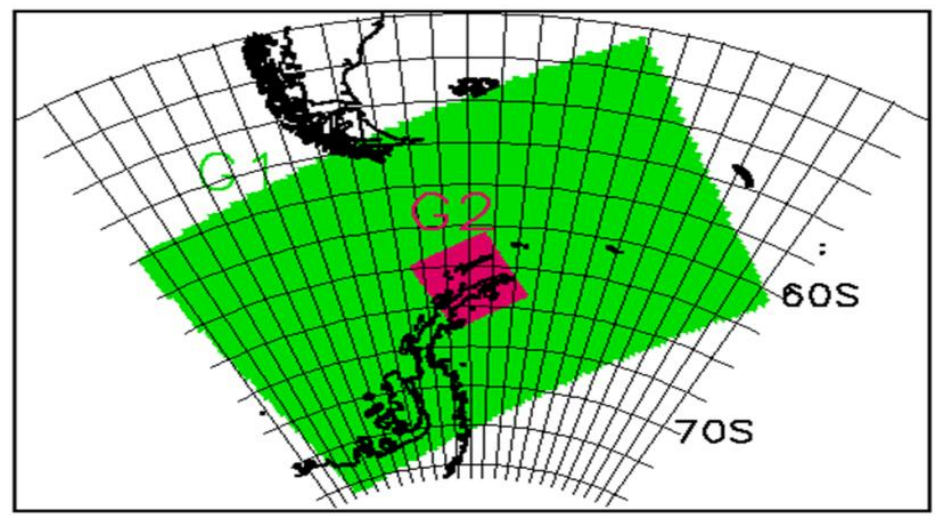

Figura 2.2-1: Domínio das grades simuladas (Fonte: modificado de Carvalho et al., 2008)

Foram realizadas nove simulações para cada um dos casos sinóticos, todas com o objetivo de testar diversas condições iniciais e de fronteira que pudessem melhorar o desempenho do modelo BRAMS.

A primeira realizada é a simulação controle (CTR), onde foram utilizadas as mesmas condições iniciais do modelo operacional (descrito em Carvalho et al., 2008), onde G1 apresenta resolução horizontal de 40 km e G2 com 10 km. A atualização da fronteira é feita a casa seis horas e não é utilizado esquema de nudging central. Neste experimento são considerados apenas o gelo continental e as plataformas de gelo permanente.

Já a simulação ANT possui as mesmas configurações da CTR, porém é sempre iniciada um dia antes ( 24 horas) dos demais experimentos. O objetivo desta simulação é determinar se os ciclones podem ser previstos adequadamente pelo modelo mesmo antes de influenciarem diretamente a região da PA.

A frequência da entrada de dados no modelo regional foi alterada na simulação ATF: em vez seis horas, que é utilizada nos demais experimentos, aqui optou-se pela entrada de dados a cada três horas. Esta simulação também usa grades com resolução de 40 km e 10 km, sem nudging central e sem gelo marinho.

Foram realizadas quatro simulações envolvendo nudging central (NDC), nestas simulações o tempo de relaxação newtoniano no centro da grade foi alterado para 1h, 6h, 12h e 24h, correspondendo, respectivamente, às simulações, N01, N06, $\mathrm{N} 12$ e N24. O que se pretende responder com tais experimentos é até que ponto a utilização deste tipo simples de assimilação de dados contribui para melhorar o desempenho do modelo de mesoescala, partindo do princípio que os dados do modelo global que servem de "input" ao modelo regional retratam adequadamente 
as condições meteorológicas observadas. Nestas simulações são utilizadas as mesmas configurações do experimento CTR, desconsiderado o gelo marinho e a atualização da fronteira é feita a cada seis horas.

O diferencial do experimento GEL, em relação aos demais, é a inclusão de gelo marinho no modelo de mesoescala usando, para isto, os dados de temperatura da superfície do mar. Esta simulação possui grade com resolução horizontal de $40 \mathrm{~km}$ e 10 km, não utiliza esquema de NDC e os dados das fronteiras laterais são atualizados a cada seis horas.

Visando captar melhor a influência da resolução horizontal nas previsões, na simulação G25 a resolução horizontal foi alterada e passou-se a usar espaçamento de 25 km na G1 e 5 km na G2, porém as demais configurações seguem as mesmas do experimento CTR.

A tabela 2.1-1 mostra um resumo das principais características que diferenciam cada uma das simulações realizadas com o modelo BRAMS.

Tabela 2.2-1: Características dos Experimentos Numéricos

\begin{tabular}{|lllllll|}
\hline Simulação & $\begin{array}{l}\text { Início do } \\
\text { Evento de } \\
\text { Fevereiro }\end{array}$ & $\begin{array}{l}\text { Início do } \\
\text { Evento de } \\
\text { Julho }\end{array}$ & $\begin{array}{l}\text { Atualização } \\
\text { da Fronteira }\end{array}$ & NDC (s) & $\begin{array}{l}\text { Gelo } \\
\text { Marinho }\end{array}$ & $\begin{array}{l}\text { Resolução } \\
\text { das Grades }\end{array}$ \\
\hline \hline ANT & $15 / 02 / 2009$ & $09 / 07 / 2009$ & $06 \mathrm{~h}$ & Não & Não & 40 e 10Km \\
CTR & $16 / 02 / 2009$ & $10 / 07 / 2009$ & $06 \mathrm{~h}$ & Não & Não & 40 e 10Km \\
ATF & $16 / 02 / 2009$ & $10 / 07 / 2009$ & $03 \mathrm{~h}$ & Não & Não & 40 e 10Km \\
GEL & $16 / 02 / 2009$ & $10 / 07 / 2009$ & $06 \mathrm{~h}$ & Não & Sim & 40 e 10Km \\
G25 & $16 / 02 / 2009$ & $10 / 07 / 2009$ & $06 \mathrm{~h}$ & Não & Não & 25 e $5 \mathrm{Km}$ \\
N01 & $16 / 02 / 2009$ & $10 / 07 / 2009$ & $06 \mathrm{~h}$ & 3600 & Não & 40 e 10Km \\
N06 & $16 / 02 / 2009$ & $10 / 07 / 2009$ & $06 \mathrm{~h}$ & 21600 & Não & 40 e 10Km \\
N12 & $16 / 02 / 2009$ & $10 / 07 / 2009$ & $06 \mathrm{~h}$ & 43200 & Não & 40 e 10Km \\
N24 & $16 / 02 / 2009$ & $10 / 07 / 2009$ & $06 \mathrm{~h}$ & 86400 & Não & 40 e 10Km \\
\hline
\end{tabular}




\subsection{DADOS E ESTAÇÕES METEOROLÓGICAS}

As estações meteorológicas selecionadas para terem seus registros comparados com as rodadas do modelo BRAMS foram escolhidas visando uma melhor distribuição espacial na Península Antártica, totalizando seis estações, como pode ser visto na Tabela 2.3-1. A distribuição espacial das estações pode ser vista na figura 2.3-1.

Tabela 2.3-1: Estações Meteorológicas utilizadas

\begin{tabular}{|lccccccc|}
\hline \multicolumn{1}{|c}{ Estação } & $\begin{array}{c}\text { Código } \\
\text { O.M.M. }\end{array}$ & Latitude & Longitude & $\begin{array}{c}\text { Altitude } \\
(\mathbf{m})\end{array}$ & $\begin{array}{c}\text { Resolução } \\
\text { temporal das } \\
\text { observações }\end{array}$ & Fevereiro & Julho \\
\hline \hline Jubany & 89053 & $62^{\circ} 14^{\prime} \mathrm{S}$ & $58^{\circ} 38^{\prime} \mathrm{W}$ & 11 & $03 \mathrm{~h}$ & Sim & Sim \\
Marambio & 89055 & $64^{\circ} 14^{\prime} \mathrm{S}$ & $56^{\circ} 43^{\prime} \mathrm{W}$ & 198 & $03 \mathrm{~h}$ & Sim & Sim \\
Ed. Frei & 89056 & $62^{\circ} 25^{\prime} \mathrm{S}$ & $58^{\circ} 53^{\prime} \mathrm{W}$ & 10 & $06 \mathrm{~h}$ & Sim & Não \\
Pratt & 89057 & $62^{\circ} 30^{\prime} \mathrm{S}$ & $59^{\circ} 41^{\prime} \mathrm{W}$ & 5 & $06 \mathrm{~h}$ & Sim & Não \\
O'Higgins & 8959 & $63^{\circ} 19^{\prime} \mathrm{S}$ & $57^{\circ} 54^{\prime} \mathrm{W}$ & 10 & $06 \mathrm{~h}$ & Sim & Não \\
Ferraz & 89252 & $62^{\circ} 05^{\prime} \mathrm{S}$ & $58^{\circ} 23^{\prime} \mathrm{W}$ & 20 & $03 \mathrm{~h}$ & Sim & Sim \\
\hline
\end{tabular}

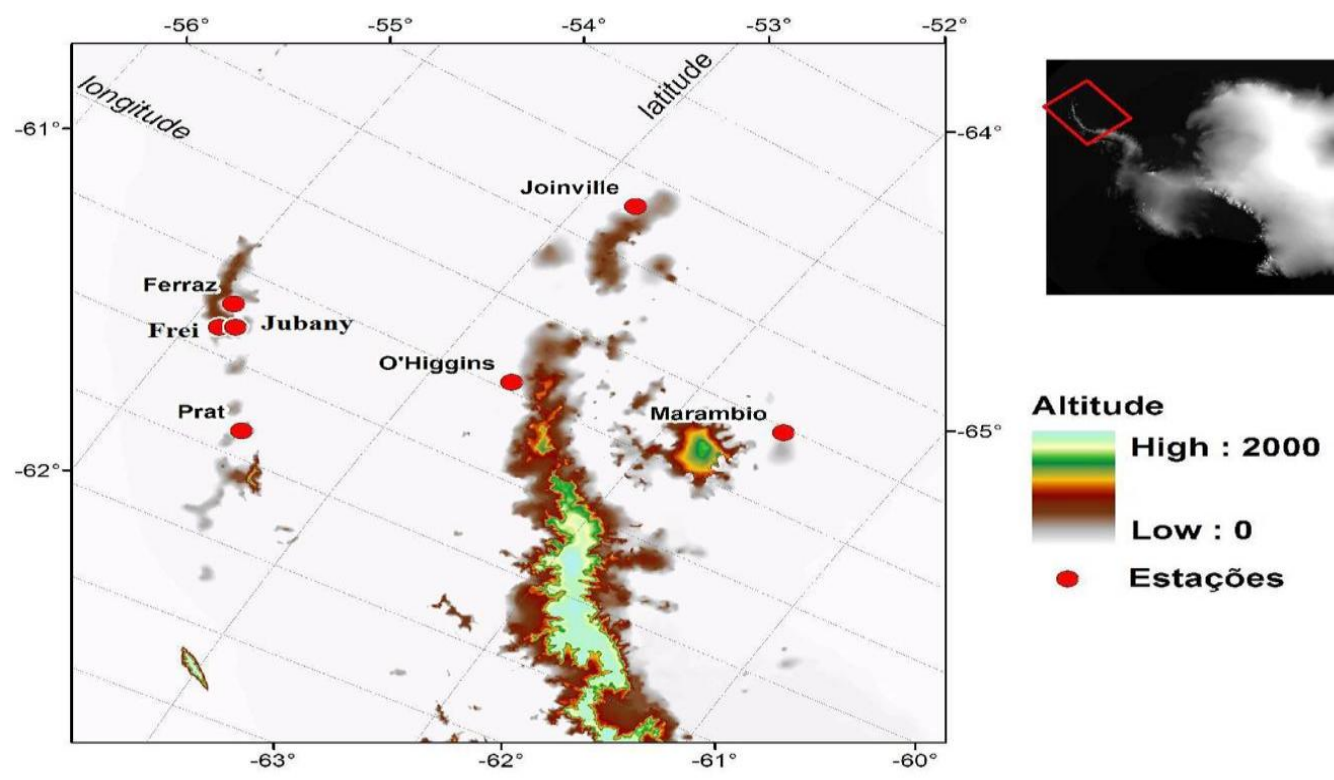

Figura 2.3-1: Localização das estações meteorológicas na PA utilizadas neste estudo;

No caso da passagem do ciclone de fevereiro, o comportamento do modelo BRAMS foi avaliado em todas as seis estações meteorológicas. Entretanto, devido à falta de dados observados no evento que ocorreu em julho, apenas os dados de três 
estações (Ferraz, Marambio e Jubany) foram utilizados para comparar com os resultados das simulações numéricas.

Neste estudo foram utilizados dados horários, no nível da estação, de: temperatura do ar, magnitude e direção do vento e pressão ao nível médio do mar, que estão disponíveis na página do Serviço Meteorológico Russo ${ }^{2}$ e no site do PROANTAR ${ }^{3}$.

As observações que foram confrontadas com as saídas do modelo passaram por um processo de preenchimento de falhas. Os procedimentos para preencher as falhas nos dados foram: (i) interpolação linear: na ausência de apenas um dado (um horário), foi realizanda a interpolação entre o horário anterior e o posterior; (ii) regressão linear: quando da ausência de dois ou mais horários, foi usada a reta de regressão entre duas estações próximas para o preenchimento, sendo elas bem correlacionadas. É importante ressaltar que estes procedimentos foram realizados apenas nas séries de temperatura do ar, temperatura do ponto de orvalho e pressão ao nível médio do mar, sendo que os dados de vento não foram preenchidos.

Além disto, para que fosse possível a comparação com as observações de cada uma das estações, as saídas do modelo foram corrigidas para a mesma altitude de cada estação. A temperatura do ar foi corrigida utilizando um lapse-rate de $9,8^{\circ} \mathrm{Cm}^{-1}$ e a pressão a superfície foi corrigida pela equação hipsométrica. Já para a redução do vento ao nível da estação foi utilizado um perfil logarítmico, para o qual foi adotado um comprimento de rugosidade $\left(z_{0}\right)$ de 0,001 .

\subsection{AVALIAÇÃO DO DESEMPENHO DO MODELO}

Com o objetivo de avaliar o desempenho do modelo em simular os casos sinóticos previamente definidos, foram calculados alguns índices estatísticos. A correlação linear de Pearson (WILKS, 1995), que determina o grau de associação entre as observações e valores simulados, foi a primeira a ser calculada. Altos

\footnotetext{
${ }^{2}$ http://meteo.infospace.ru/main.htm

${ }^{3}$ http://antartica.cptec.inpe.br/
} 
valores de correlação indicam um bom acordo entre as séries, ou seja, as variações ocorrem no mesmo sentido. A correlação de Pearson é definida como:

$$
r_{p o}=\frac{\frac{1}{n-1} \sum_{i=1}^{n}\left[\left(p_{i}-\bar{p}\right)(o i-\bar{o})\right]}{\left\{\left[\frac{1}{n-1}\right] \sum_{i=1}^{n}\left(p_{i}-\bar{p}\right)^{2}\right\}^{\frac{1}{2}}\left\{\left[\frac{1}{n-1}\right]_{i=1}^{n}\left(o_{i}-\bar{o}\right)^{2}\right\}^{\frac{1}{2}}}
$$

onde $p$ representa os valores previstos pelo modelo, $o$ as observações, $\bar{p}$ é a média dos valores previstos pelo modelo, $\bar{o}$ é a média das observações e $n$ é o número de instantes de tempo. É importante salientar que os dados extraídos das simulações são interpolados para a latitude e longitude de cada estação.

Além disso, o desvio padrão $(\sigma)$ das observações e das simulações também foi calculado. As medidas de desvio padrão indicam o grau de dispersão da série em relação à média, ou seja, quanto maior o valor de $\sigma$ maior é a variabilidade da série.

$$
\begin{aligned}
& \sigma_{o}=\left[\frac{1}{n} \sum_{i=1}^{n}\left(o_{i}-\bar{o}\right)^{2}\right]^{\frac{1}{2}} \\
& \sigma_{p}=\left[\frac{1}{n} \sum_{i=1}^{n}\left(p_{i}-\bar{p}\right)^{2}\right]^{\frac{1}{2}}
\end{aligned}
$$

onde $\sigma_{o}$ e $\sigma_{p}$ são, respectivamente, o desvio padrão das observações e da simulação.

Foi calculado também o erro médio ou BIAS, uma vez que apenas os valores de correlação não são suficientes para determinar a acurácia do modelo. O BIAS é a diferença entre os valores simulados e os observados, indicando apenas se o modelo subestima ou superestima os valores médios e é dado pela seguinte equação: 


$$
B I A S=\frac{1}{n} \sum_{i=1}^{n}\left(p_{i}-o_{i}\right)=\bar{p}-\bar{o}
$$

Outra medida bastante comum para avaliar a acurácia das simulações é raiz do erro médio quadrático (RMSE), que é a raiz do quadrado da diferença entre valores simulados e observados. A RMSE é mais sensível a valores extremos da série e altos valores deste erro indicam a discrepância entre as séries.

$$
R M S E=\left[\frac{1}{n} \sum_{i=1}^{n}\left(p_{i}-o_{i}\right)^{2}\right]^{\frac{1}{2}}
$$

Além disso, Pielke (2002) define a raiz do erro médio quadrático após a remoção do desvio (RMSE $E_{\mathrm{UB}}$ ) como outro índice estatístico utilizado para avaliar a habilidade (skill) de uma simulação:

$$
R M S E_{U B}=\left\{\frac{1}{n} \sum_{i=1}^{n}\left[\left(p_{i}-\bar{p}\right)-(o i-\bar{o})\right]^{2}\right\}^{\frac{1}{2}}
$$

Ainda segundo Pielke (2002) a habilidade de uma simulação é determinada pelas seguintes situações:

\section{a. $\quad \sigma_{0} \cong \sigma_{p}$ \\ b. RMSE $<\sigma_{\text {o }}$ \\ c. $\mathrm{RMSE}_{\mathrm{UB}}<\sigma_{\mathrm{o}}$}

Este método foi aplicado em todas as simulações realizadas e, assim como em Freitas (2003), os resultados serão apresentados em tabela e referidos como "análise de skill". 


\section{Resultados e Discussões}

Primeiramente será apresentada uma análise sinótica de cada um dos eventos sinóticos que servem como base para o desenvolvimento deste trabalho e, posteriormente, as simulações numéricas realizadas com o modelo BRAMS serão avaliadas estatisticamente.

A avaliação estatística do modelo será divida em duas partes: análise qualitativa e análise de sensibilidade. Na primeira será avaliado o comportamento das séries temporais de cada experimento, comparando-os com as observações meteorológicas, com as análises do GFS e, ainda, com as previsões do GFS. Já a análise de sensibilidade consiste do cálculo de diversos parâmetros estatísticos que indicaram os erros e acertos de cada experimento. Para que uma simulação seja considerada de bom desempenho deve se sair bem em ambas análises (qualitativa e de sensibilidade).

\subsection{ANÁLISE SINÓTICA DOS EVENTOS CICLÔNICOS}

\subsubsection{CASO DE FEVEREIRO}

$\mathrm{Na}$ imagem do satélite GOES-10 no canal infravermelho do dia 14 de fevereiro de 2009 às 23:45 UTC (Figura 3.1-3f) observa-se um vórtice ciclônico (Cf1) do tipo A (Streten e Troup, 1973) em desenvolvimento, localizado no oceano Pacífico a oeste do extremo sul da América do Sul (AS), mais precisamente em 50S/90W. Um cavado está associado a este vórtice e pode ser visto no campo de pressão ao nível médio do mar (Figura 3.1-1a) do dia 15 de fevereiro as 00 UTC. Além disso, outros três centros de baixa pressão podem ser identificados na figura 3.1-1a, um a noroeste do mar de Bellingshausen, um ao sul da AS, que está em fase de decaimento e o último a nordeste do mar de Weddell. Em níveis médios (500 hPa) um cavado no campo do geopotencial se aproxima da AS (Figura 3.1-1b).

A advecção quente de temperatura em $850 \mathrm{hPa}$ (Figura 3.1-1c) e a advecção de vorticidade ciclônica em $500 \mathrm{hPa}$ (Figura 3.1-1d) a leste do cavado em $500 \mathrm{hPa}$ contribuem para o desenvolvimento do ciclone em superfície. A corrente de jato em altos níveis não contribui para o desenvolvimento do sistema (Figura 3.1-1e), isto 
porque o cavado em baixos níveis está sob a região de convergência do lado polar do jato. Nas seis horas posteriores, o vórtice que estava ao sul da AS se dissipou e o do tipo $A$ evoluiu para vórtice do tipo $B$, quando há uma banda de nebulosidade bem definida a leste do centro e atrás da banda frontal uma área com poucas nuvens, e a ele estava associado um centro de baixa pressão de $990 \mathrm{hPa}$ (figuras não apresentadas).

A figura 3.13.1-2, do dia 16 as 00UTC, mostra que o ciclone está localizado sobre a costa leste do extremo sul da AS, deixando evidente seu deslocamento em direção à região costeira do extremo sul da AS onde há um maior contraste térmico (Figura 3.1-2b). Um novo ciclone, com pressão central de $970 \mathrm{hPa}$, avança em direção à Passagem de Drake fundindo-se com o centro de baixa que estava a noroeste do mar de Bellingshausen. Em baixos níveis a advecção de ar quente contribuiu para a amplificação do cavado em níveis médios (Figura 3.1-2b e c). A região de divergência na entrada da corrente de jato (Figura 3.1-2e) proporcionou um acoplamento entre a superfície e os altos níveis, o que contribuiu para o desenvolvimento do sistema em superfície. A banda de nebulosidade frontal associada ao ciclone não fica tão evidente na figura 3.1-2f, pois está misturada à nebulosidade relacionada ao jato. 

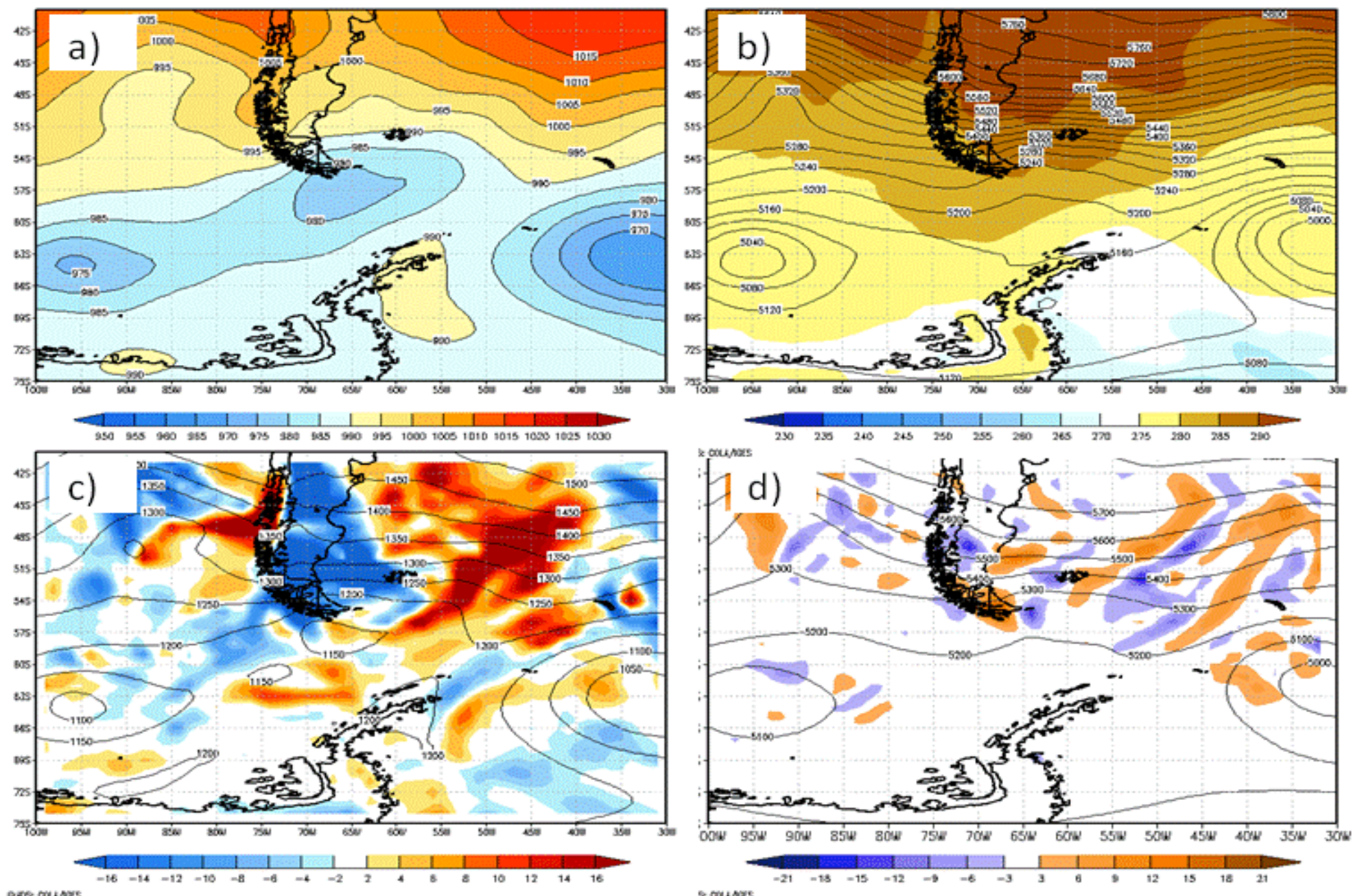

Figura 3.1-1: (a) Pressão ao nível médio do mar (hPa); (b) temperatura potencial (sombreado, em K) e geopotencial (linha contínua, em m) em $500 \mathrm{hPa}$; (c) advecção de temperatura (sombreado, em Kdia ${ }^{-1}$ ) e geopotencial (linha contínua, em m) em 850 hPa; (d) advecção de vorticidade relativa (sombreado, em $10^{-8} \mathrm{~s}^{-1}$ ) e geopotencial (linha contínua, em m) em $500 \mathrm{hPa}$; (e) magnitude do vento horizontal (sombreado, em ms- ${ }^{-1}$ ) e geopotencial (linha contínua, em m) em $250 \mathrm{hPa}$, todas para o dia 15 de fevereiro de 2009 as 00 UTC; (f) imagem do satélite GOES-10, no canal infravermelho, do dia 14 de fevereiro as 23:45 UTC 

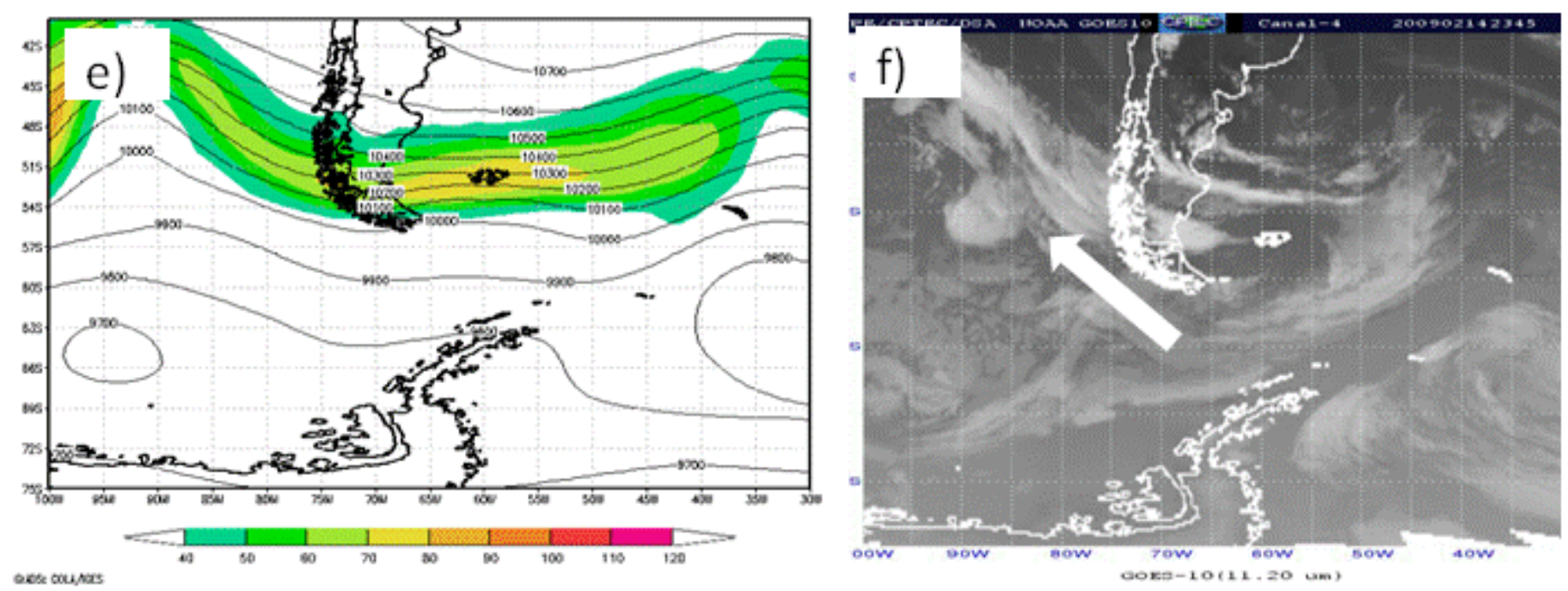

Figura 3.1-1: Continuação 

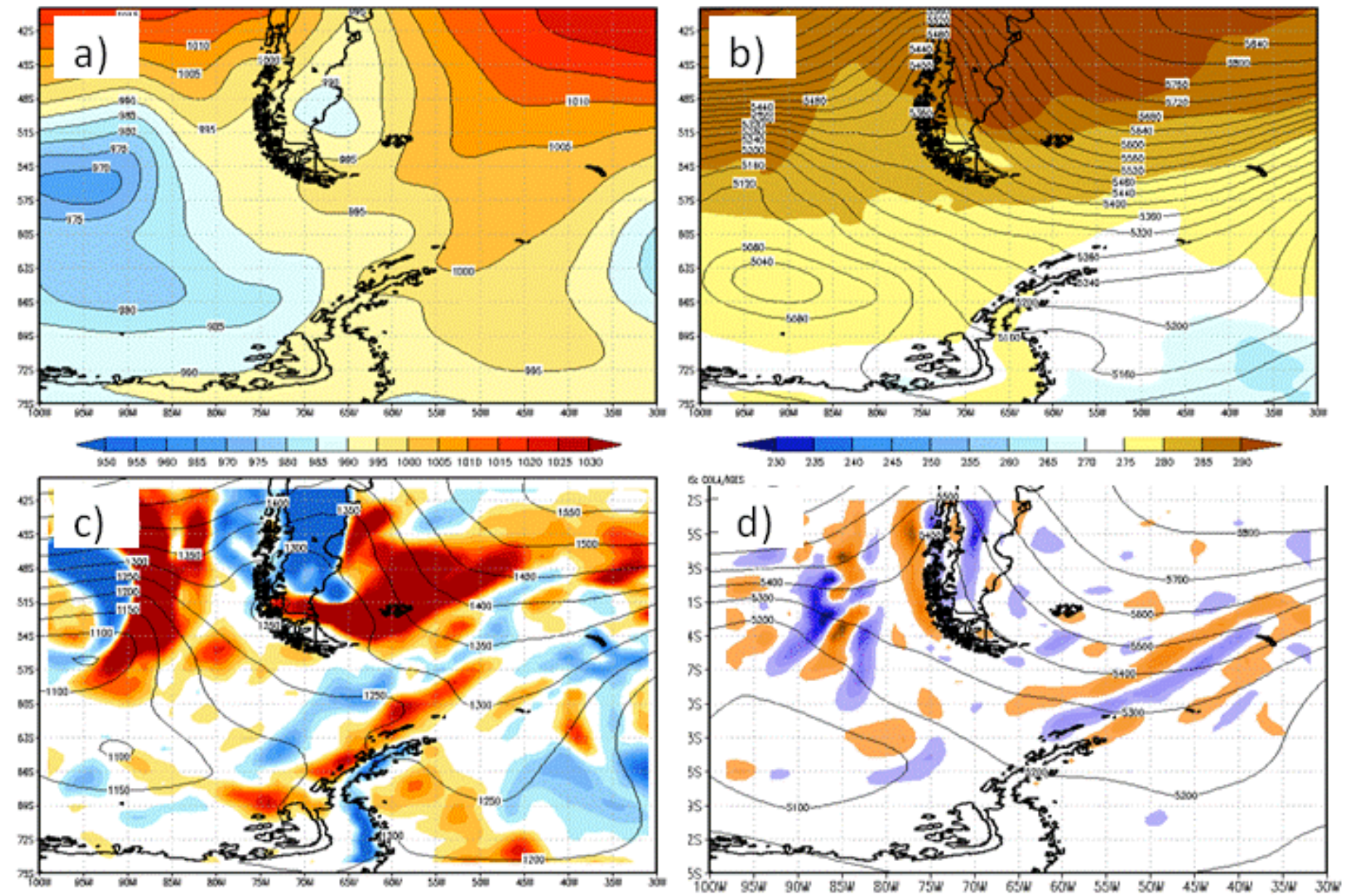

erescousas

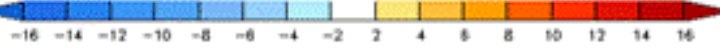

aco ochas

Figura 3.1-2: De (a) a (e) idem à figura 3.1-1, porém para o dia 16 de fevereiro de 2009 as 00 UTC; (f) imagem do satélite GOES-10, no canal infravermelho, do dia 15 de fevereiro as 23:45 UTC 

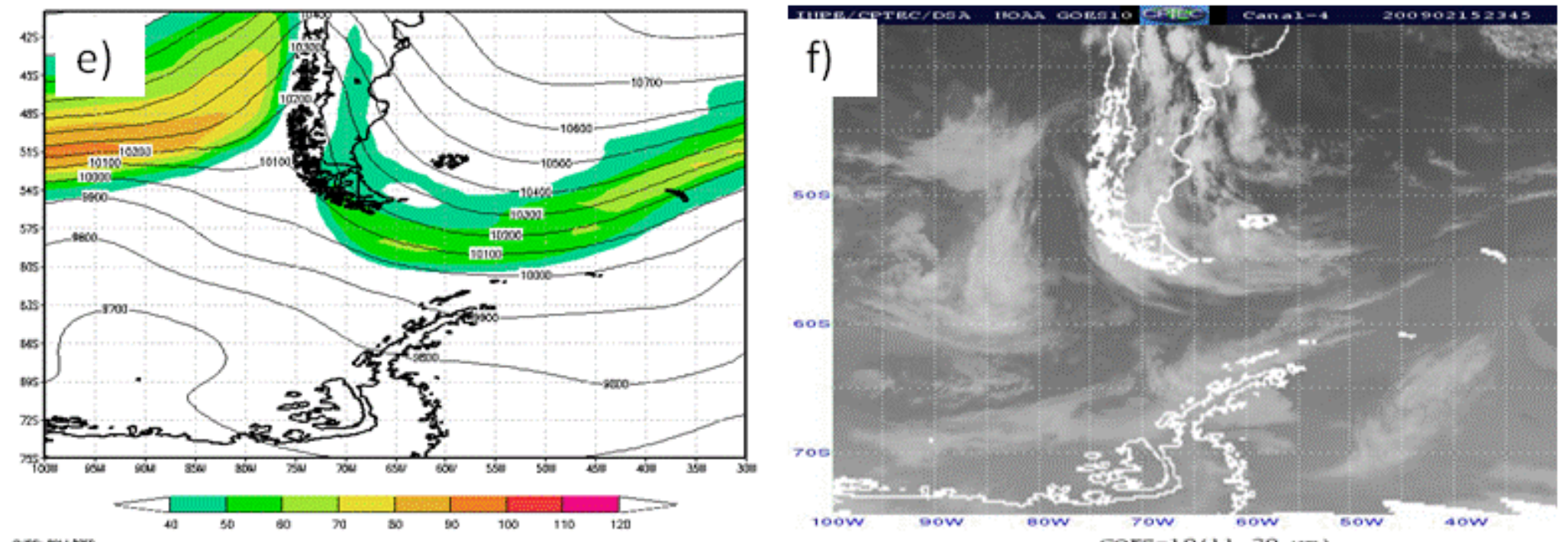

Figura 3.2-2: Continuação 
A figura 3.1-3a mostra que o ciclone no extremo da AS se deslocou mais para sul, estando localizado na passagem de Drake, já o centro de baixa pressão que estava a noroeste do mar de Bellingshausen moveu-se para leste. Além disto, houve uma inclinação do cavado para leste em níveis médios (Figura 3.1-3b) e altos (Figura 3.1-3d), acompanhando a forte advecção quente em 850hPa como mostra a Figura 3.1-3c. Esta advecção e a presença da corrente de jato em 250 hPa (Figura 3.1-3e), atuando no sentido de organizar os movimentos convectivos, culminaram na intensificação da frente quente associada ao ciclone em superfície como pode ser visto na figura 3.1-3f. A advecção de vorticidade ciclônica (Figura 3.1-3d) a leste do cavado contribui para a diminuição da pressão no centro do centro da baixa.

Durante o dia 17 de fevereiro, o centro de baixa pressão que estava na passagem de Drake mantém-se sobre a região, com centro sobre as Ilhas Shetland Sul, onde está localizada a EACF. Entretanto, o centro de baixa que estava mais a oeste $(57 \mathrm{~S} / 82 \mathrm{~W})$ se move para leste, fundindo-se com o primeiro sistema. Desta forma, ocorre a intensificação do ciclone que estava na região de Drake, e isto pode ser visto pelo forte gradiente de pressão na região (Figura 3.1-4a). O vórtice ciclônico atinge a maturidade como mostra a figura 3.13.1-4f, onde bandas alternadas de nebulosidade e ar claro espiralam ao redor de um centro bem definido. Tanto em médios como em altos níveis fecham se baixas no campo do geopotencial que estão empilhadas sobre o centro de baixa pressão em superfície, desfavorecendo os movimentos ascendentes, o que confirma que o ciclone atingiu sua maturidade total.

Além disto, as advecções de temperatura em baixos níveis e de vorticidade relativa em $250 \mathrm{hPa}$, figuras 3.13.1-4c e d, respectivamente, não são suficientes para manter o sistema, de forma que o ciclone entra em fase de decaimento sobre a região do mar de Weddell. 

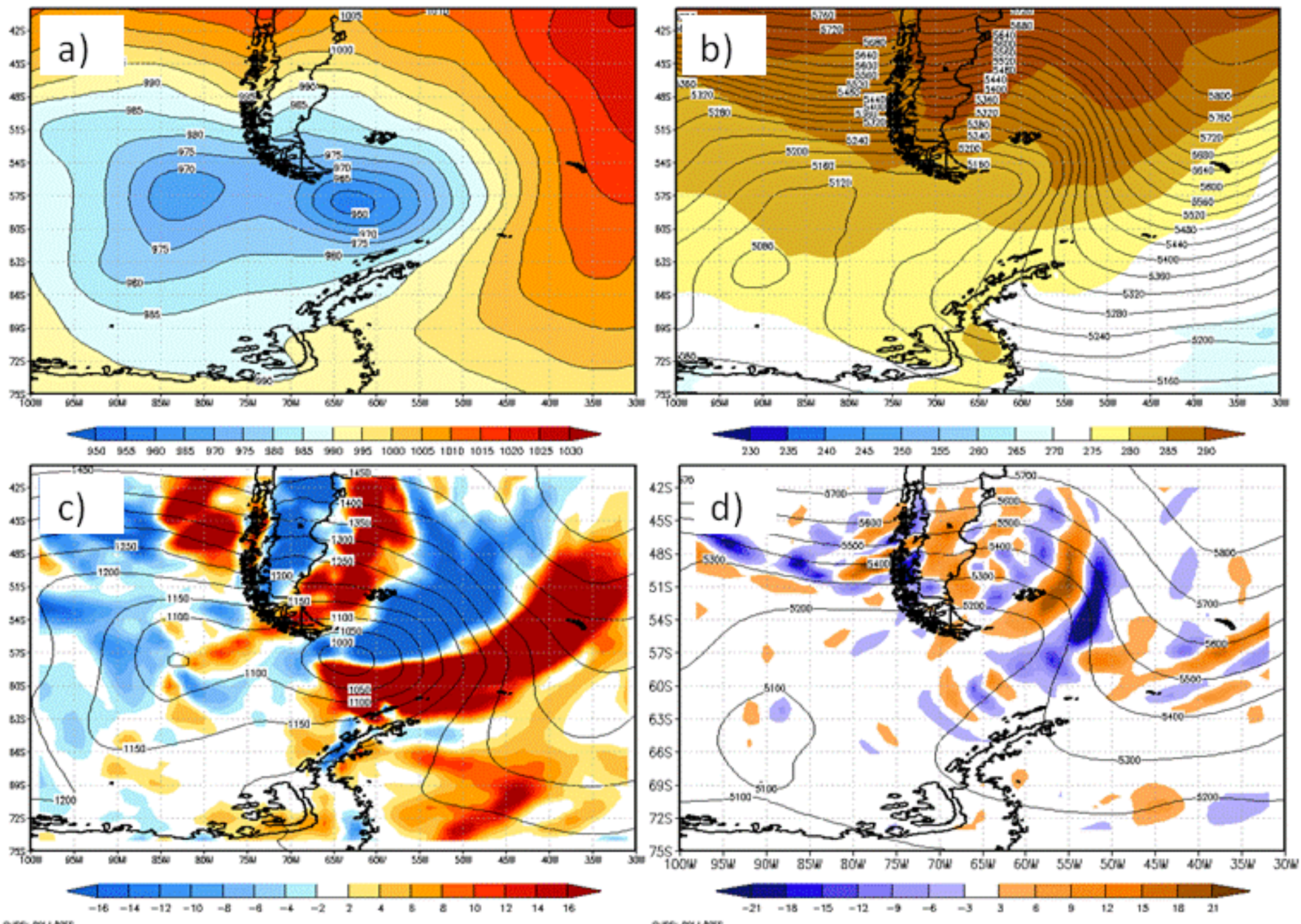

Figura 3.1-3: De (a) a (e) idem à figura 3.1-1, porém para o dia 17 de fevereiro de 2009 as 00 UTC; (f) imagem do satélite GOES-10, no canal infravermelho, do dia 17 de fevereiro as 02:45 UTC 

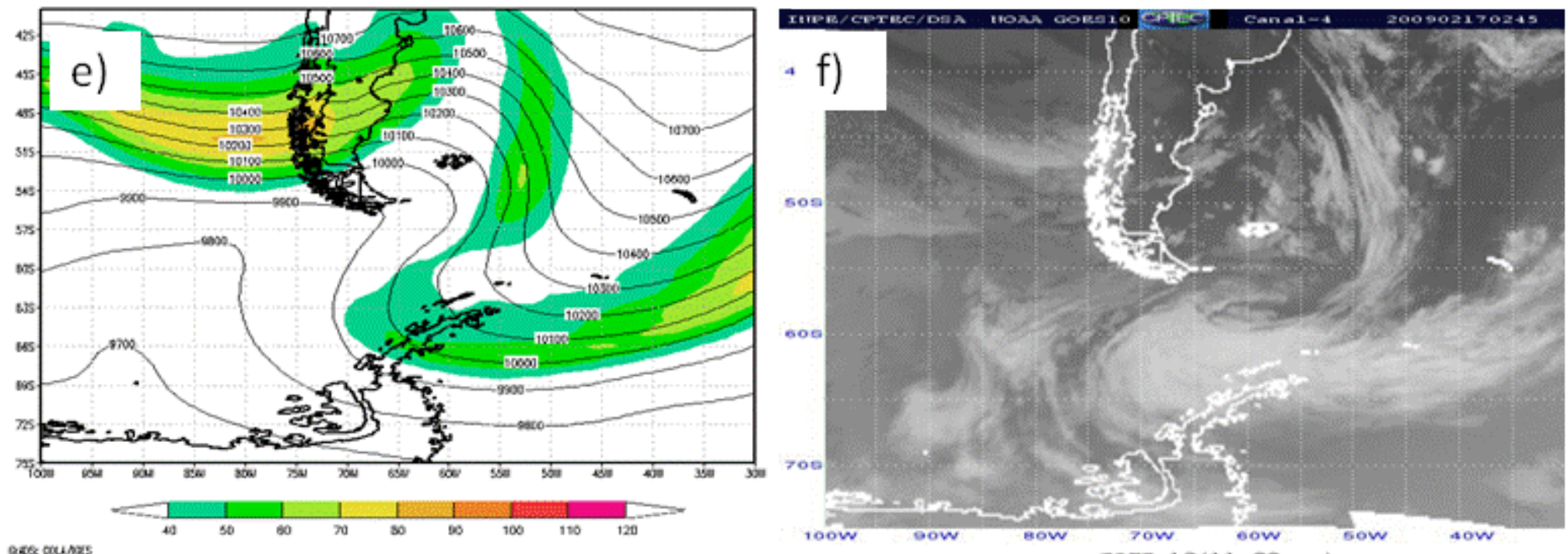

Figura 3.1-3: Continuação 

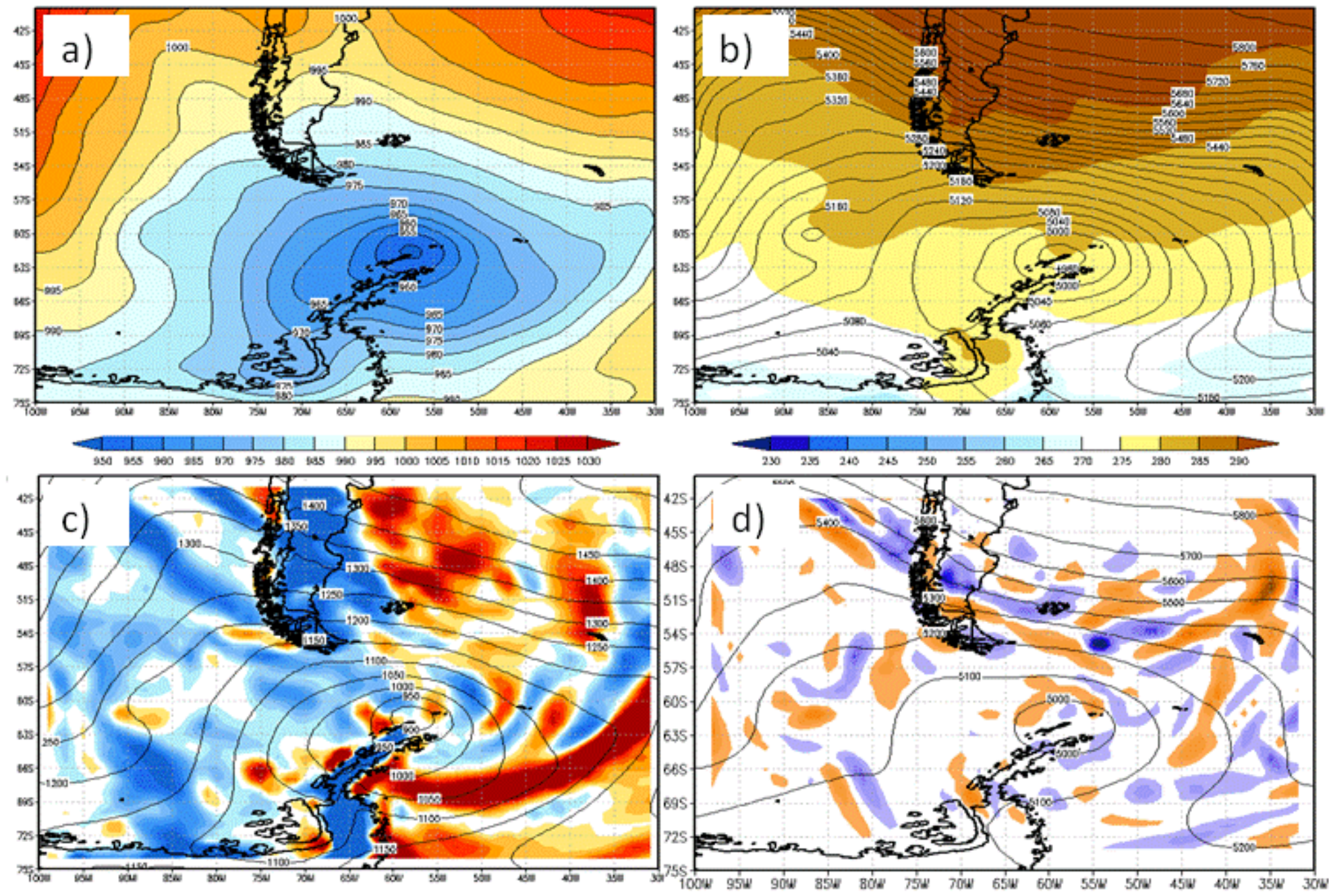

$\operatorname{arcsense}$
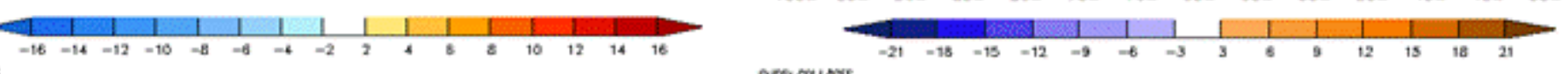

Figura 3.1-4: De (a) a (e) idem à figura 3.1-1, porém para o dia 18 de fevereiro de 2009 as 00 UTC; (f) imagem do satélite GOES-10, no canal infravermelho, do dia 17 de fevereiro as 20:45 UTC 

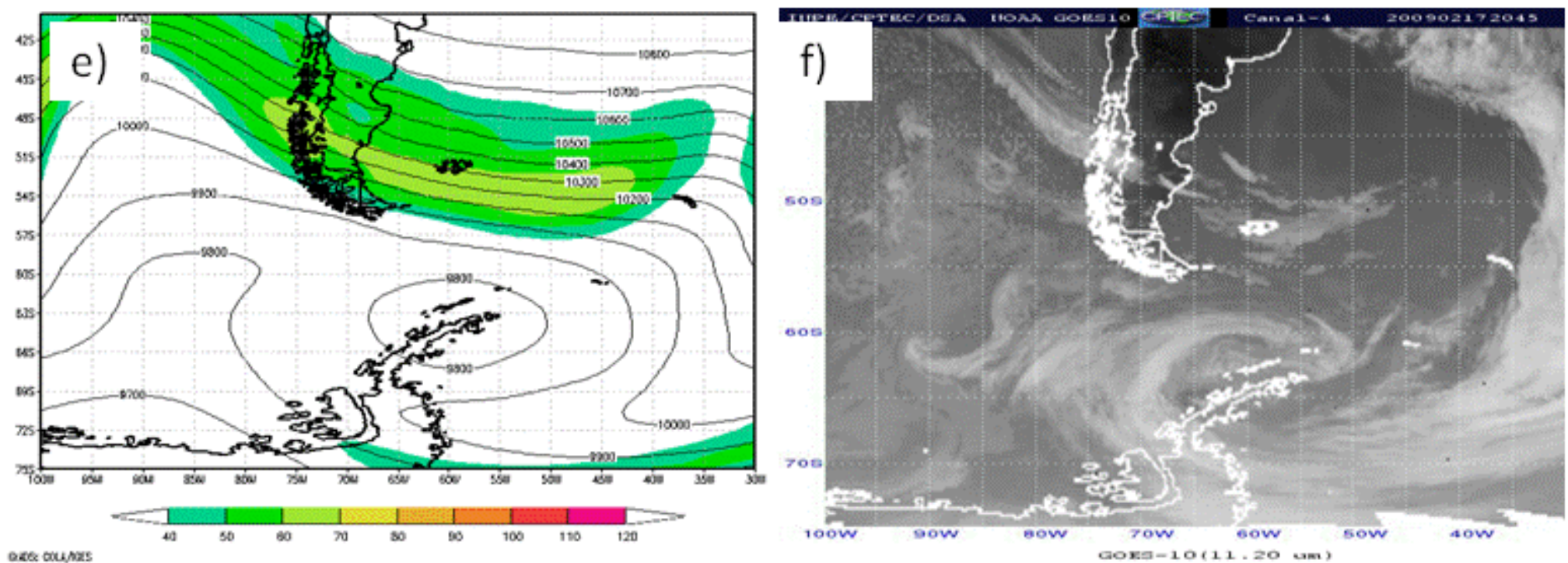

Figura 3.1-4: Continuação 


\subsubsection{CASO DE JULHO}

No caso de julho de 2009, na Figura 3.1-5a pode ser observado um centro de baixa pressão a noroeste do mar de Bellingshausen, associado a uma banda de nebulosidade frontal (Figura 3.1-5f). Outros três centros de baixa podem ser vistos na área de interesse, um a leste da península Antártica, um a leste do extremo sul da AMS e um terceiro sobre o oceano Atlântico localizado em 52S/32W. Em níveis médios um cavado de pequena amplitude no campo do geopotencial (Figura 3.1-5b), localizado em 60S/90W a oeste da baixa em superfície, dá suporte ao ciclone em superfície.

Vinte e quatro horas depois, a advecção de vorticidade ciclônica em $500 \mathrm{hPa}$ (Figura 3.1-6d) e a advecção positiva de temperatura em 850 hPa (Figura 3.1-6c), que estão a leste do cavado de níveis médios e o posicionamento da região de divergência na saída do jato (Figura 3.1-6e), geram condições favoráveis a manutenção do ciclone em superfície, pois dão suporte aos movimentos verticais. 

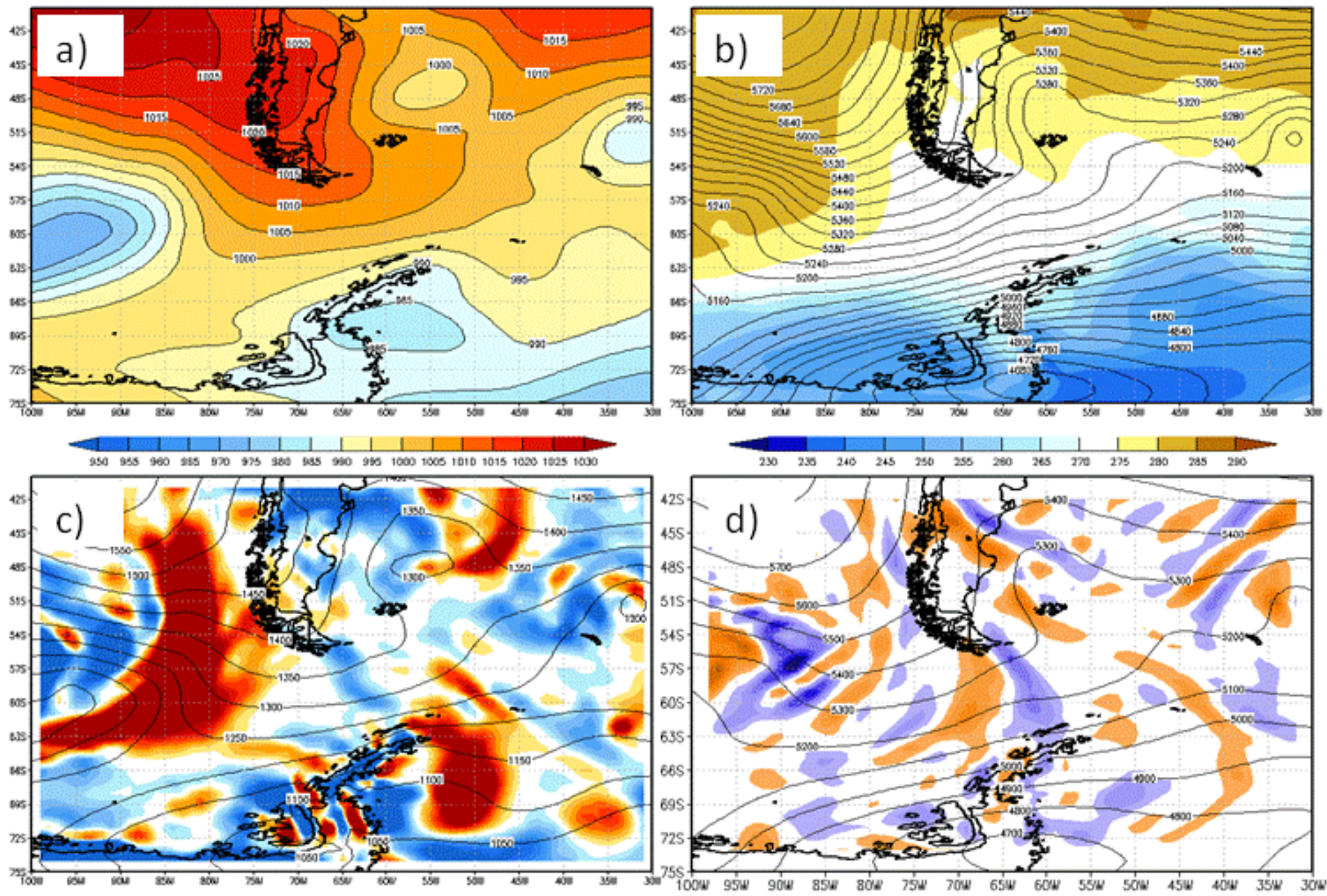

ascosines
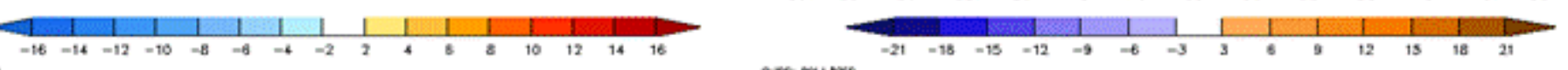

Figura 3.1-5: De (a) a (e) idem à figura 3.1-1, porém para o dia 10 por de julho de 2009 as 00 UTC; (f) imagem do satélite GOES-10, no canal infravermelho, do dia 10 de julho as 23:45 UTC 

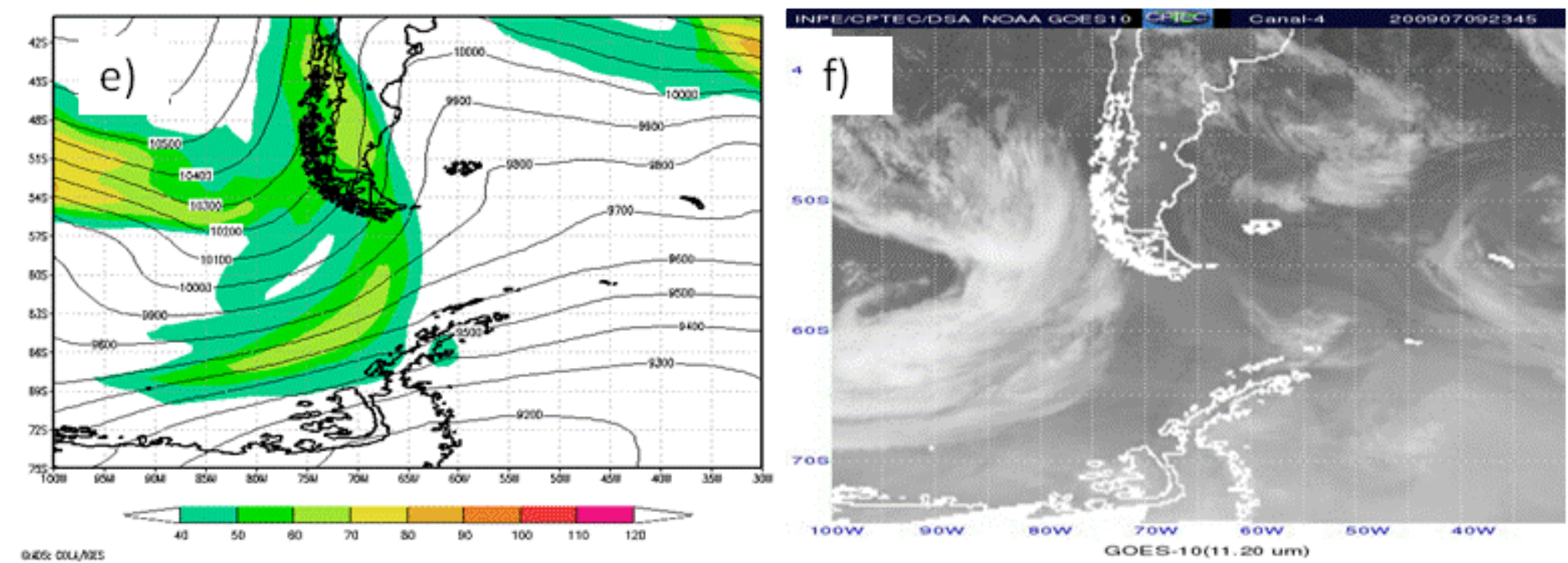

Figura 3.1-5: Continuação 

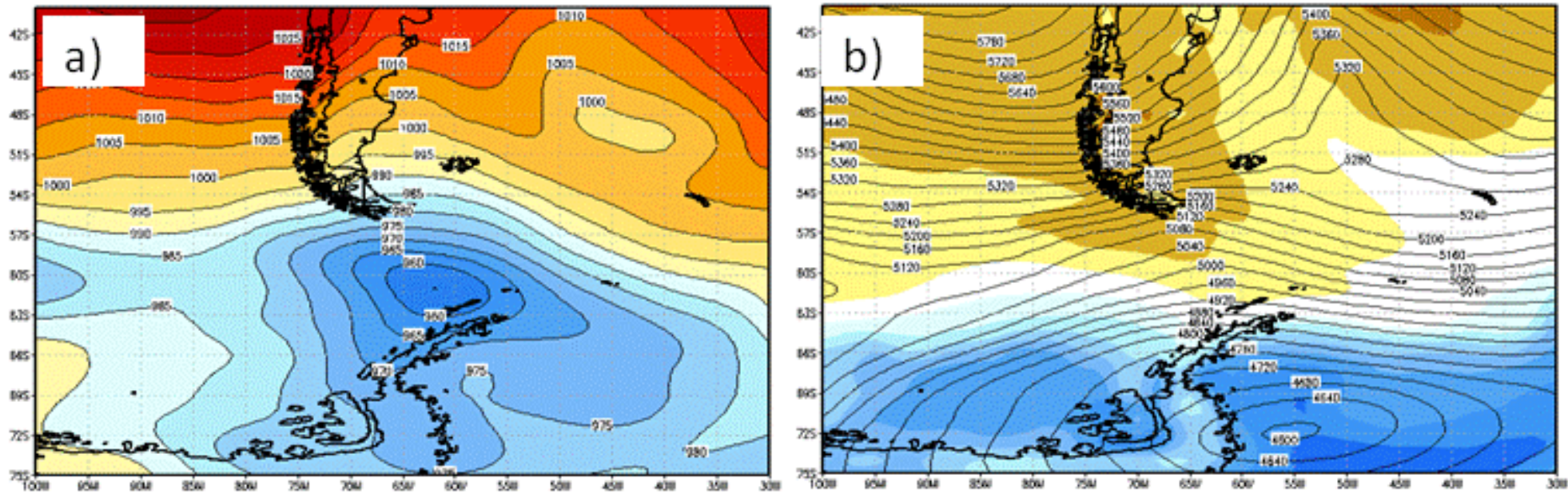

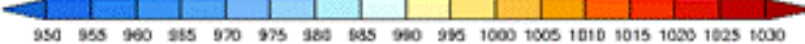
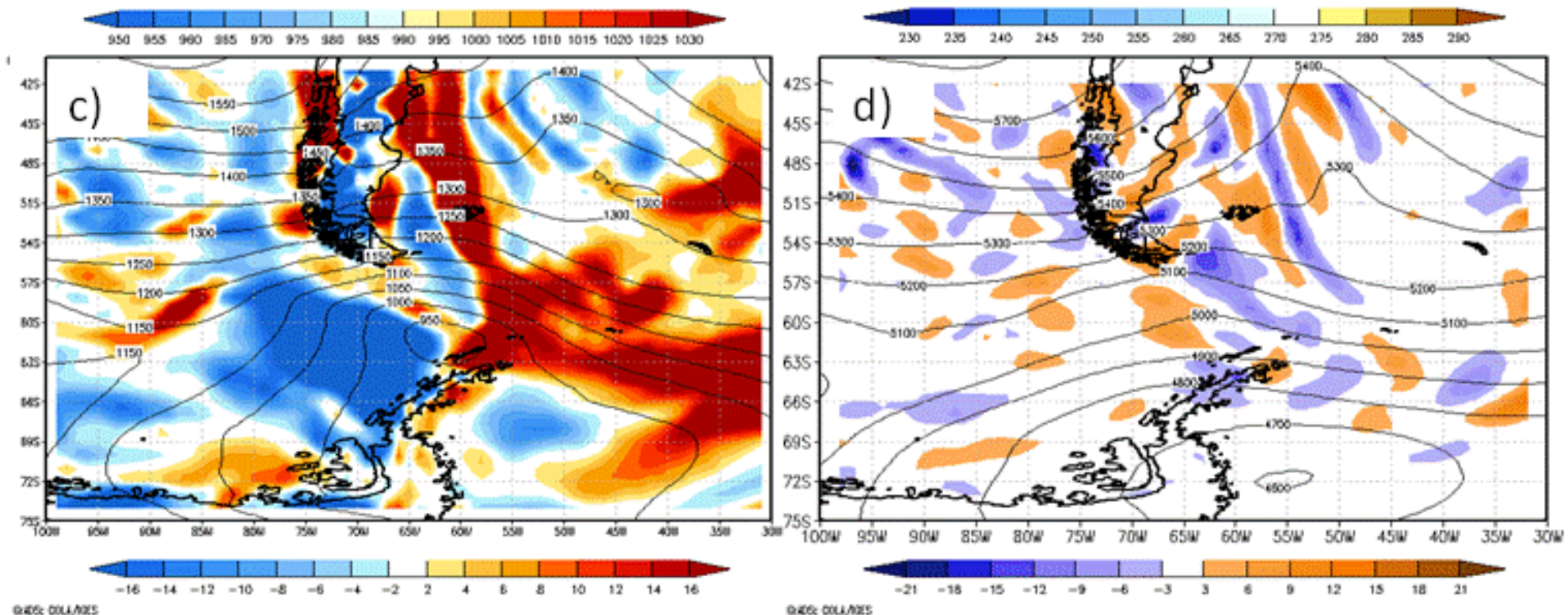

Figura 3.1-6: De (a) a (e) idem à figura 3.1-1, porém para o dia 11 de julho de 2009 as 00 UTC; (f) imagem do satélite GOES-10, no canal infravermelho, do dia 10 de julho as 23:45 UTC 

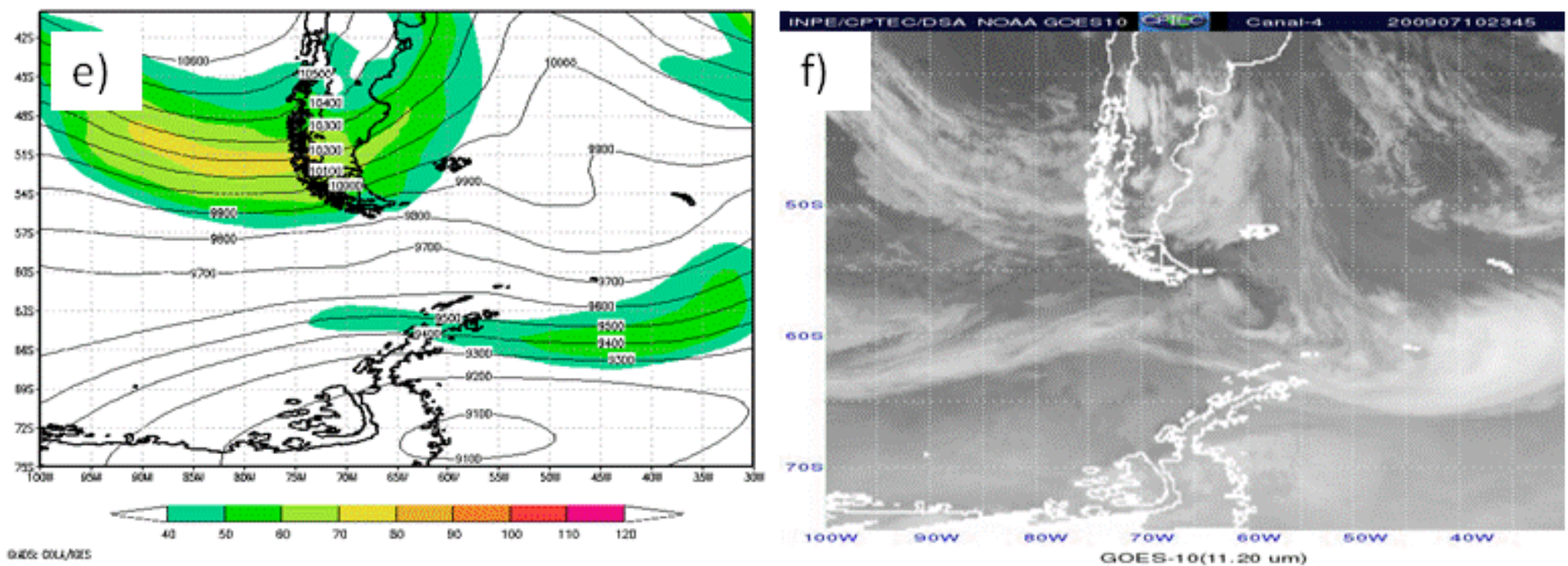

Figura 3.2-6: Continuação 
Durante o dia 10 de julho o ciclone que estava a noroeste de Bellingshausen moveu-se em direção a passagem de Drake, região com maior gradiente térmico (Figura 3.1-6b), onde no dia 11 de julho ele está localizado, apresentando $960 \mathrm{hPa}$ no centro do sistema como mostra a Figura 3.1-6a. Já o centro de baixa pressão que estava a leste da PA decaiu sobre o mar de Weddell e se transformou em uma região de baixa pressão que se estende em direção a baixa que está agindo sobre as Ilhas Shetland Sul. A baixa que estava a leste da costa da AS se deslocou para sudeste. A forte advecção de ar frio na retaguarda da frente (Figura 3.1-6c) e a fraca advecção de vorticidade relativa negativa (Figura 3.1-6d) a leste do cavado em altos níveis contribuem para o enfraquecimento do vórtice ciclônico que está localizado ao norte da PA, como pode ser visto na imagem de satélite do canal infravermelho (Figura 3.1-6f). A corrente de jato não contribui positivamente para a manutenção do sistema, como se observa na figura 3.1-6e.

Na figura 3.1-7, do dia 12 de julho as 00 UTC fica evidente o deslocamento do ciclone em direção ao mar de Weddell. A nebulosidade associada ao vórtice dissipou-se quase completamente como mostra a imagem de satélite (Figura 3.1-7f). As baixas no campo de geopotencial em níveis médios (Figura 3.1-7b) e altos (Figura 3.1-7d,e) indicam o desacoplamento do sistema em superfície com a média e alta troposfera. E ainda, a advecção fria na retaguarda (Figura 3.1-7c) contribuiu para a dissipação da banda frontal. 

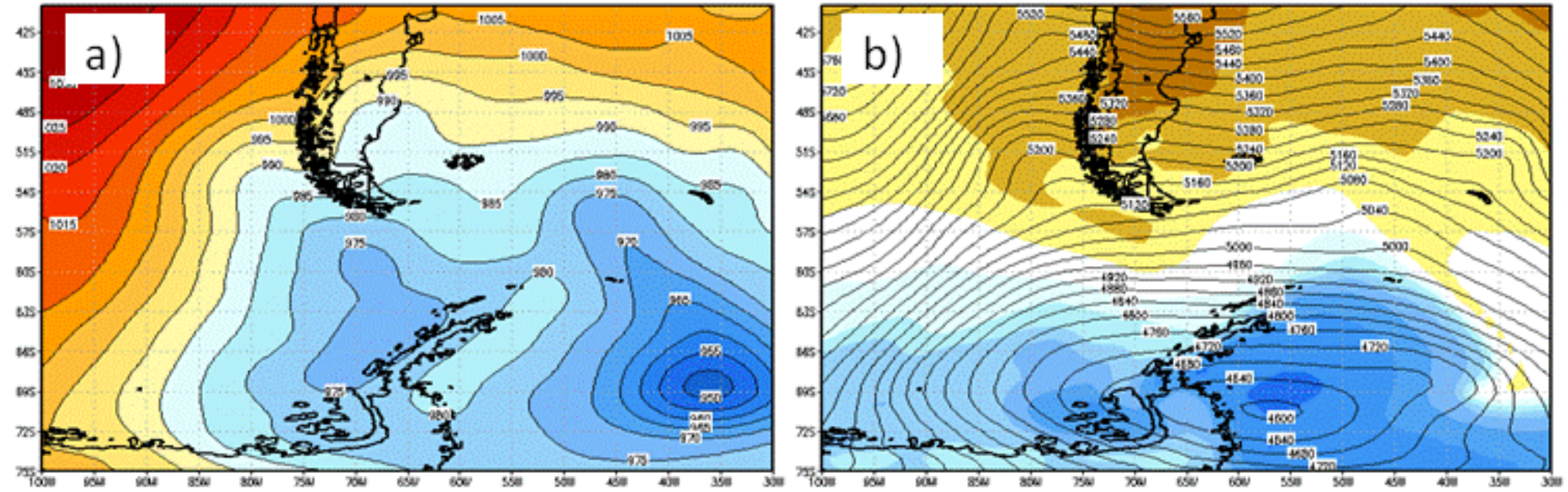

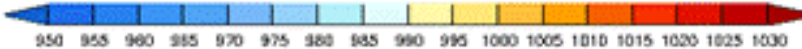

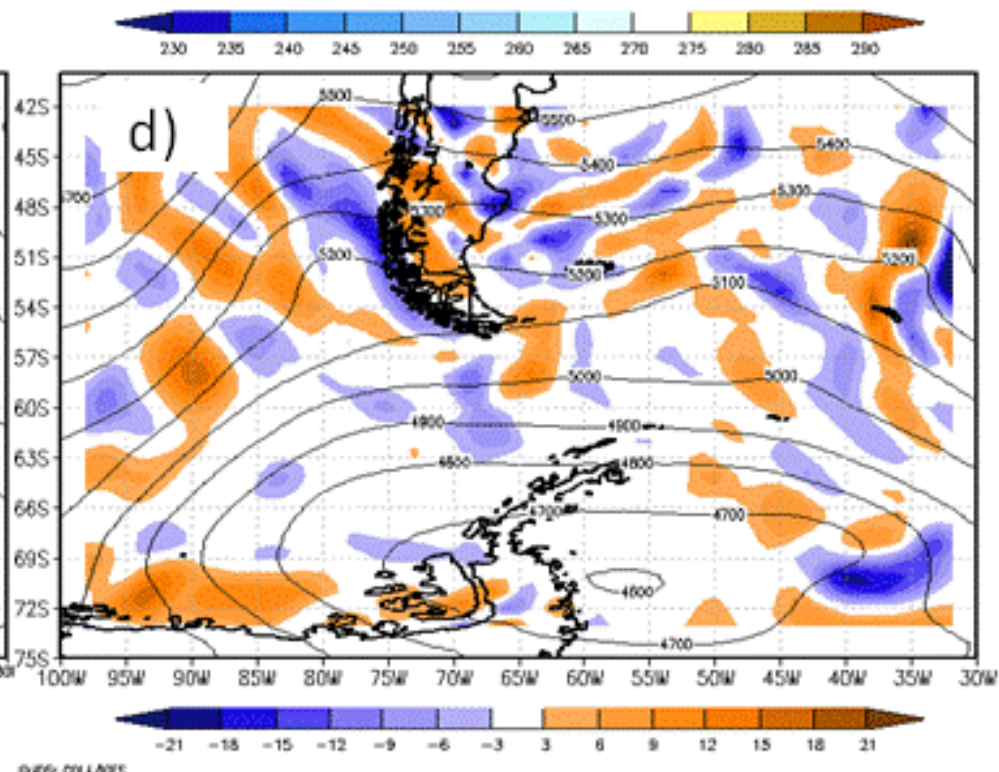

Figura 3.1-7 De (a) a (e) idem à figura 3.1-1, porém para o dia 12 de julho de 2009 as 00 UTC; (f) imagem de satélite do canal infravermelho do dia 11 de julho as 23:45 UTC 

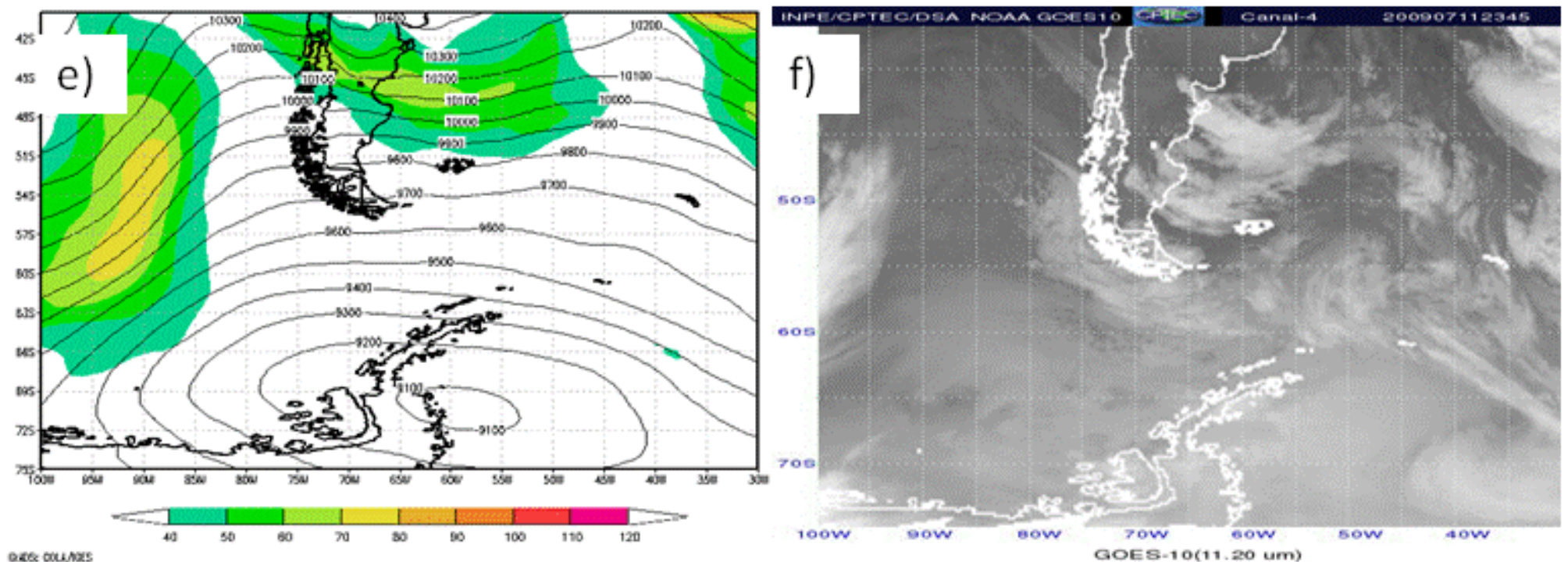

Figura 3.2-7: Continuação 


\subsubsection{COMPARAÇÃO DOS CASOS}

A figura 3.1-8 mostra os valores de pressão reduzida ao nível médio do mar e temperatura do ar em superfície, observados na EACF durante a passagem, pela região da PA, dos ciclones descritos anteriormente. Nesta figura, o horário "zero" representa as 00 UTC do dia 15 no caso de fevereiro e as 00 UTC do dia 09 no caso de julho de 2010. Nota-se que apesar do ciclone de fevereiro ter atingido valores de pressão menores do que aqueles observados durante a passagem do sistema de julho, a temperatura do ar não apresentou variações muito significativas. Por outro lado, observa-se que, quando se atinge o menor valor de pressão no evento de julho, a temperatura começa a diminuir drasticamente, com uma variação de aproximadamente 15으 $\mathrm{C}$ em cerca de 4 horas. Logo após o mínimo de pressão ser observado, a mesma aumenta gradativamente enquanto que a temperatura continua a decrescer, indicando que uma massa de ar muito frio está atuando sobre a estação.

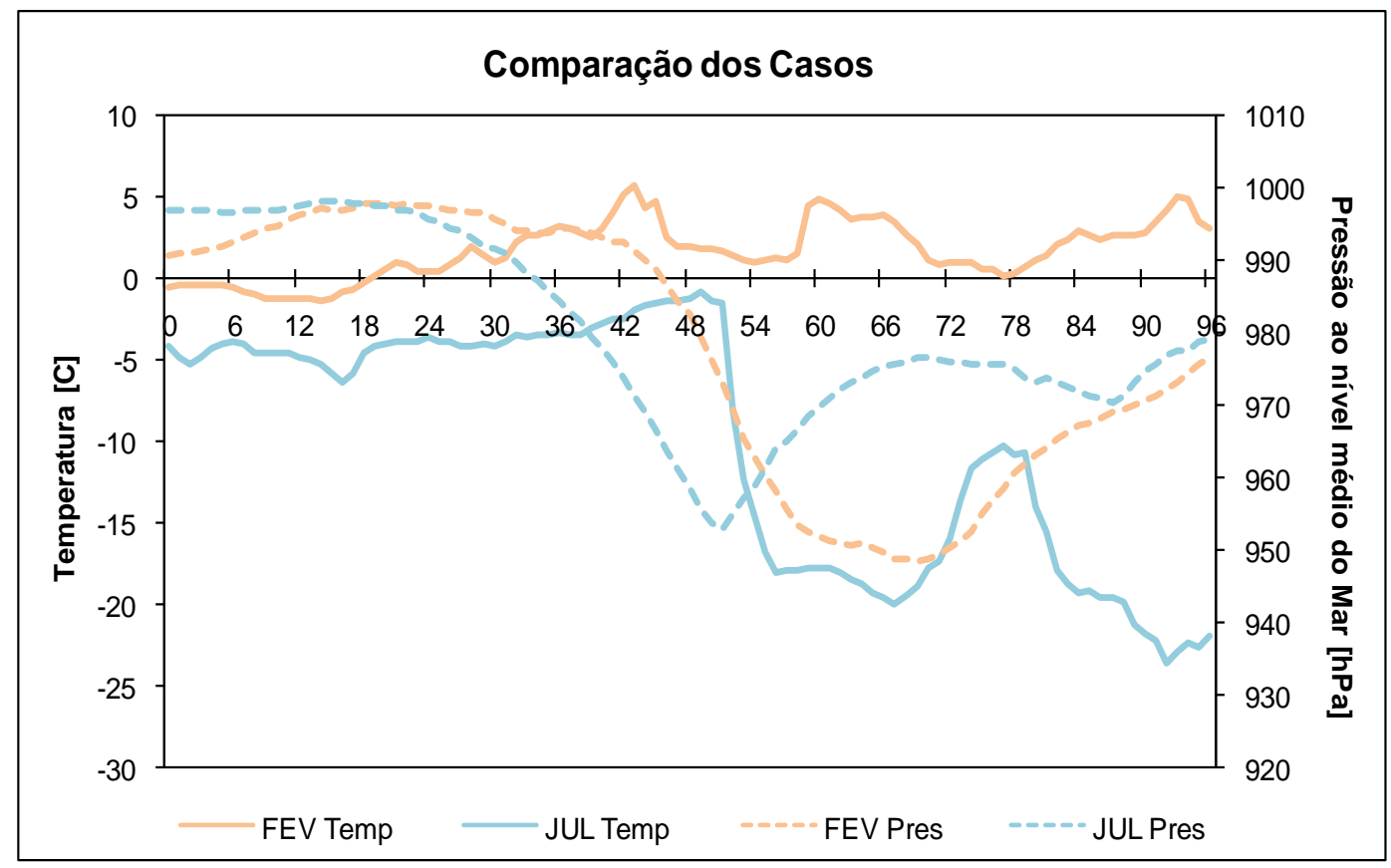

Figura 3.1-8: Observação da temperatura e pressão na EACF. As linhas cheias representam a temperatura do $\operatorname{ar}\left({ }^{\circ} \mathrm{C}\right)$ e as linhas tracejadas a pressão ao nível médio do mar $(\mathrm{hPa})$, para os casos de fevereiro (laranja) e julho (azul) de 2009. A hora "zero" no gráfico representa o horário de 00 UTC do dia 15 no caso de fevereiro e 00 UTC do dia 09 no caso de julho de 2009

Na figura 3.1-9, que mostra o escoamento e a temperatura do ar em baixos níveis para o caso de fevereiro $(a, b, c)$ e o de julho $(d, e, f)$ a partir do momento em 
que o centro dos ciclones está sobre a região das ilhas Shetland Sul. No primeiro momento de cada um dos casos, observa-se que em julho (fig. 3.1-9d), diferentemente do caso de fevereiro (fig. 3.1-9a), existe uma região de circulação horária sobre o mar de Weddell localizada em 69S/48W.
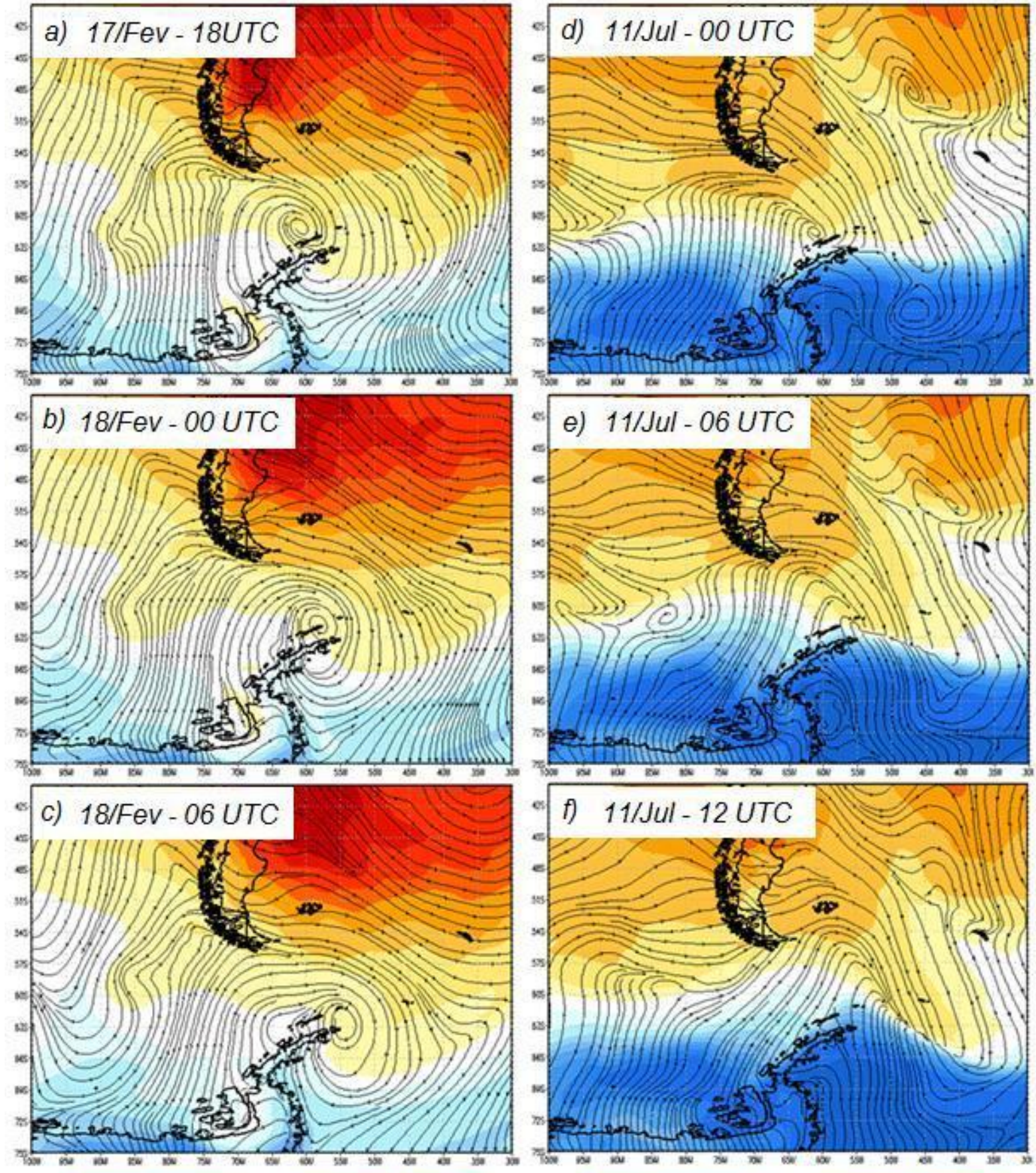

oescouna:

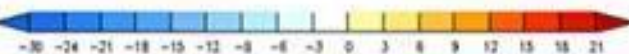

oescouns

Figura 3.1-9: Temperatura do ar a 2 metros $\left[{ }^{\circ} \mathrm{C}\right]$ em sombreado e Linhas de corrente em 925 $\mathrm{hPa}$, nos dias e horários indicados na figura. 
A circulação horária relacionada a esta região de confluência, que por sua vez esta associada ao ciclone ao norte da PA, faz com que o ar frio vindo do interior do continente Antártico chegue à EACF. Isto fica evidente nas figuras Figura 3.1-9d e Figura3.1-9e, onde se nota um forte escoamento de sul, à leste da cadeia de montanhas. Assim, o escoamento força a advecção de ar muito frio e seco para a retaguarda da frente, região das ilhas Shetland Sul, como mostra a Figura 3.1-10b. Este tipo de atuação de ciclones em conjunto foi também encontrado por Felício (2007), onde encontrou que quando há um vórtice ciclônico em superfície sobre a região do mar de Weddel, a circulação horária determina a predominância dos ventos e direciona a advecção fria para a EACF. Por outro lado, no caso de fevereiro, quando não há uma circulação horária sobre o mar de Weddell, o escoamento tem uma componente de norte mais significativa que joga ar mais quente em direção às Ilhas Rei George, fazendo com que a advecção negativa de temperatura na retaguarda da frente torne-se menos intensa (fig. 3.1-10a).

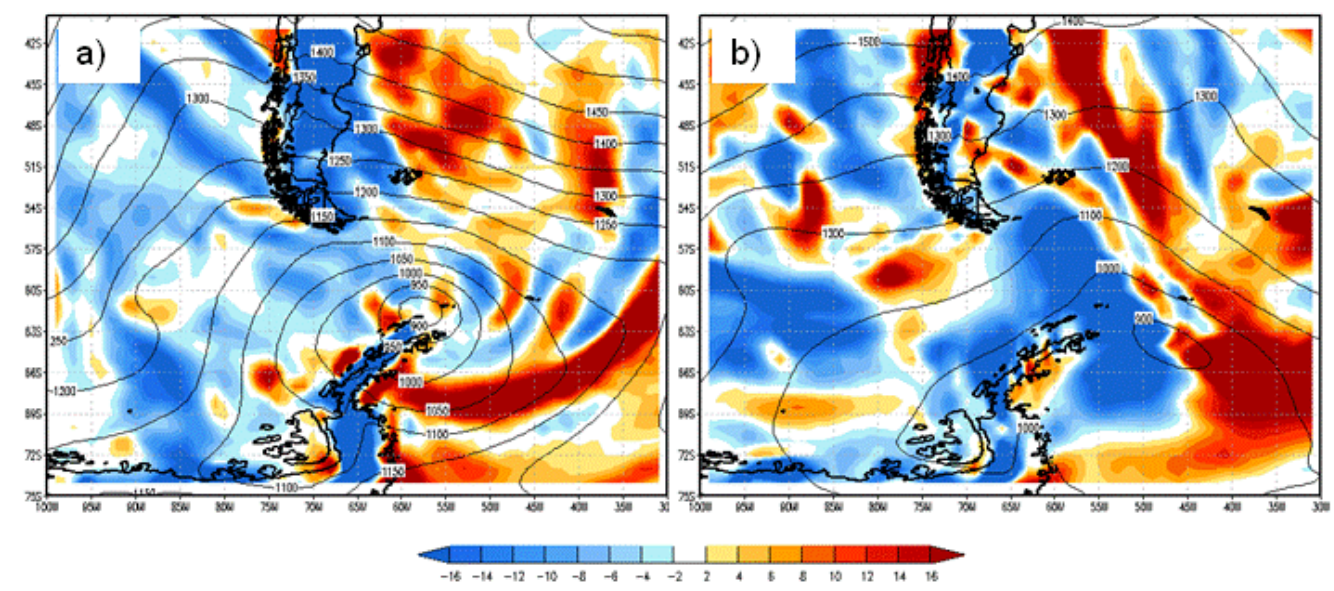

Figura 3.1-10: Altura geopotencial $(\mathrm{m})$ nas linhas e advecção de temperatura em $850 \mathrm{hPa}$ em (K/dia), para o caso de fevereiro (a) e para o caso de julho de 2009 (b)

\subsection{ANÁLISE QUALITATIVA DAS SIMULAÇÕES}

As figuras que fazem parte da análise qualitativa mostram as séries temporais de cada estação para uma dada variável. Aqui será avaliado o comportamento de cada simulação em relação às observações.

Nas figuras que serão apresentadas a seguir, a série representada pelos losangos pretos são as observações nas estações de superfície, as bolas vermelhas as análises do GFS e os triângulos azuis são as previsões do GFS para os mesmos 
pontos das estações. Todas as séries representadas por linhas são os experimentos numéricos realizados com o BRAMS, sendo que as linhas cheias vermelhas são a simulação controle (CTR) que possui as mesmas características do modelo operacional, onde nenhuma configuração especial foi implementada para a área de estudo. Já as linhas cheias verdes representam a simulação onde a frequência de atualização das condições de fronteira (ATF) foi alterada, de a cada seis horas para a cada três horas. A simulação onde foi utilizada uma versão do modelo BRAMS que possui gelo marinho (GEL) é descrita pelas linhas cheias roxas, já a simulação G25 que possui maior resolução horizontal é evidenciada pelas linhas cheias azuis. Todas as linhas tracejadas dizem respeito às simulações que envolvem nudging central (NDC), nelas os tempos de relaxação foram alterados para 1h (N01), 6h (N06), 12h (N12) e 24h (N24), sendo representadas pelas cores laranja, azul rosa e verde, respectivamente.

O eixo "x" nas figuras representa a variação no tempo e está no formato DDHH, onde os dois primeiros dígitos (DD) representam o dia e os dois últimos $(\mathrm{HH})$ a hora em relação ao meridiano de Greenwich (UTC).

\subsubsection{TEMPERATURA DO AR}

\subsubsection{FEVEREIRO}

A figura 3.2-1 mostra as variações de temperatura ${ }^{4}$ para a EACF. No dia 16 de fevereiroa temperatura do ar era cerca de 0,5ㄷ․ No decorrer deste dia, a temperatura tendeu a uma elevação, atingindo um máximo de $5,2^{\circ} \mathrm{C}$ às 18 UTC. $\mathrm{A}$ partir de então, a temperatura voltou a cair, comportamento este que adentrou a madrugada do dia 17 de fevereiro, quando foi então observada a temperatura mínima de $0,9^{\circ} \mathrm{C}$. No mesmo dia a máxima alcançou $4,9^{\circ} \mathrm{C}$. Já no dia 18 de fevereiro a mínima chegou a $0,3^{\circ} \mathrm{C}$ às 06 UTC, subiu nas horas seguintes e permaneceu próxima dos $3^{\circ} \mathrm{C}$ entre às 09 UTC e 18 UTC, atingindo a máxima somente às 21 UTC quando a temperatura chegou aos $5^{\circ} \mathrm{C}$.

\footnotetext{
${ }^{4} \mathrm{~A}$ temperatura do ar a $2 \mathrm{~m}$ é mencionada nestas análises apenas como "temperatura".
} 
De modo geral, o modelo tentou simular as variações de temperatura na EACF, diferentemente da análise e da previsão do GFS que mostraram pouca variação da temperatura, com valores entre $-1,5^{\circ} \mathrm{C}$ e $2,0^{\circ} \mathrm{C}$. Porém, os valores de temperatura do BRAMS são, em geral, mais elevados que aqueles observados. O modelo não consegue simular adequadamente as quedas da temperatura, sendo que 0 experimento G25 foi o que se saiu melhor neste sentido. O experimento ATF, onde se considera uma maior frequência de atualização dos dados de fronteira, simula melhor os picos mais altos da temperatura mas, a partir das 09 UTC do dia 17, permanece com a temperatura mais elevada que os demais experimentos, na maior parte do tempo.

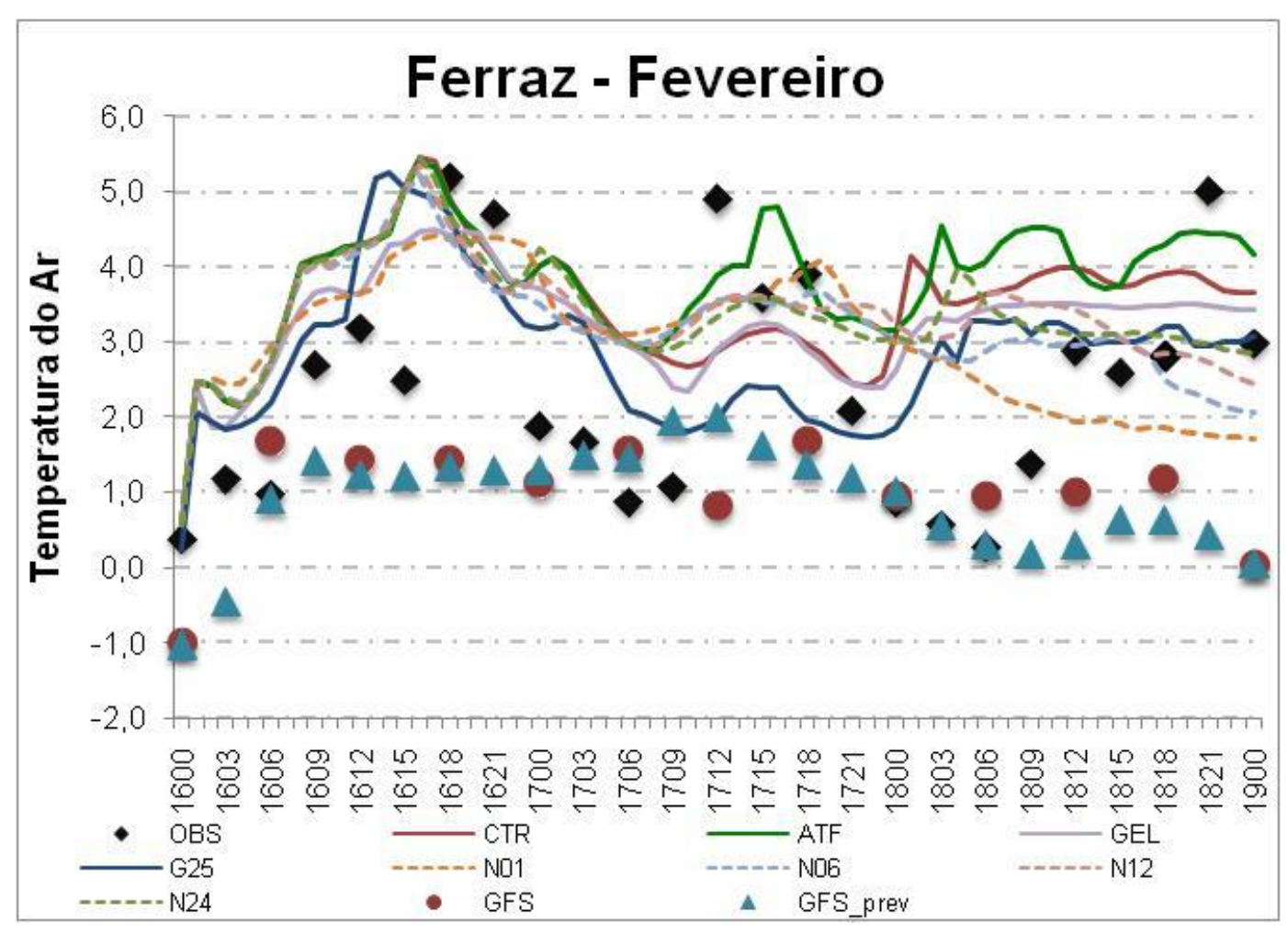

Figura 3.2-1: Série temporal da temperatura do ar para a EACF no evento de fevereiro 


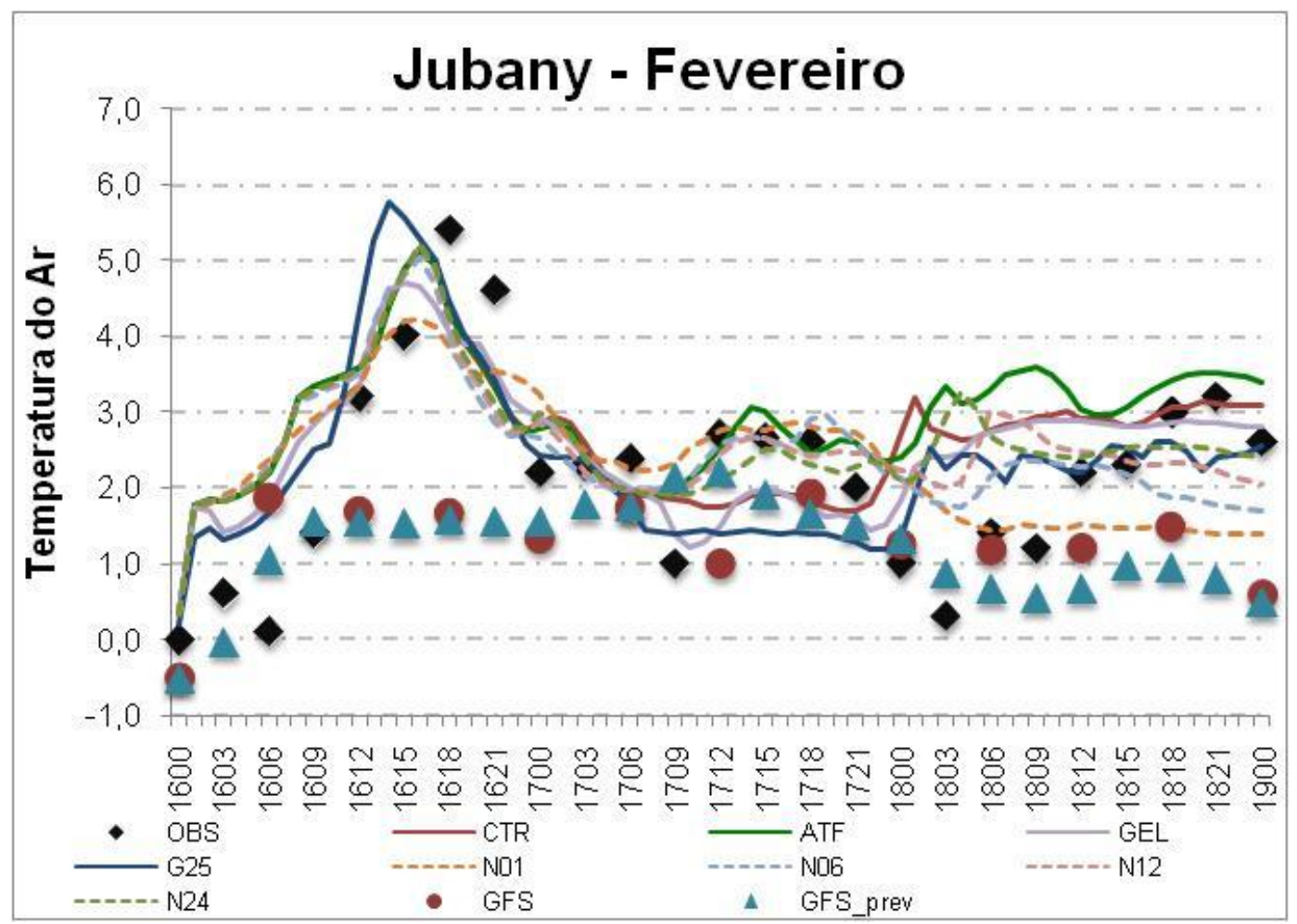

Figura 3.2-2: Série temporal da temperatura do ar para a estação Jubany no evento de fevereiro

$\mathrm{Na}$ estação Jubany (fig. 3.2-2), o dia 16 de fevereiro começou com temperatura de $0 \stackrel{\circ}{\circ}$ aos poucos a temperatura entrou em elevação e atingiu a máxima de $5,4^{\circ} \mathrm{C}$ às 18 UTC. A partir de então entrou em declínio, padrão que se manteve na madrugada do dia 17 de fevereiro. Às 09 UTC, a estação Jubany registrou $1^{\circ} \mathrm{C}$, sendo esta a menor temperatura do dia. Já no dia 18 de fevereiro é possível observar uma pequena amplitude térmica, onde as temperaturas oscilaram entre $0,3^{\circ} \mathrm{C}$ e $3,2^{\circ} \mathrm{C}$. Fica claro, também, que nem a análise e nem a previsão do GFS conseguiram captar adequadamente as variações de temperatura registradas na estação e, além disso, os valores de temperatura ficaram muito abaixo dos observados.

Para a estação Jubany o modelo foi melhor ao simular as variações de temperatura. $\mathrm{O}$ experimento GEL apresenta-se cerca de $0,5^{\circ} \mathrm{C}$ mais frio quando foi registrado o máximo de temperatura do período. O segundo pico na série só foi simulado pelos experimentos ATF, GEL, N01, N06, N12 e N24. Já o experimento G25 apresentou o maior valor de temperatura dentre todas as rodadas. Outro fato a ser notado é que nenhum dos experimentos representou adequadamente as variações de temperatura do dia 18 de fevereiro. 
Dentre as estações com as quais foi possível analisar o comportamento das variáveis meteorológicas durante a passagem do ciclone no mês de fevereiro, Marambio (fig.3.2-3) foi a que apresentou menos variações na temperatura. Após a mínima de $-3,6^{\circ} \mathrm{C}$ às 03 UTC do dia 16 de fevereiro, a temperatura entrou em elevação até o meio da tarde, que foi quando alcançou a máxima de -0,4ㄷ․ Após as 18 UTC do dia 16, observa-se poucas variações de temperatura até às 18 UTC do dia 17. A partir disso, a estação registrou uma acentuada queda de temperatura, que se estendeu do dia ao longo da madrugada do dia 18, atingindo um mínimo de $4,7^{\circ} \mathrm{C}$ às 15 UTC. É importante observar, ainda, que a temperatura da previsão do GFS esteve, durante todo o período em análise, mais quente em relação às demais séries de dados, sejam elas simuladas ou observadas.

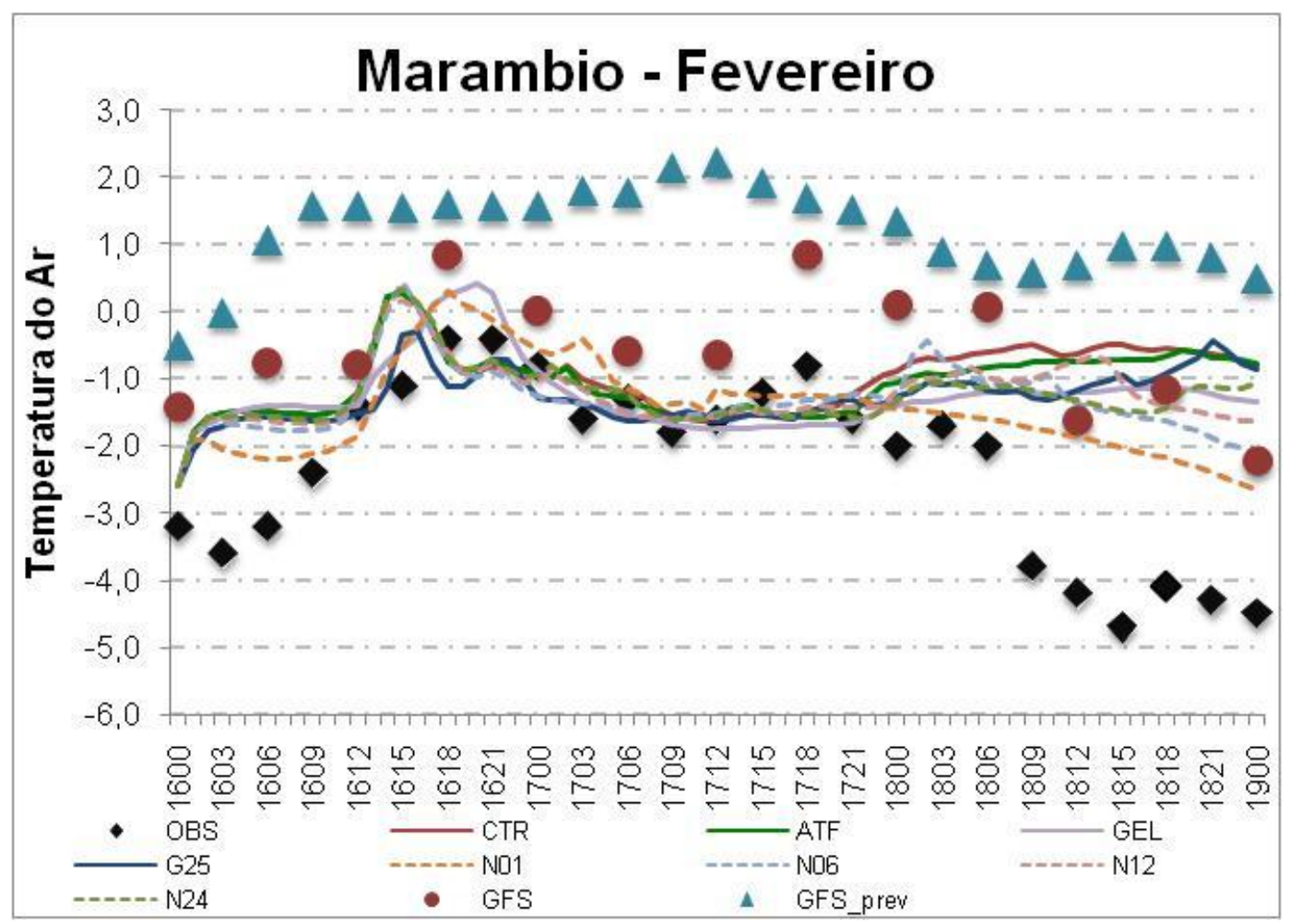

Figura 3.2-3: Série temporal da temperatura do ar para a estação Marambio no evento de fevereiro

O modelo tentou simular as variações de temperatura na estação Marambio (fig. 3.2-3), se mostrando pior a partir das 06 UTC do dia 18 de fevereiro quando houve um resfriamento mais intenso do ar. O experimento N06, mesmo que de maneira bem sutil, conseguiu prever o aumento de temperatura que ocorreu às 03 
UTC do dia 18. O experimento GEL foi aquele que melhor representou o aumento da temperatura observado às 18 UTC do dia 16.

A figura 3.2-4 apresenta as variações de temperatura da estação Arturo Pratt, entre os dias 16 e 18 de fevereiro. Desde as 00 UTC do dia 16 a temperatura esteve em elevação até que atingiu sua máxima às 00 UTC do dia 17 de fevereiro, chegando aos $2^{\circ} \mathrm{C}$. Durante o dia 17 e 18, a temperatura entrou em declínio, que foi seguido de um acentuado aquecimento da atmosfera no dia 18.

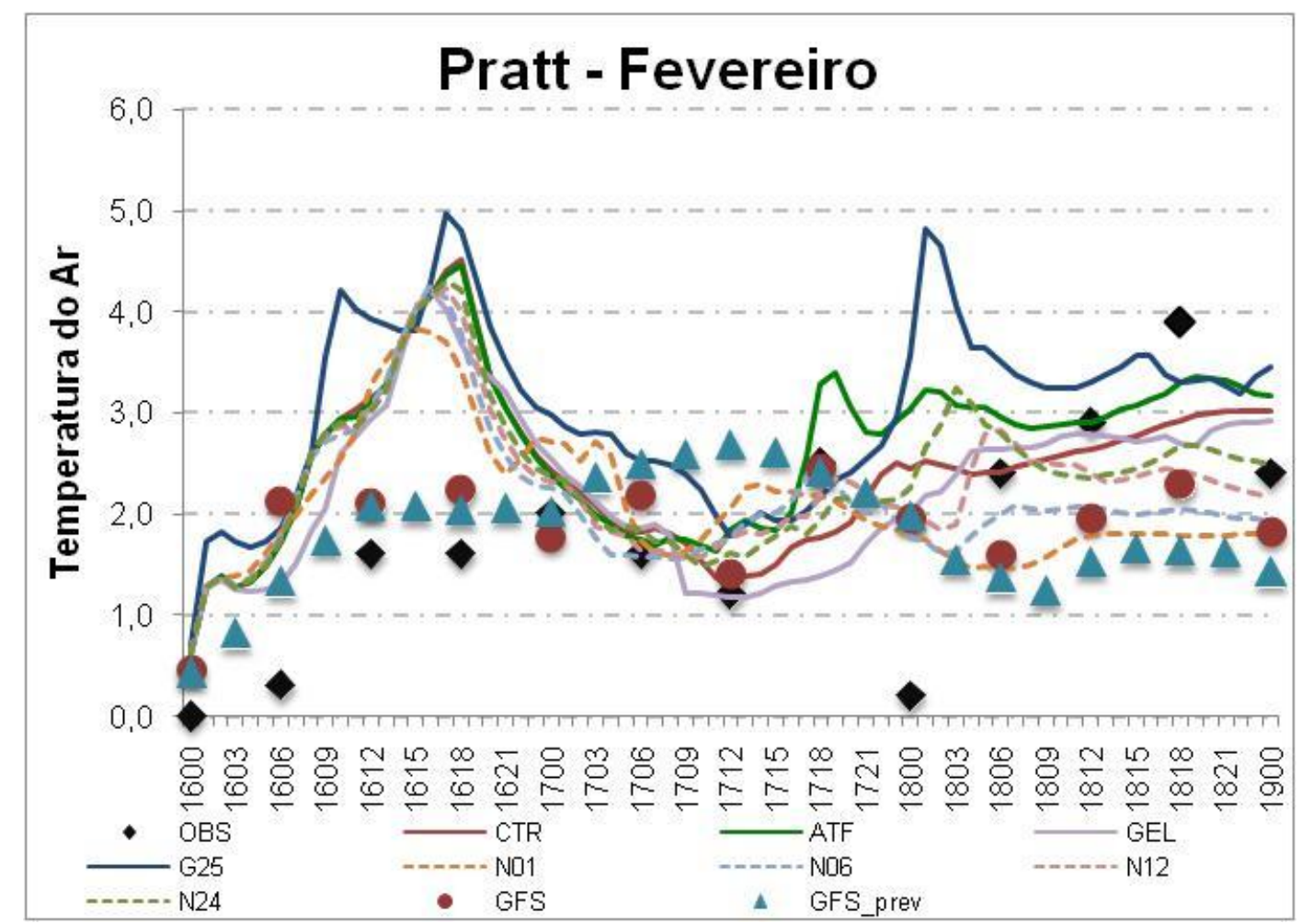

Figura 3.2-4: Série temporal da temperatura do ar para a estação Pratt no evento de fevereiro

Na estação Pratt (fig. 3.2-4) o modelo simulou um pico de temperatura entre às 15 UTC e 18 UTC do dia 16 de fevereiro e, também, entre às 03 UTC e 06 UTC do dia 18. Os experimentos G25 e ATF são aqueles que mostraram os maiores valores de temperatura. Além disso, o experimento ATF foi o único que tentou representar o aumento de temperatura registrado às 18 UTC do dia 17 de fevereiro. Os experimentos N06 e N12, mesmo sutilmente, tentaram simular a queda de temperatura que ocorreu às 00 UTC do dia 18. O experimento GEL simula o primeiro pico de temperatura, assim como as demais simulações, porém as variações posteriores das temperaturas são bem sutis, assim como ocorre com a previsão do GFS. 
Observando a figura 3.2-5, que mostra oscilações da temperatura do ar na estação Eduardo Frei para o período de 16 a 19 de fevereiro de 2009, fica bem evidente as bruscas variações de temperatura durante a passagem do ciclone no mês de fevereiro. Durante o período em análise foram registrados dois mínimos de temperatura: às 00 UTC do de 16 de fevereiro e outro às 06 UTC do dia 17 de fevereiro, quanto a temperatura alcançou $0^{\circ} \mathrm{C}$. Já o máximo de temperatura chegou à $2,9^{\circ} \mathrm{C}$ às 18 UTC do dia 17 . De forma geral, as temperaturas na estação de Frei foram superestimadas experimentos do BRAMS.

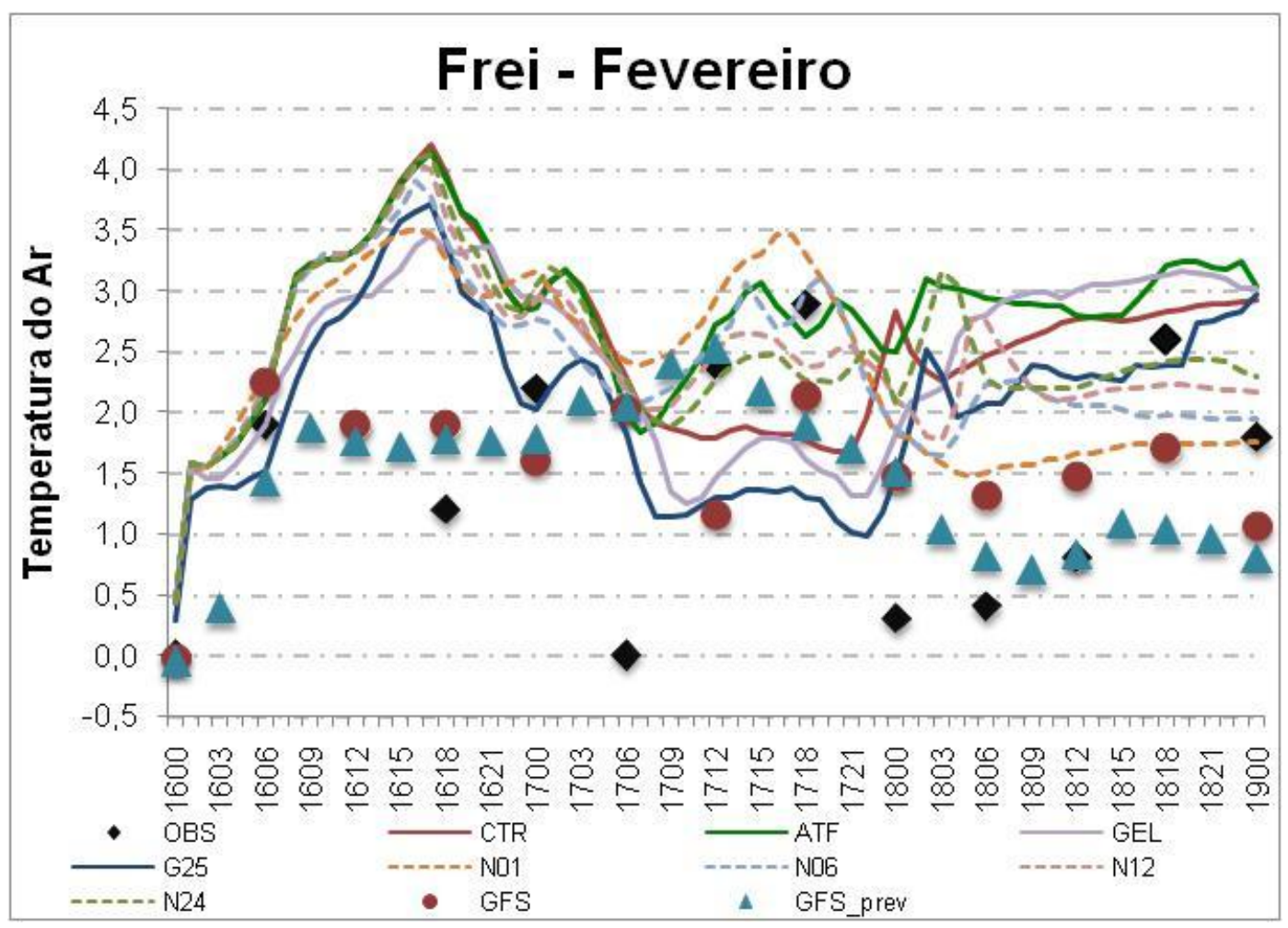

Figura 3.2-5: Série temporal da temperatura do ar para a estação Frei no evento de fevereiro

Assim como em Pratt, para a estação Frei o BRAMS simulou um pico de temperatura às 06 UTC e outro 21 UTC do dia 16 de fevereiro. Nesta estação, o experimento G25 foi o que apresentou as menores temperaturas até às 00 UTC do dia 18, quando então, ocorre um aumento bastante significativo. Apesar dos valores de temperatura e da amplitude desta oscilação, este rápido aumento da temperatura também foi observado entre às 00 UTC e 18 UTC do dia 18 de fevereiro. Já as rodadas CRT, GEL e G25 não simularam a elevação da temperatura que ocorre no decorrer do dia 17 de fevereiro, diferente do que dos demais experimentos que, mesmo com menor amplitude, tentaram captar este aquecimento. Entre às 21 UTC 
do dia 17 e às 06 UTC do dia 18 de fevereiro as rodadas CTR, G25, N06 e N12 simularam uma pequena elevação das temperaturas que não foram mostradas nem nas observações ou nas análises e previsões do GFS.

$\mathrm{Na}$ maior parte do dia 16 de fevereiro a temperatura esteve em elevação na estação O'higgins, como mostra a figura 3.2-6, mas partir da noite do dia 16 a temperatura entrou em declínio. Entre as 12 e 18 UTC do dia 17 houve um pequeno aumento da temperatura, seguido de uma rápida diminuição da temperatura, que voltou a se elevar a partir das 00 UTC do dia 18 de fevereiro

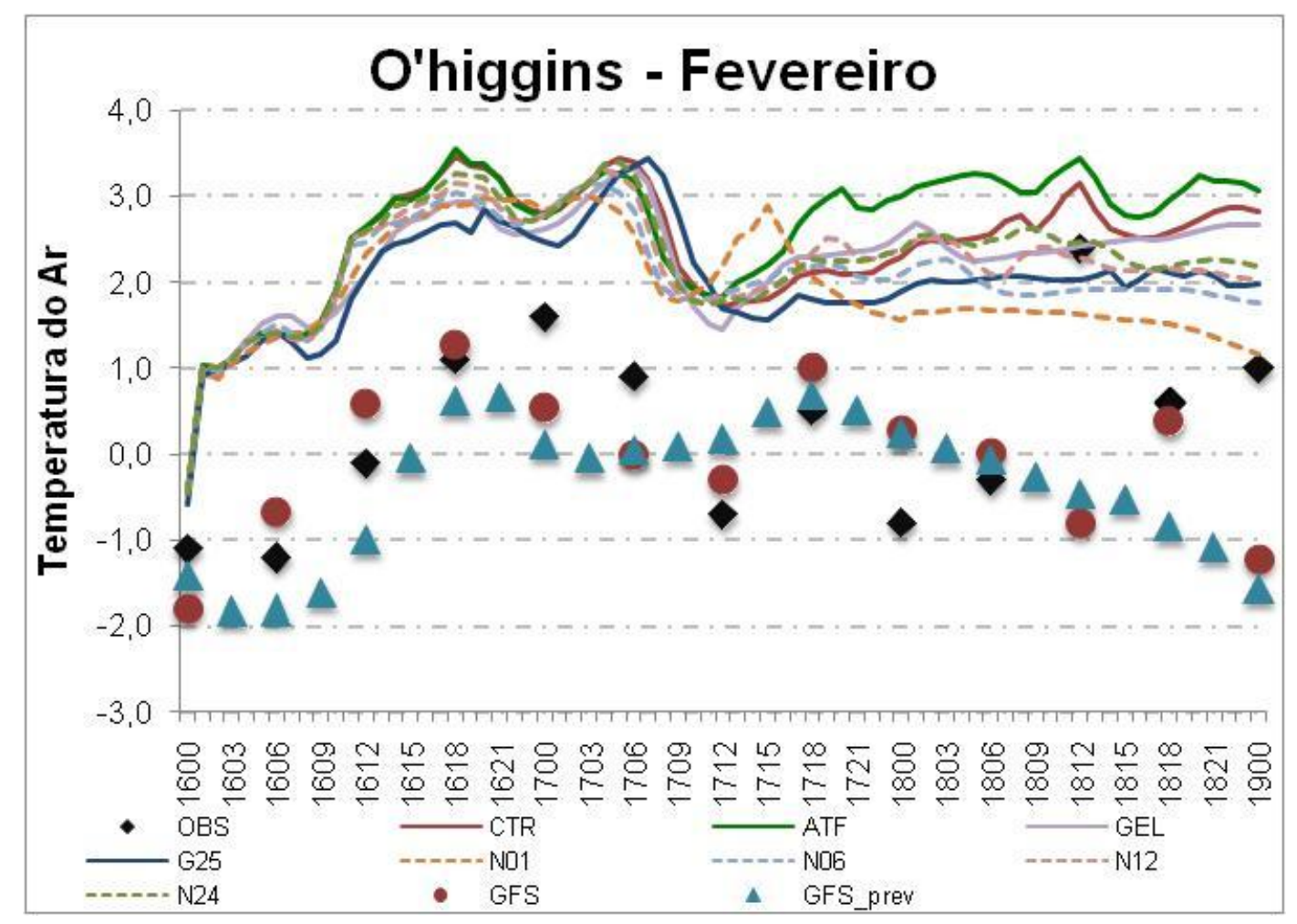

Figura 3.2-6: Série temporal da temperatura do ar para a estação O’higgins no evento de fevereiro

.Analisando a figura 3.2-6, para a estação de O'higgins é evidente que todos os experimentos tiveram temperaturas mais elevadas que a observação, simulando o primeiro máximo de temperatura, registrado às $18 \mathrm{UCT}$ do dia 16 . O experimento G25 foi o que apresentou as temperaturas mais baixas durante mais tempo. $O$ Experimento N12 simulou o segundo pico de temperatura, porém de uma forma menos intensa. Exceto os experimentos que envolviam NDC, todos os experimentos mostraram um leve aumento da temperatura no último dia de simulação, assim como observado a partir das 00 UTC do dia 18. 


\subsubsection{JULHO}

A figura 3.2-7 apresenta as variações de temperatura do ar na EACF durante a passagem de um ciclone pela PA entre os dias 10 e 13 de julho de 2009. Nesta figura é possível observar que até às 00 UTC do dia 11 de fevereiro, a temperatura do ar pouco variou, ficando entre $-5^{\circ} \mathrm{C}$ e $0^{\circ} \mathrm{C}$. Entretanto a temperatura cai muito a partir das 00 UTC do dia 11 , atingindo $-19,5^{\circ} \mathrm{C}$ no mesmo dia. Apesar desta abrupta queda de temperatura, o menor valor registrado durante o período de interesse, foi de $-22,9^{\circ} \mathrm{C}$ às 21 UTC do dia 12 de julho.

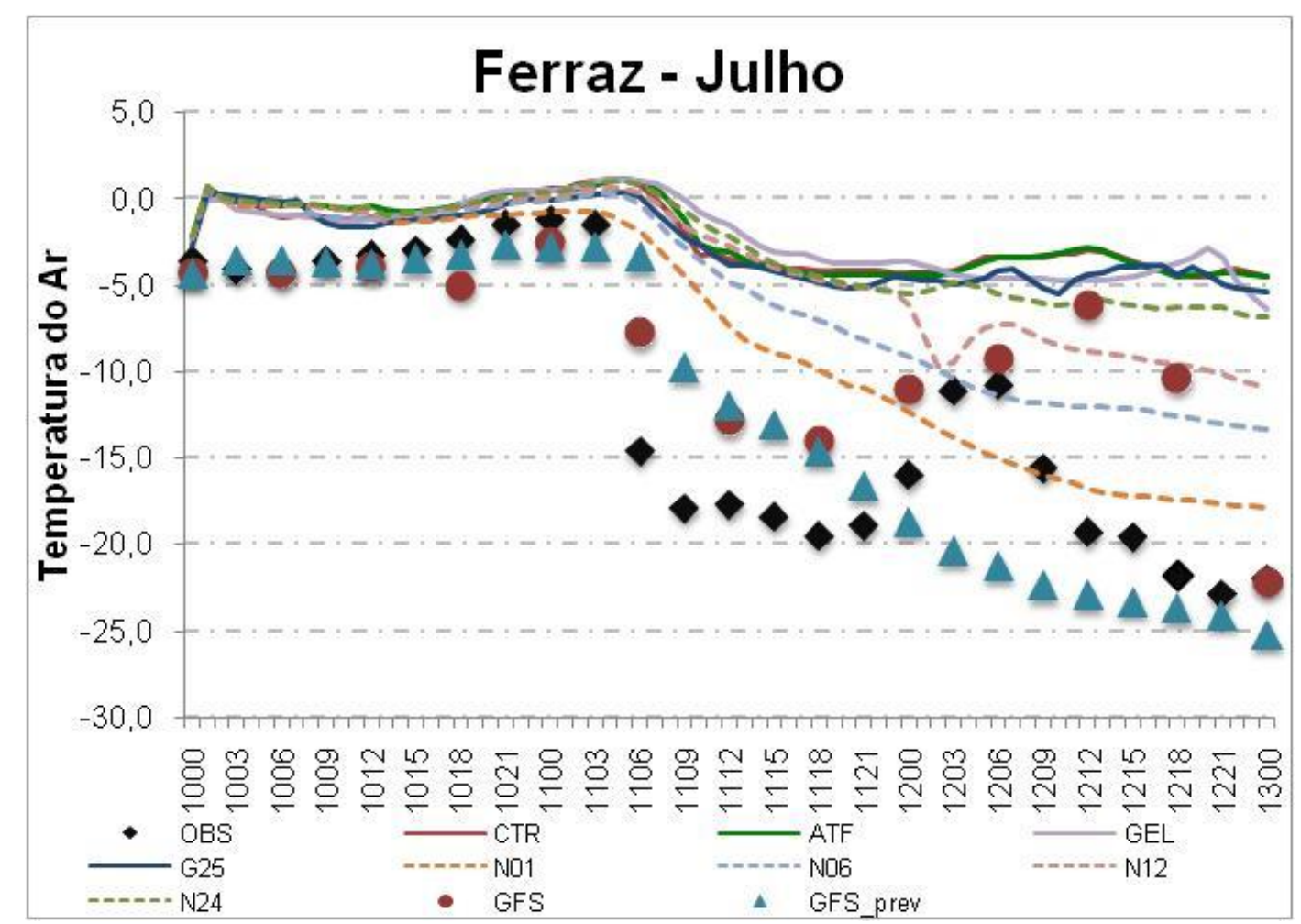

Figura 3.2-7: Série temporal da temperatura do ar para EACF no evento de julho

Comportamento bem parecido à EACF foi observado na estação Jubany (Figura 3.2-8), onde a temperatura diminuiu cerca de $19^{\circ} \mathrm{C}$ em 18 horas (entre às 00 e 18 UTC do dia 11 de julho ). Esta queda de temperatura que foi seguida de uma rápida elevação da mesma. 


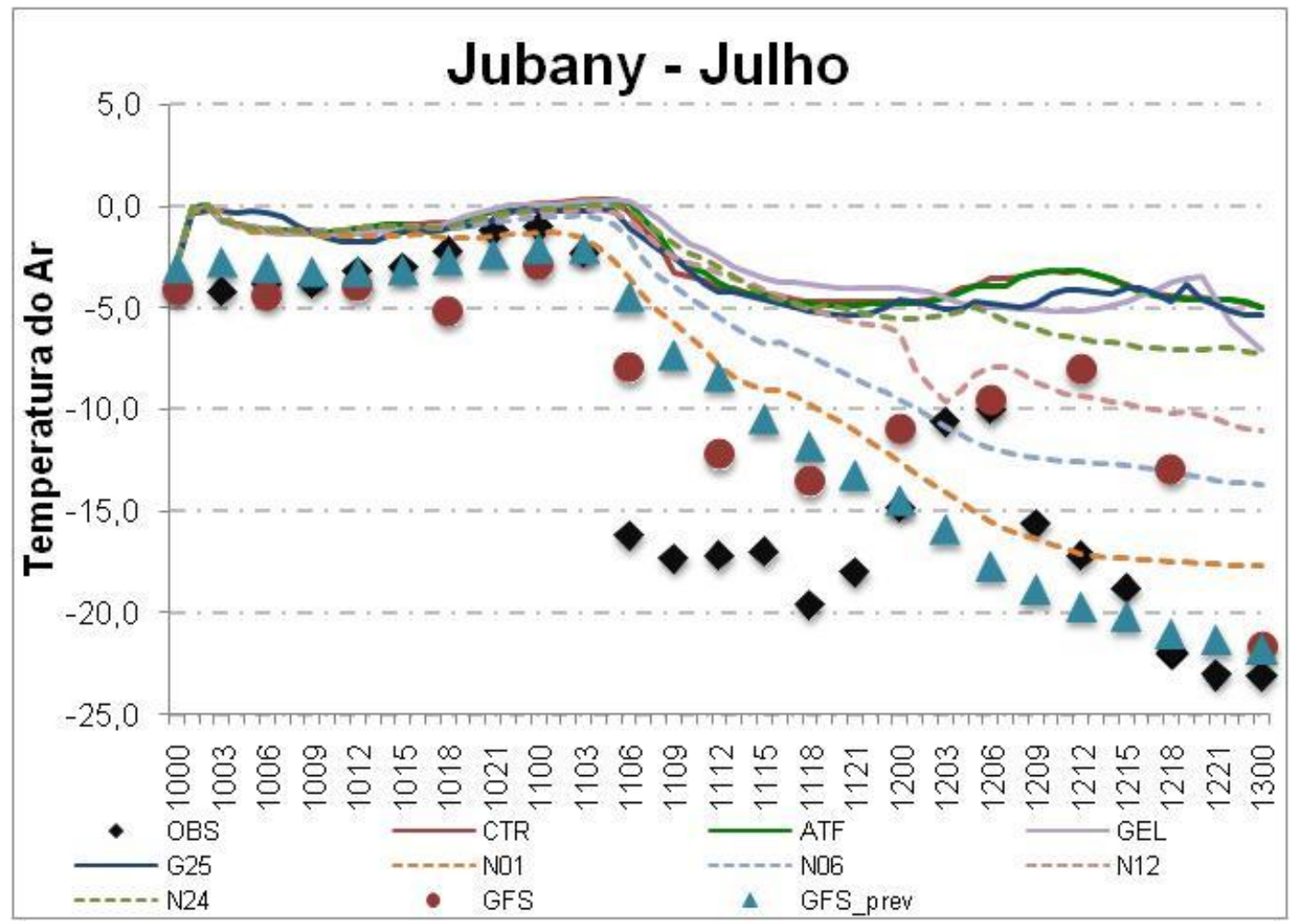

Figura 3.2-8: Série temporal da temperatura do ar para Jubany no evento de julho

Para as estações EACF e Jubany, localizadas nas ilhas Shetland Sul, os experimentos que não envolviam NDC não conseguiram simular adequadamente esta variação de temperatura, ficando aproximadamente $15^{\circ} \mathrm{C}$ mais quente que as temperaturas observadas. Os experimentos N01, N06, e N24, apesar de mostrar um declínio das temperaturas mais significativo, apenas seguiram os dados das previsões do GFS que mostravam o declínio da temperatura. Por outro lado o experimento $\mathrm{N} 12$, além de prever a diminuição da temperatura, foi o único que tentou simular o pico de temperatura registrado às 06 UTC do dia12 de julho.

Em Marambio (Fig. 3.2-9), que está situada na região do mar de Weddell, a queda de temperatura observada logo após atingir-se um mínimo de pressão atmosférica (que será vista mais adiante) é ainda mais intensa, atingindo $-34,2^{\circ} \mathrm{C}$ às 00 UTC do dia 12 de julho. Posteriormente, as temperaturas se mantiveram bastante baixas, variando entre $-30^{\circ} \mathrm{C}$ e $-35^{\circ} \mathrm{C}$. 


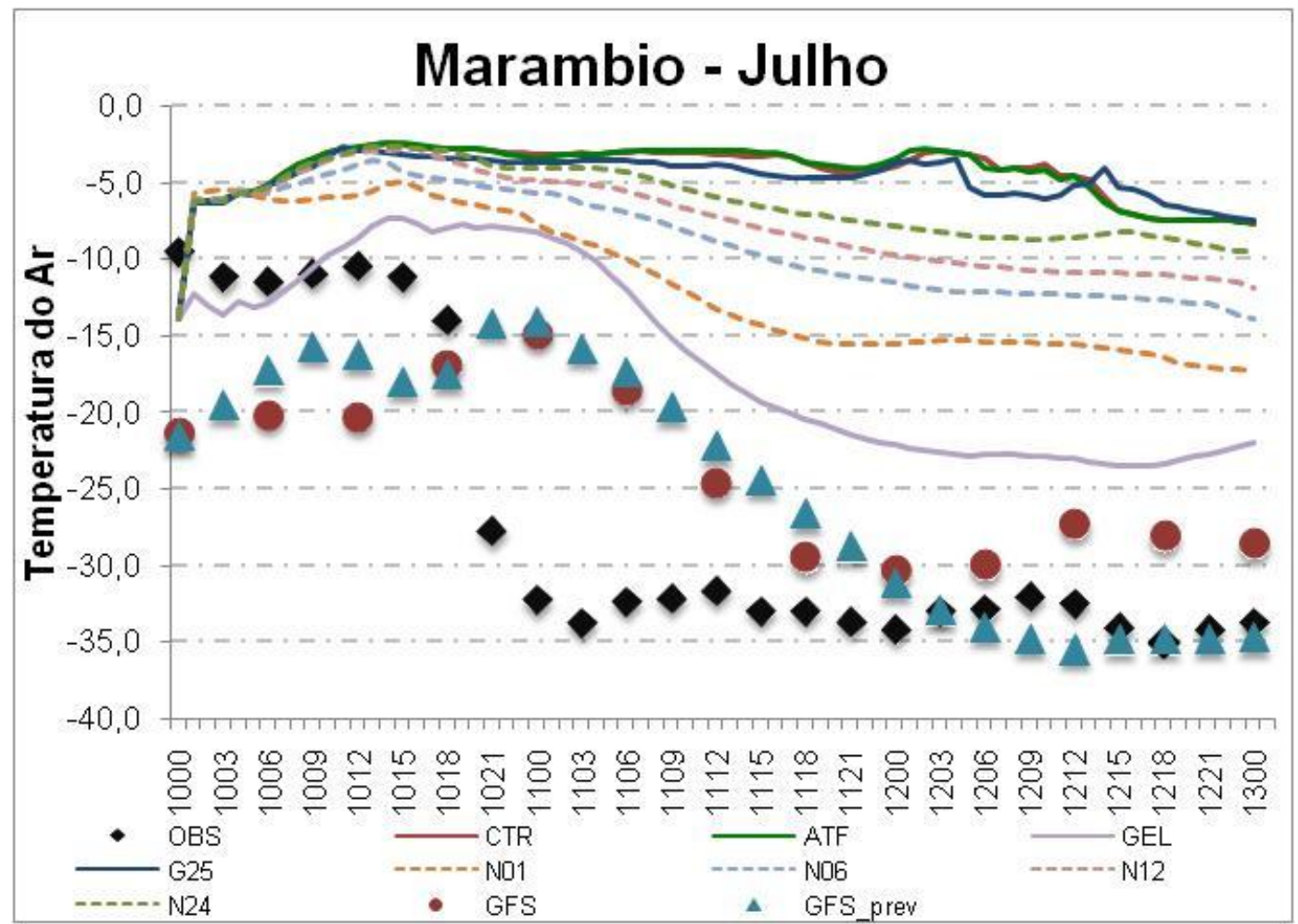

Figura 3.2-9: Série temporal da temperatura do ar para Marambio no evento de julho

Tal como acontece nas demais estações nas quais foi possível fazer este tipo de avaliação durante o caso do mês de julho, em Marambio (Fig. 3.2-9) os experimentos que não possuem NDC não conseguem simular a queda de temperatura que ocorre após a passagem do centro de baixa. Por outro lado, o experimento GEL mostrou uma forte queda de temperatura, acompanhando o que foi observado, apesar de seus valores mínimos estarem cerca de $10^{\circ} \mathrm{C}$ mais elevados.

A influência do gelo marinho na dinâmica e termodinâmica da atmosfera é concentrada na camada limite atmosférica (Thomas e Dieckmann, 2003). Esta influência se dá em diversos processos físicos e em várias escalas espaciais temporais. Assim, a presença de gelo marinho é essencial para o resfriamento das camadas mais baixas na atmosfera em regiões polares. Analisando a figura 3.2-10 que mostra a cobertura de gelo nas duas versões do modelo BRAMS, observa-se que na versão do modelo que apresenta gelo marinho (Fig. 3.2-10b) sua extensão não ultrapassa a PA, deixando as Ilhas Shetland Sul, onde estão localizadas a estações EACF, Pratt, Frei e Jubany, e também a costa oeste da PA livre de gelo marinho. Entretanto a figura 3.2-11, que representa a extensão do gelo marinho 
registrada no mês de julho de 2009, mostra que o gelo marinho se estendia além da costa oeste da PA.

A ausência do gelo marinho em uma região pode atuar de duas maneiras para aumentar a temperatura do ar nesta área. A intensa cobertura de nuvens resultado do avanço do vórtice ciclônico e as nuvens que se formam por evaporação em áreas livre de gelo atuam no sentido de minimizar o resfriamento da atmosfera, já que aprisionam a radiação de onda longa. Além disto, a atmosfera perde calor através da emissão de radiação infravermelha, provocando um resfriamento nas camadas de ar mais próximas às superfícies frias. Assim, na ausência da superfície de gelo marinho este resfriamento radiativo não ocorrerá muito intensamente, de forma que não será percebida esta intensa diminuição na temperatura do ar, que é exatamente o que ocorre nas simulações do modelo BRAMS.
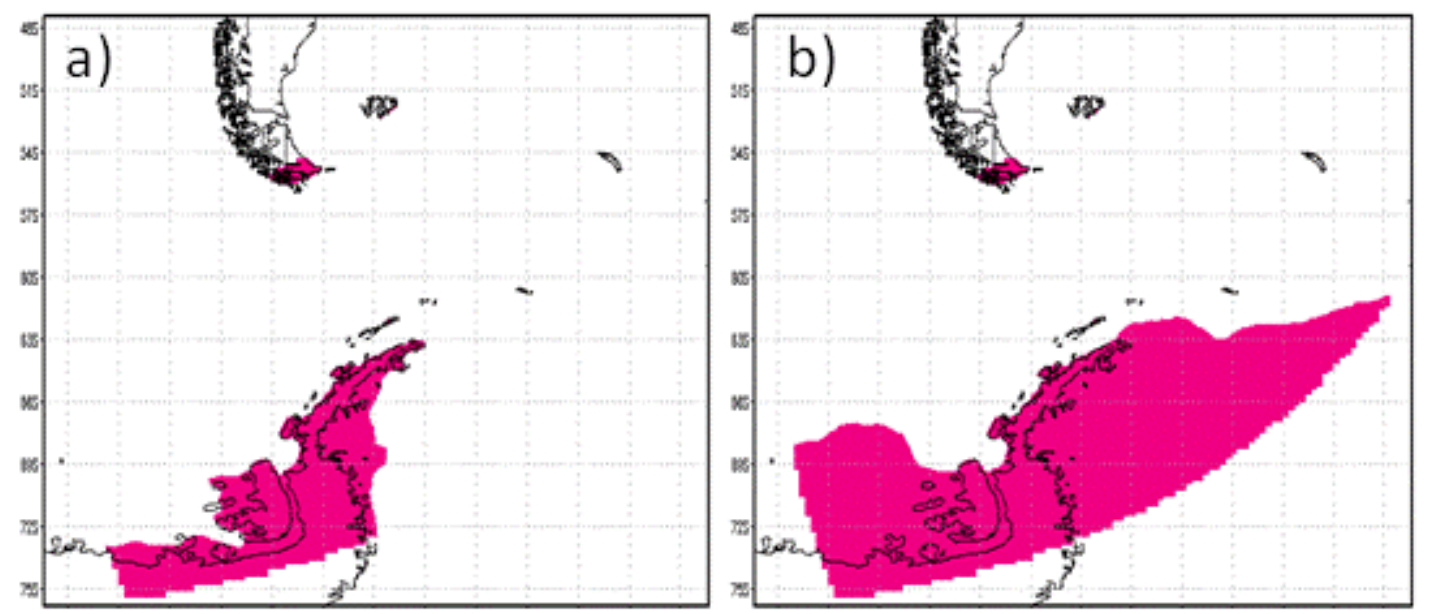

Figura 3.2-10: Cobertura de gelo no modelo BRAMS durante o mês de julho de 2009; a) apenas gelo continental e plataformas de gelo; b) gelo continental, plataformas de gelo e gelo marinho (experimento GEL) 


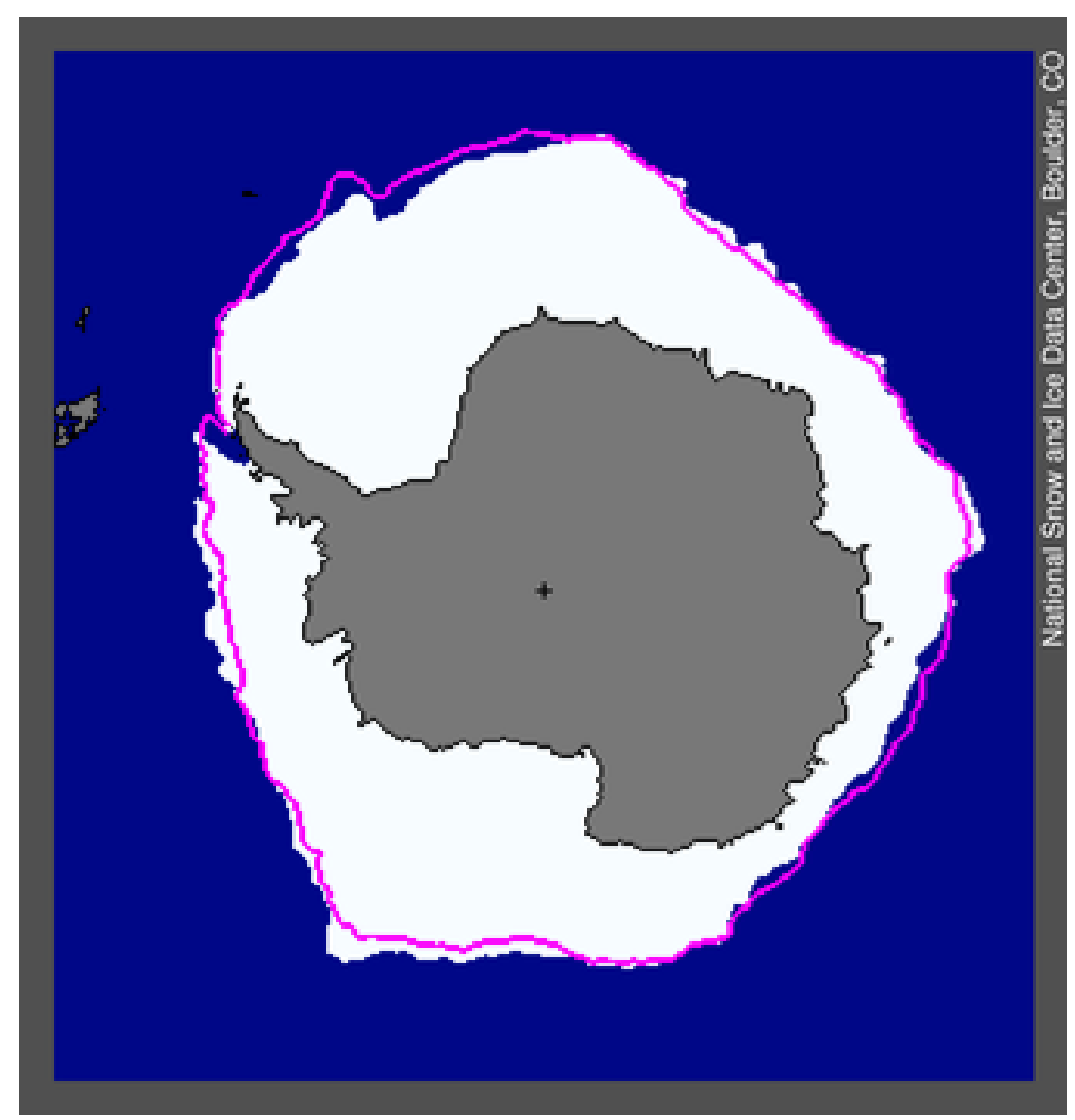

Figura 3.2-11: Extensão de gelo marinho para o mês de julho de 2009. (Fonte: National Snow and Ice Center)

\subsubsection{PRESSÃO ATMOSFÉRICA}

\subsubsection{FEVEREIRO}

As figuras de 3.2-12 a 3.2-17 representam as variações de pressão média reduzidas ao nível do mar em cada uma das estações avaliadas durante a passagem do ciclone extratropical no mês de fevereiro de 2009. Analisando estas figuras é possível ver que em todas as estações, o comportamento da pressão ${ }^{5}$ é muito semelhante. Conforme o ciclone se aproximava da estação, a pressão vai gradualmente diminuindo até atingir um mínimo que ocorre quando o centro do sistema está sobre a PA, entre às 12 UTC do dia 17 e às 00 UTC do dia 18 de fevereiro.

\footnotetext{
${ }^{5}$ Durante a discussão dos resultados a pressão ao nível médio do mar foi mencionada apenas como "pressão".
} 


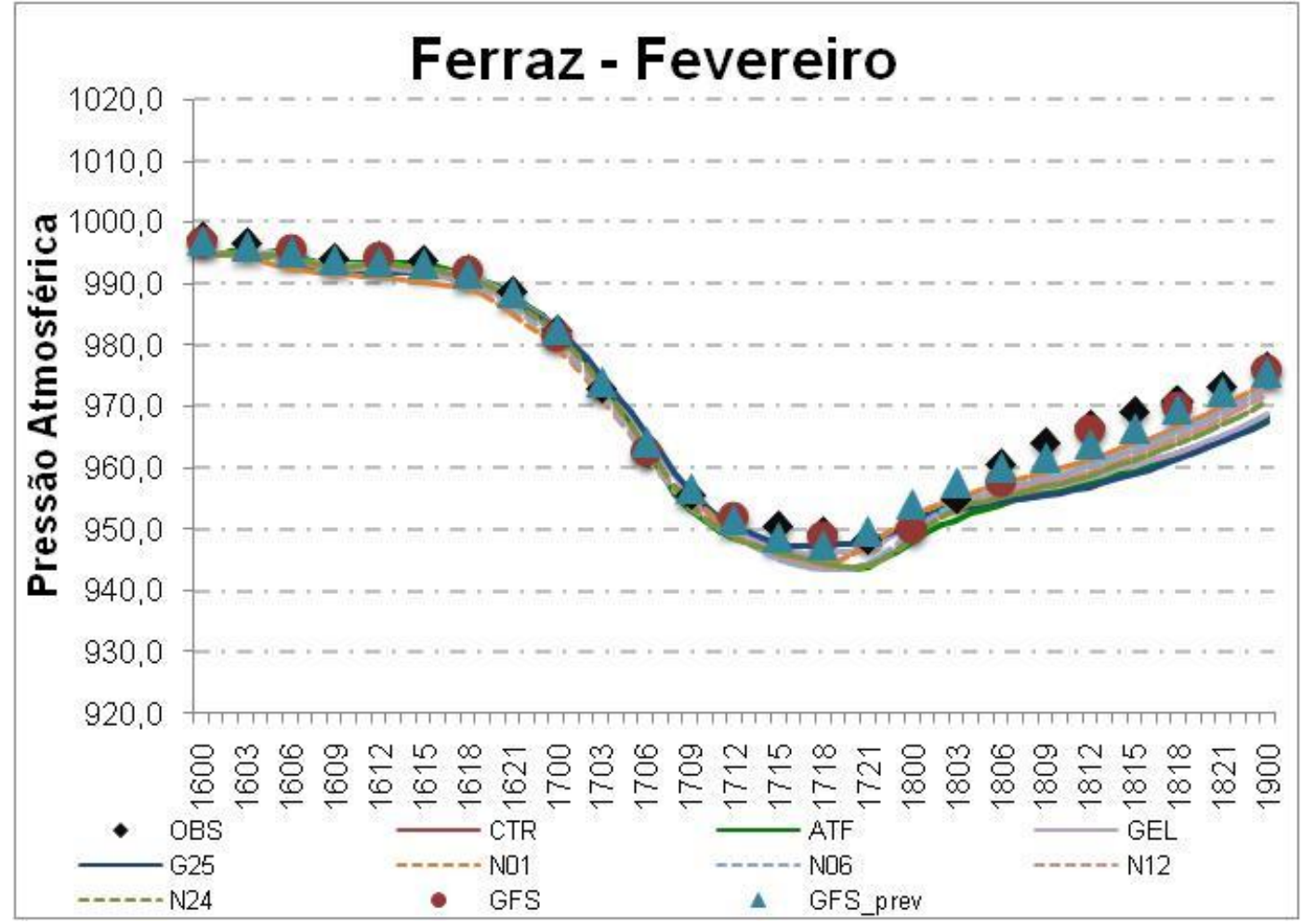

Figura 3.2-12: Série temporal da pressão ao nível médio do mar para EACF no evento de fevereiro

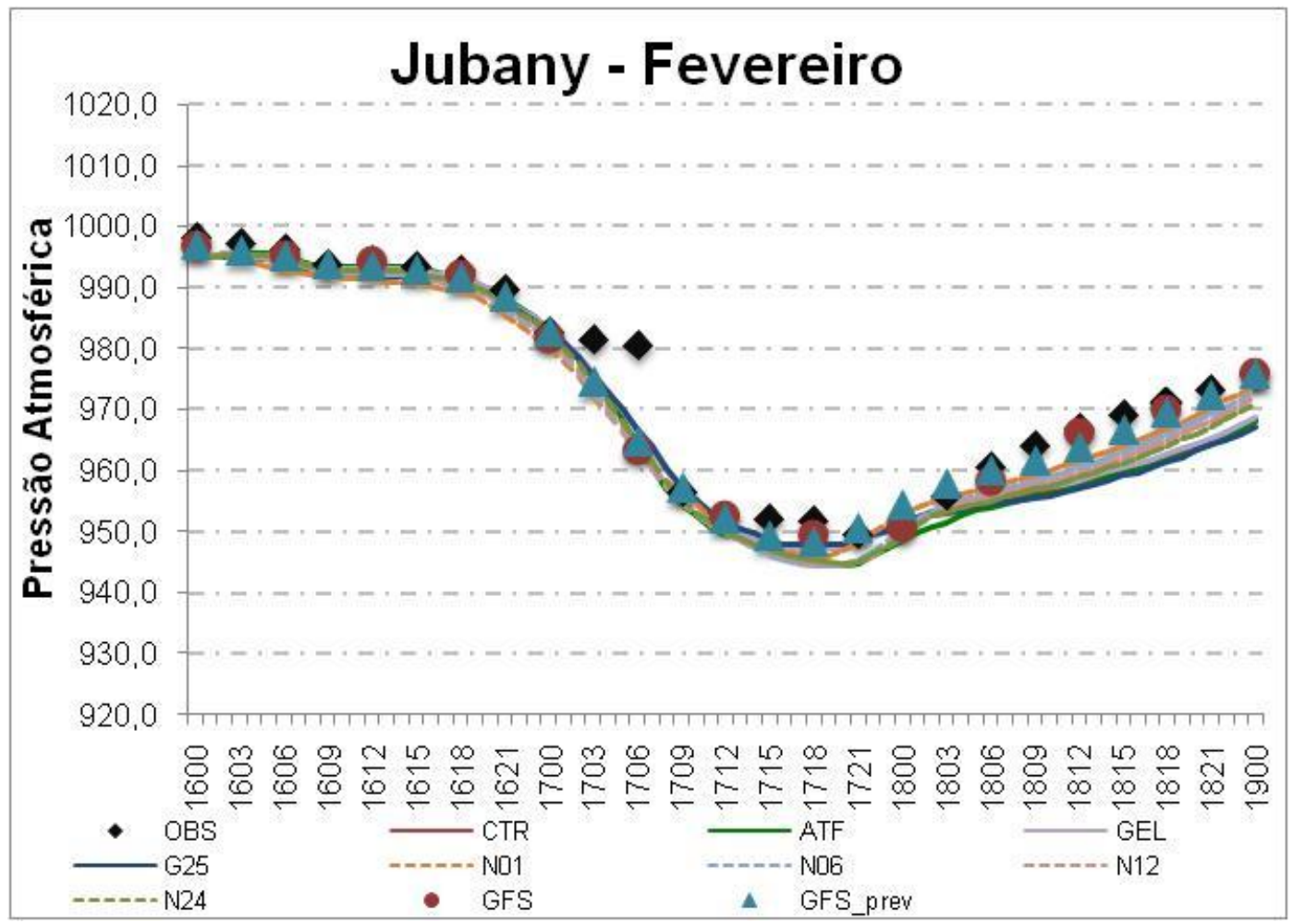

Figura 3.2-12: Série temporal da pressão ao nível médio do mar para Jubany no evento de fevereiro

Nas estações EACF e Jubany, figuras 3.2-12 e 3.2-13, as simulações apresentaram um comportamento bastante parecido durante a passagem do ciclone, 
com uma subestimativa em torno de $5 \mathrm{hPa}$ quando atinge-se o mínimo de pressão. Todos os experimentos subestimam o aumento de pressão no final do tempo de simulação. Para ambas as estações os experimentos G25 e GEL são aqueles que mais se aproximaram do valor mínimo da série, por outro lado, foram também os que mais se afastaram das observações nas últimas 24 horas de simulação (cerca de 10 $\mathrm{hPa})$.

Em Jubany, que apresenta uma queda mais abrupta da pressão entre as 03 e 06 UTC do dia 17 de fevereiro, nota-se que o BRAMS acompanha a previsão do GFS que suavizou o decaimento da série.

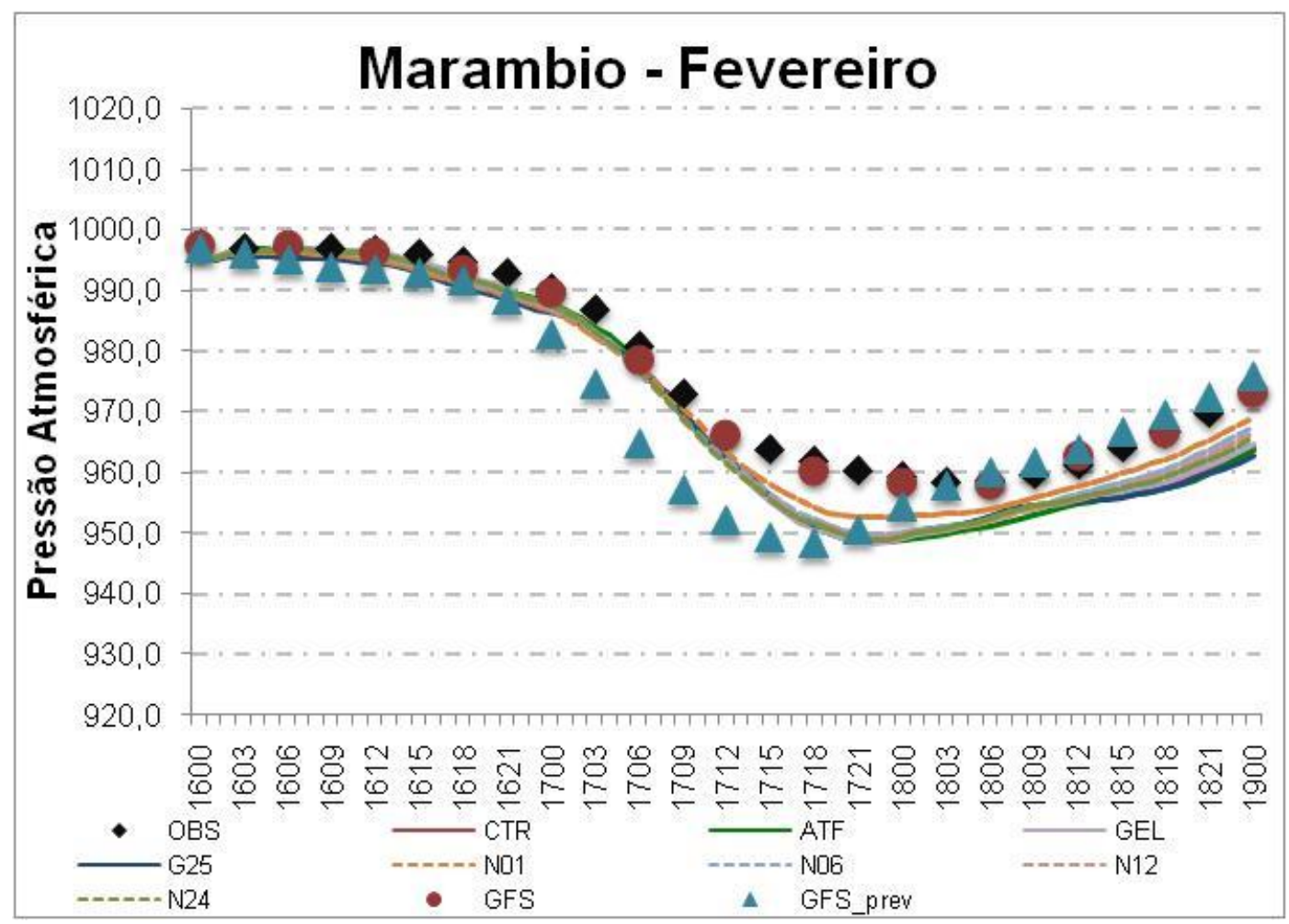

Figura 3.2-13: Série temporal da pressão ao nível médio do mar para Marambio no evento de fevereiro 


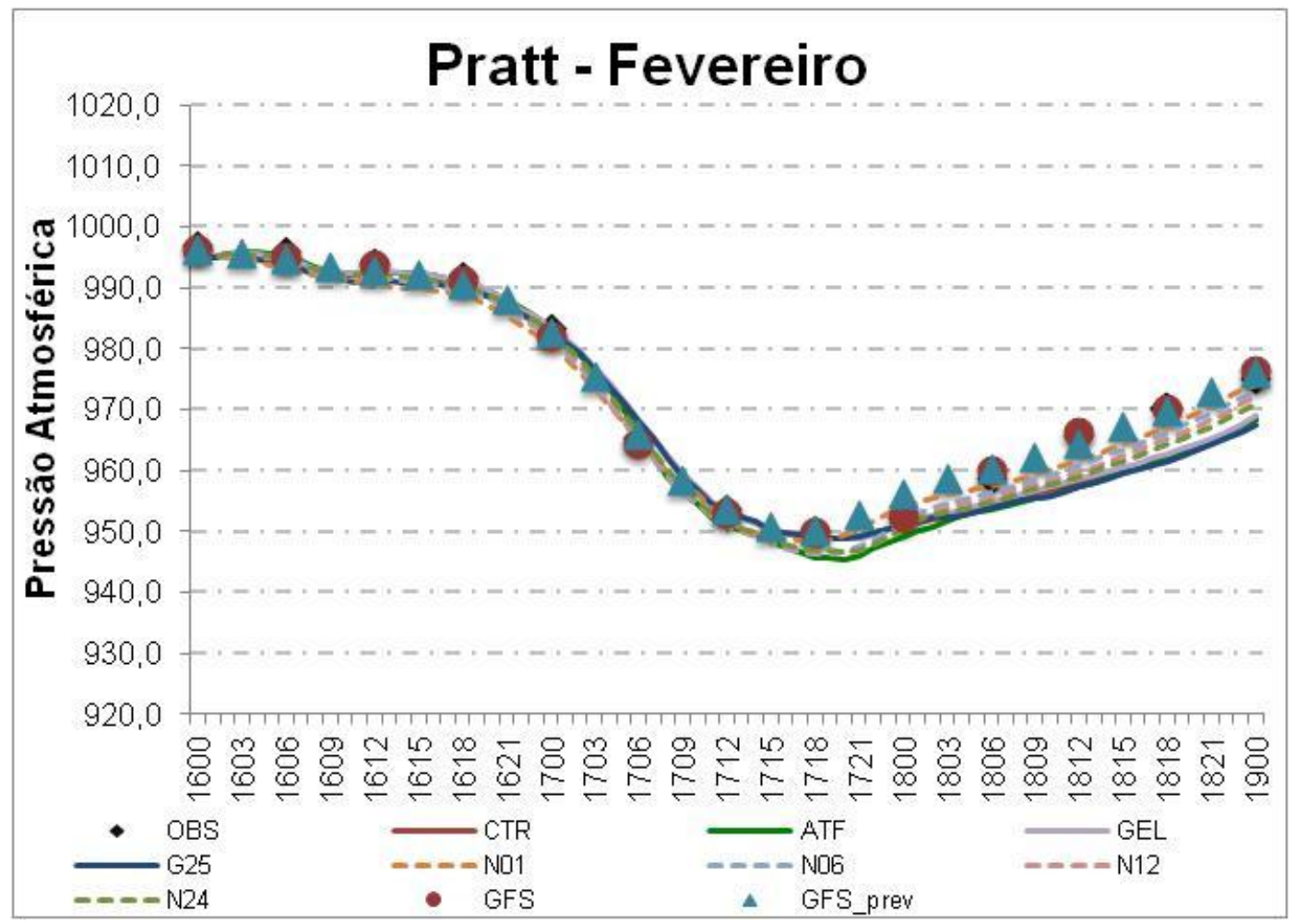

Figura 3.2-14: Série temporal da pressão ao nível médio do mar para Pratt no evento de fevereiro

Analisando as estações de Marambio e O'higgins, figuras 3.2-14 e 3.2-17, observa-se que o modelo apresentou maior subestimativa da pressão nestas estações durante a passagem do centro de baixa pressão. A partir das 12 UTC do dia 16 de fevereiro as saídas do BRAMS tiverem sempre valores menores que a observação e a análise do GFS, sendo que em Marambio quando o mínimo de pressão é registrado, esta subestima fica em torno de $10 \mathrm{hPa}$.

As estações onde o modelo foi mais eficiente em simular as variações de pressão durante a passagem do ciclone foram Pratt e Frei como mostram as figuras 3.2-15 e 3.2-16. Nestas estações os experimentos mostram pequenas subestimativas nas últimas 24 horas de simulação, mas até às 12 UTC do segundo dia simulado, o modelo regional previu adequadamente as variações de pressão. 


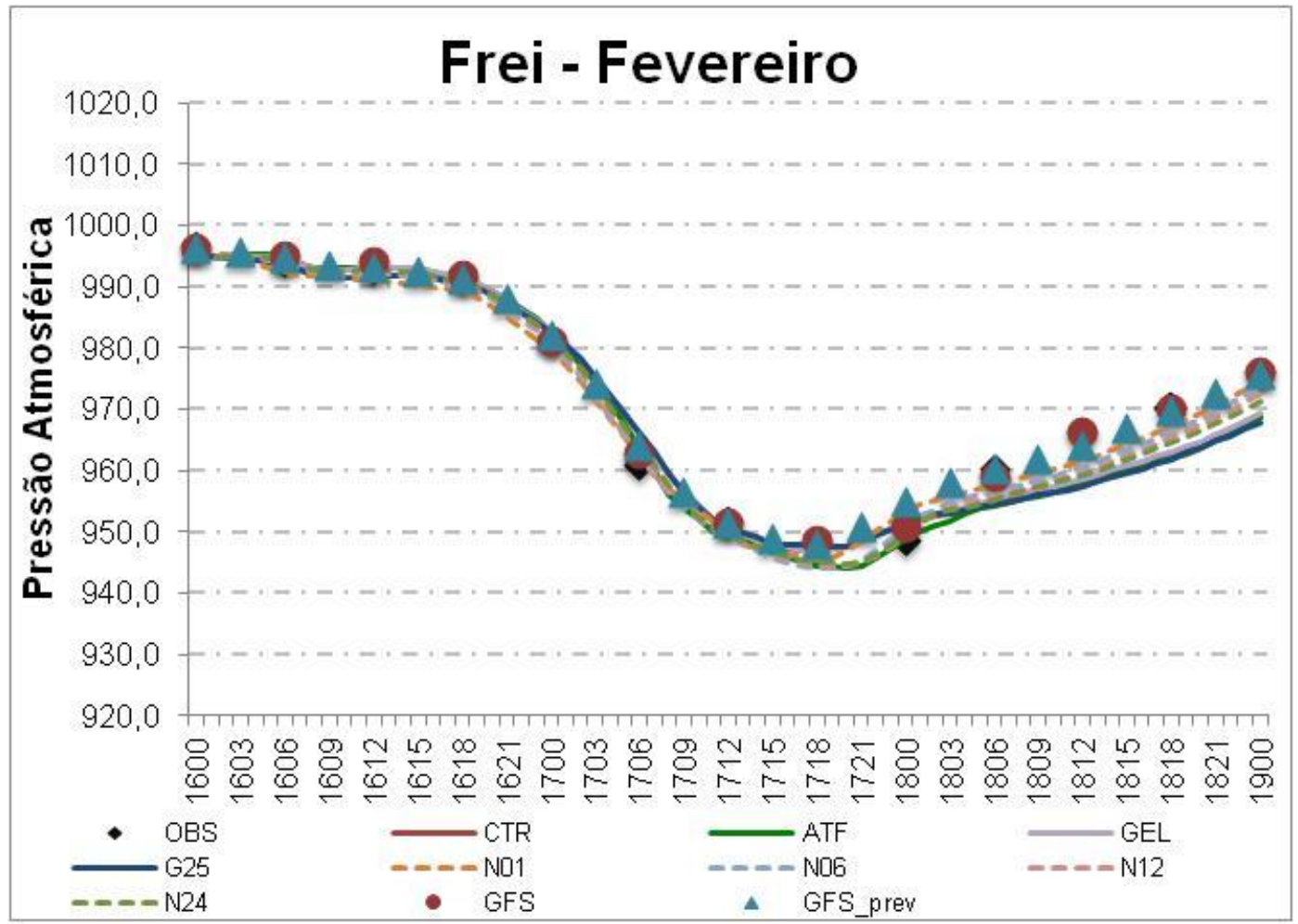

Figura 3.2-15: Série temporal da pressão ao nível médio do mar para Frei no evento de fevereiro

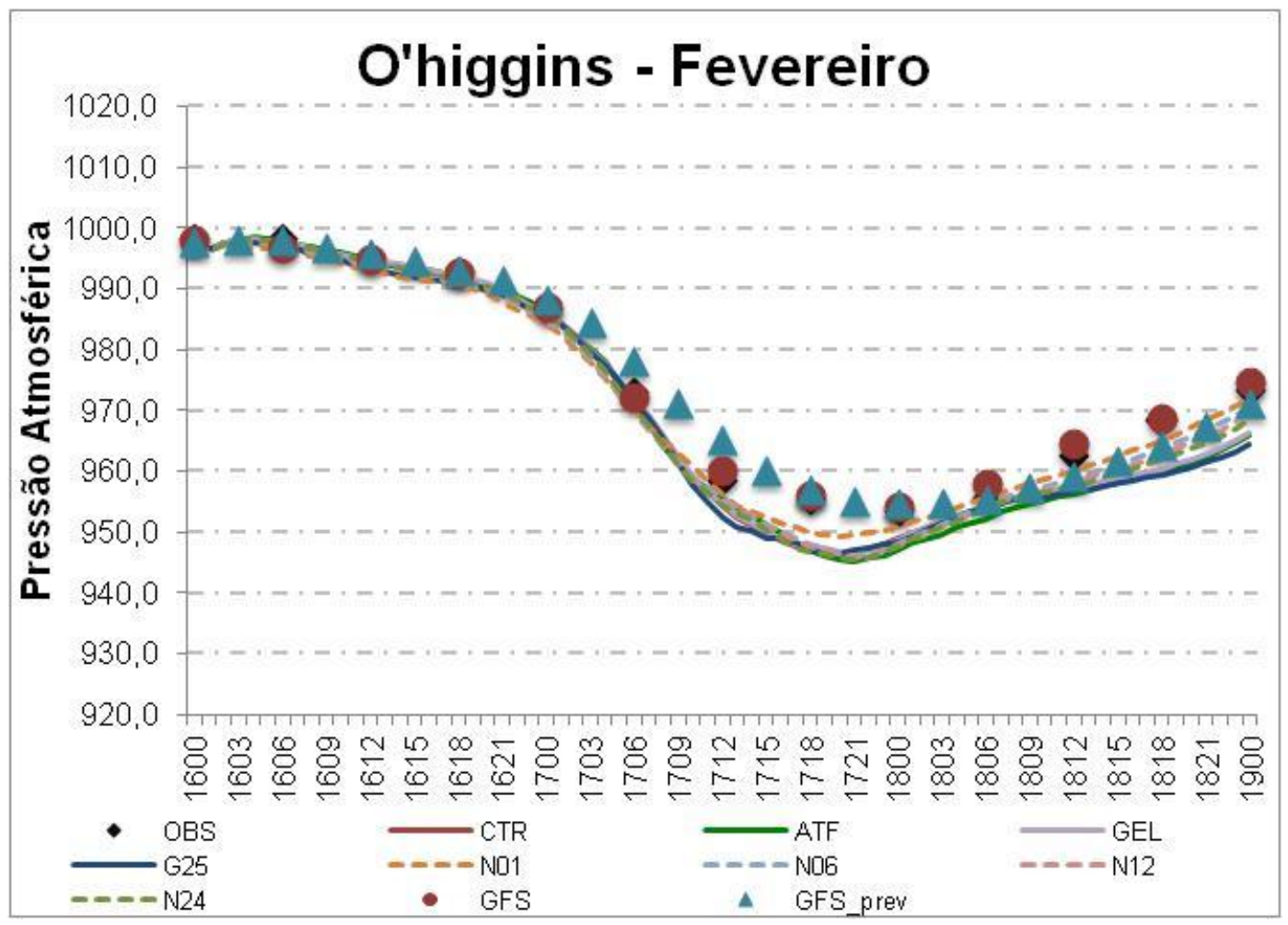

Figura 3.2-16: Série temporal da pressão ao nível médio do mar para O’higgins no evento de fevereiro 
De modo geral o BRAMS representou adequadamente as variações de pressão durante a passagem do ciclone pela região da PA que ocorreu no mês de fevereiro. A pequena diferença entre as observações e as simulações pode estar associada à representatividade do modelo em relação à topografia.

\subsubsection{JULHO}

As estações de Marambio e EACF (fig. 3.2-18 e 19) apresentaram um comportamento muito parecido de variação de pressão durante a passagem do ciclone extratropical pela PA. Nestas estações observa-se que aos poucos a pressão vai diminuindo até atingir um mínimo, por volta das 03 UTC do dia 11 de julho, que é quando o centro de baixa pressão do ciclone está localizado sobre a PA. $\mathrm{Na}$ sequencia, a pressão aumenta rapidamente, diferente do que ocorre no caso de fevereiro quando isto ocorre de forma mais gradual. Este aumento mais abrupto está associado a uma forte advecção de ar frio em direção à PA, logo após a passagem do ciclone pela região.

Durante a passagem do ciclone em julho de 2009, as previsões do modelo BRAMS não foram tão acuradas quantos aquelas feitas para o caso de fevereiro, como é possível observar nas figuras 3.2-18, 3.2-19 e 3.2-20, que correspondem às estações de EACF, Jubany e Marambio, respectivamente.

Para as estações de Jubany e EACF o experimento G25 foi aquele que mais diferiu das observações. No experimento GEL fica evidente a tentativa, em relação aos demais, do modelo de simular o intenso aumento de pressão que ocorreu após a passagem do centro de baixa pressão. Os experimentos que envolviam NDC superestimaram a pressão a partir 06 UTC do dia 12 de julho. Estes experimentos foram aqueles que mais se aproximaram das observações, mostrando que a previsão do modelo GFS, com as quais o modelo BRAMS inicializado, já indicava que ocorreria este aumento de pressão observado, como fica claro nas figuras. 


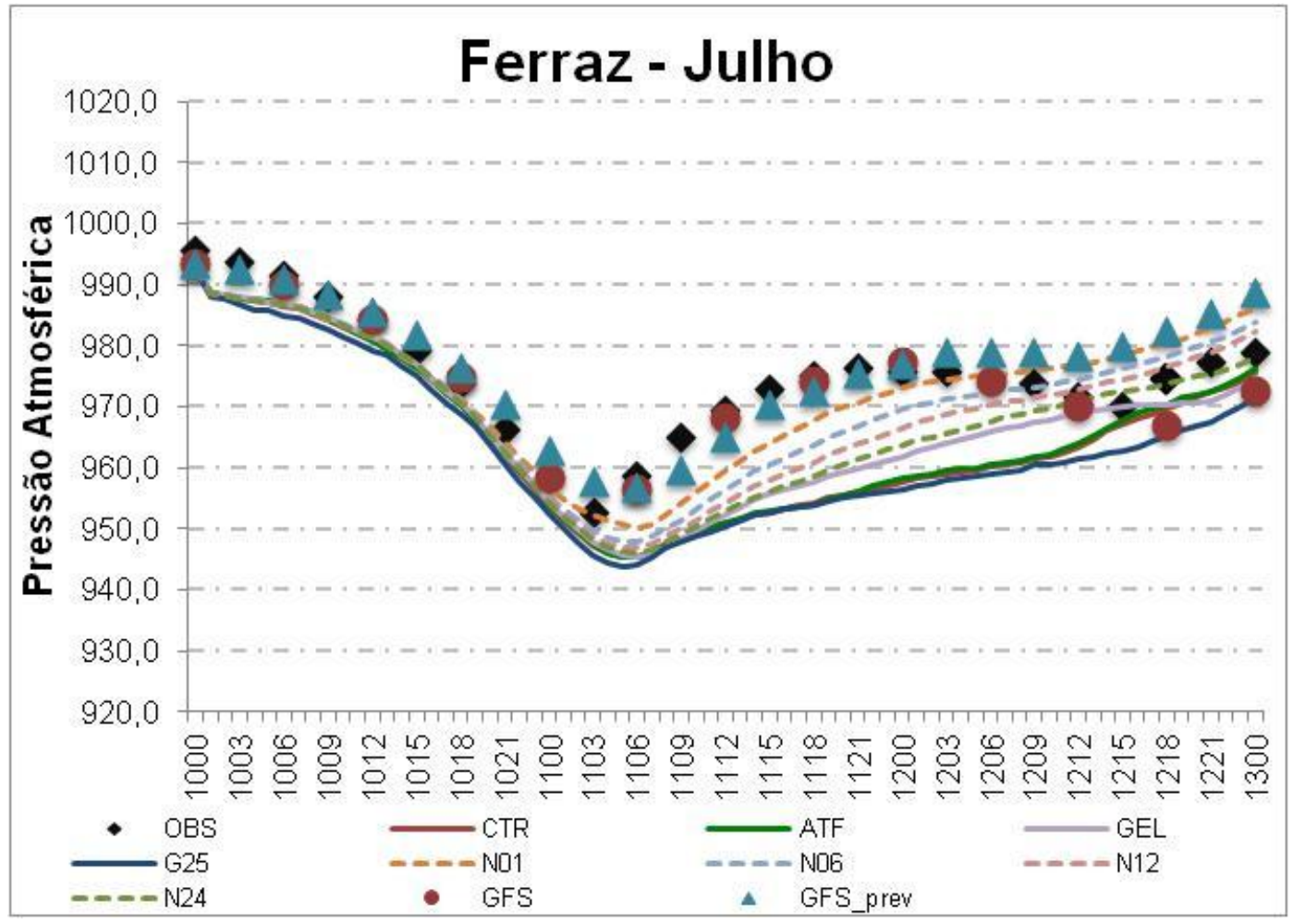

Figura 3.2-17: Série temporal da pressão ao nível médio do mar para EACF no evento de julho

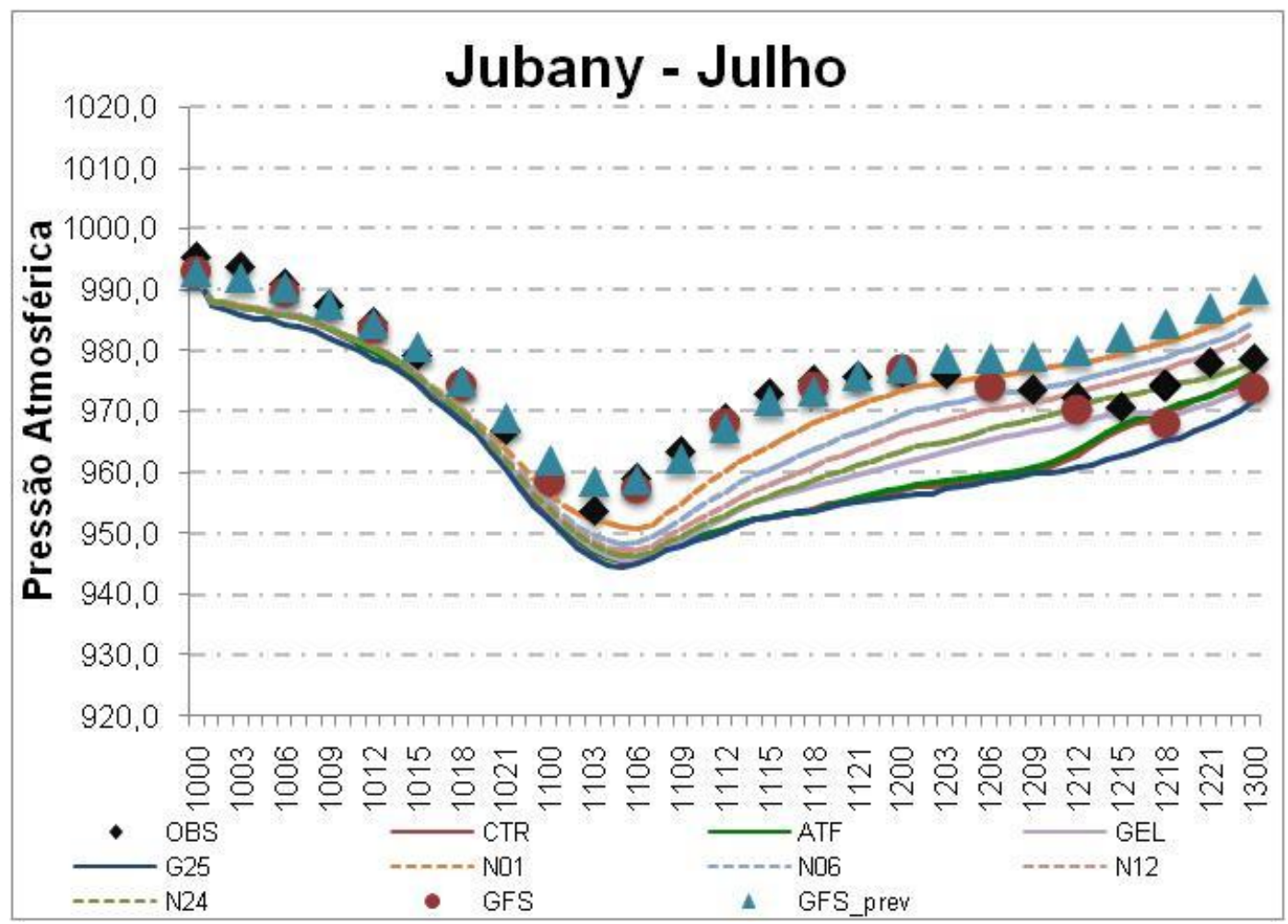

Figura 3.2-18: Série temporal da pressão ao nível médio do mar para Jubany no evento de julho 
A primeira coisa que nota-se na figura 3.2-20, que exibe o comportamento da pressão em Marambio, é a menor amplitude das variações deste parâmetro meteorológico em relação às outras duas estações. Enquanto que na EACF e Jubany o mínimo de pressão fica próximo de 955 hPa, em Marambio o valor mínimo da pressão é cerca de $15 \mathrm{hPa}$ maior.

Em Marambio, os experimentos CTR, ATF e G25 são aqueles onde o comportamento do modelo mais diferiu das observações, quando a diferença às 21 UTC do dia 11 de julho é em torno de $30 \mathrm{hPa}$. Novamente o experimento GEL tentou acompanhar o aumento de pressão, assim como ocorreu em N01, N06, N12 e N24. Fica evidente, ainda, que no evento de julho, as simulações do BRAMS estão 3 horas adiantadas em relação às observações.

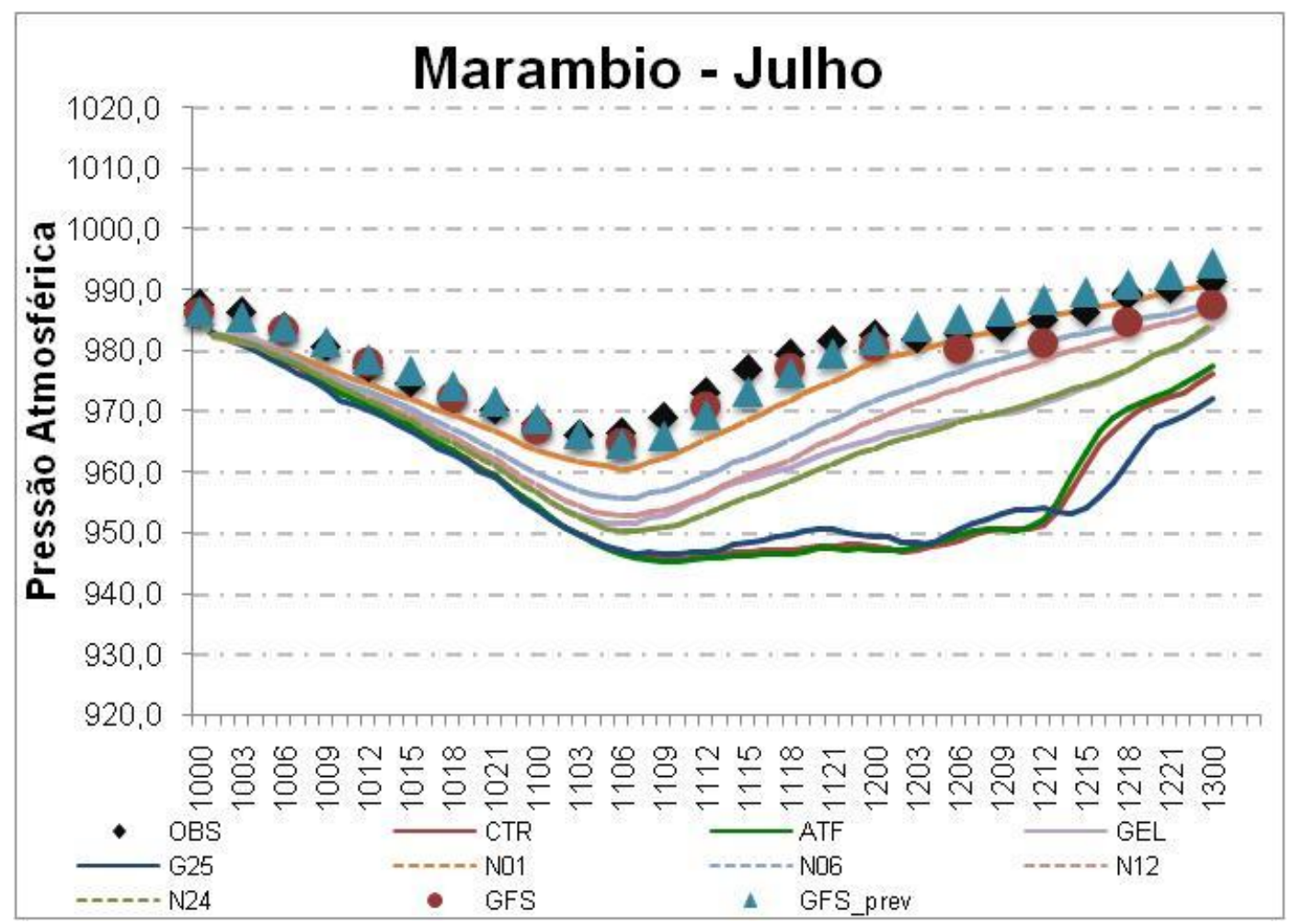

Figura 3.2-19: Série temporal da pressão ao nível médio do mar para Marambio no evento de julho

Com relação à pressão ao nível médio do mar, ficou claro que o modelo BRAMS consegue prever adequadamente suas variações, mas não consegue capturar os aumentos de pressão que ocorrem após a passagem do ciclone. Sendo que o modelo está atrasado em 3 horas no evento de julho. 
A estação de Marambio, que está localizada sobre o mar de Weddell, apresentou as maiores divergências entre simulações e observação, principalmente no evento sinótico de julho. Isto pode ser explicado pelo fato que após a passagem do ciclone sobre a PA, ocorre a formação de um centro de baixa a leste da cadeia de montanhas, exatamente sobre a região onde está localizada Marambio, como pode ser visto na figura 3.2-21 e, por tal motivo, os experimentos sem NDC não conseguem prever adequadamente o aumento de pressão.

Vorticidade em $850 \mathrm{hPa}$, Pressao ao Num e Temperaruto do or a $2 \mathrm{~m}$ 22211JUL2009

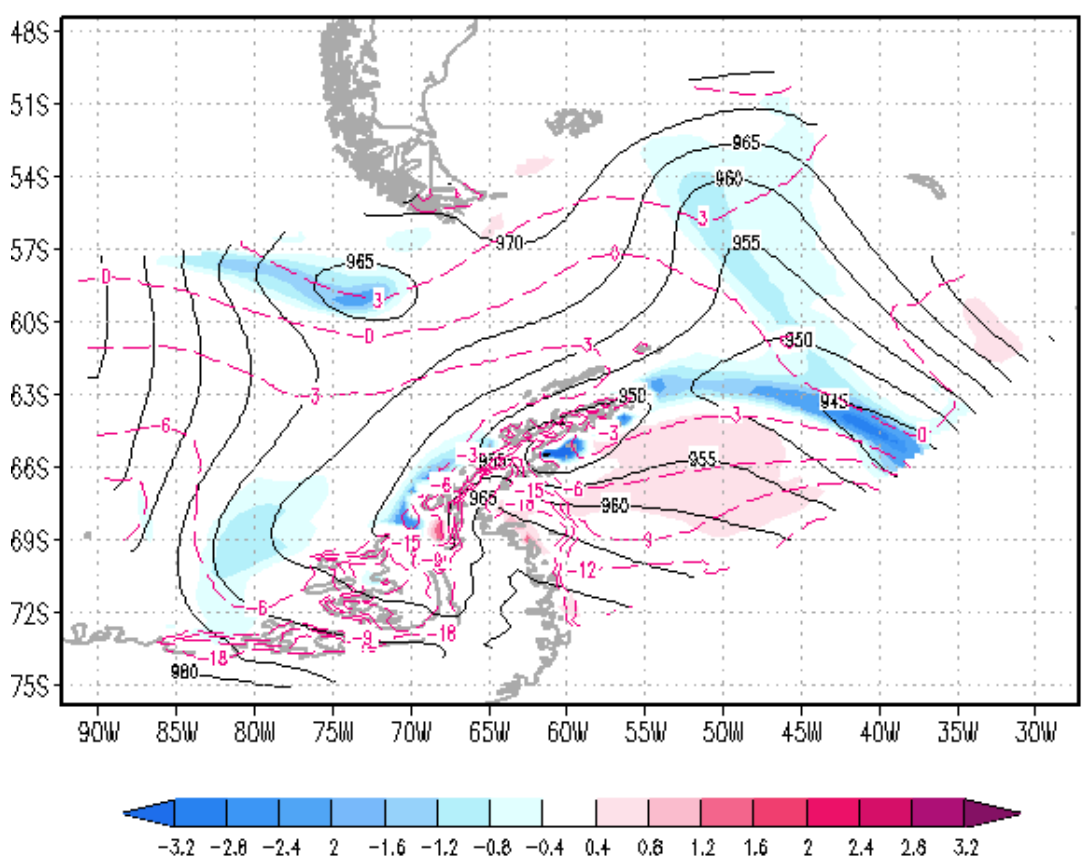

Figura 3.2-20: Vorticidade em $850 \mathrm{hPa}\left(10^{-5} \mathrm{~s}^{-1}\right)$ em sombreado; pressão ao nível médio do mar $(\mathrm{hPa})$ nas linhas pretas cheias e temperatura a 2 metros $\left({ }^{\circ} \mathrm{C}\right)$ nas linhas tracejadas rosa às 22 UTC do dia 11 de julho de 2009 para o experimento CTR

\subsubsection{VENTO ZONAL}

\subsubsection{FEVEREIRO}

A figura 3.2-22 mostra as variações da componente zonal do vento na EACF durante o caso da passagem do ciclone no mês de fevereiro. Analisando as observações é possível notar que na maior parte do período analisado o vento zonal se manteve soprando de leste, virando para oeste a partir das 00 UTC do dia 18 de fevereiro. 
Analisando a figura 3.2-22 pode se observar que, de forma geral, todas as simulações conseguiram prever o comportamento médio da componente zonal do vento na estação EACF. Além disso, o experimento G25 parece estar atrasado em relação às observações. As simulações que envolviam nudging central acompanharam as previsões do GFS, que por sua vez não previu as variações do vento zonal que ocorreram entre 06 UTC do dia 17 de fevereiro e 06 UTC do dia 18 de fevereiro de 2009. Somente o experimento N24 tentou expressar a desintensificação do vento leste observada às 00 UTC do dia 17 de fevereiro. Outro fato a ser observado é que as simulações do BRAMS se saíram melhor em simular o valor máximo do vento de leste, cerca de $15 \mathrm{~m} / \mathrm{s}$, tanto em relação à analise quanto às previsões do GFS.

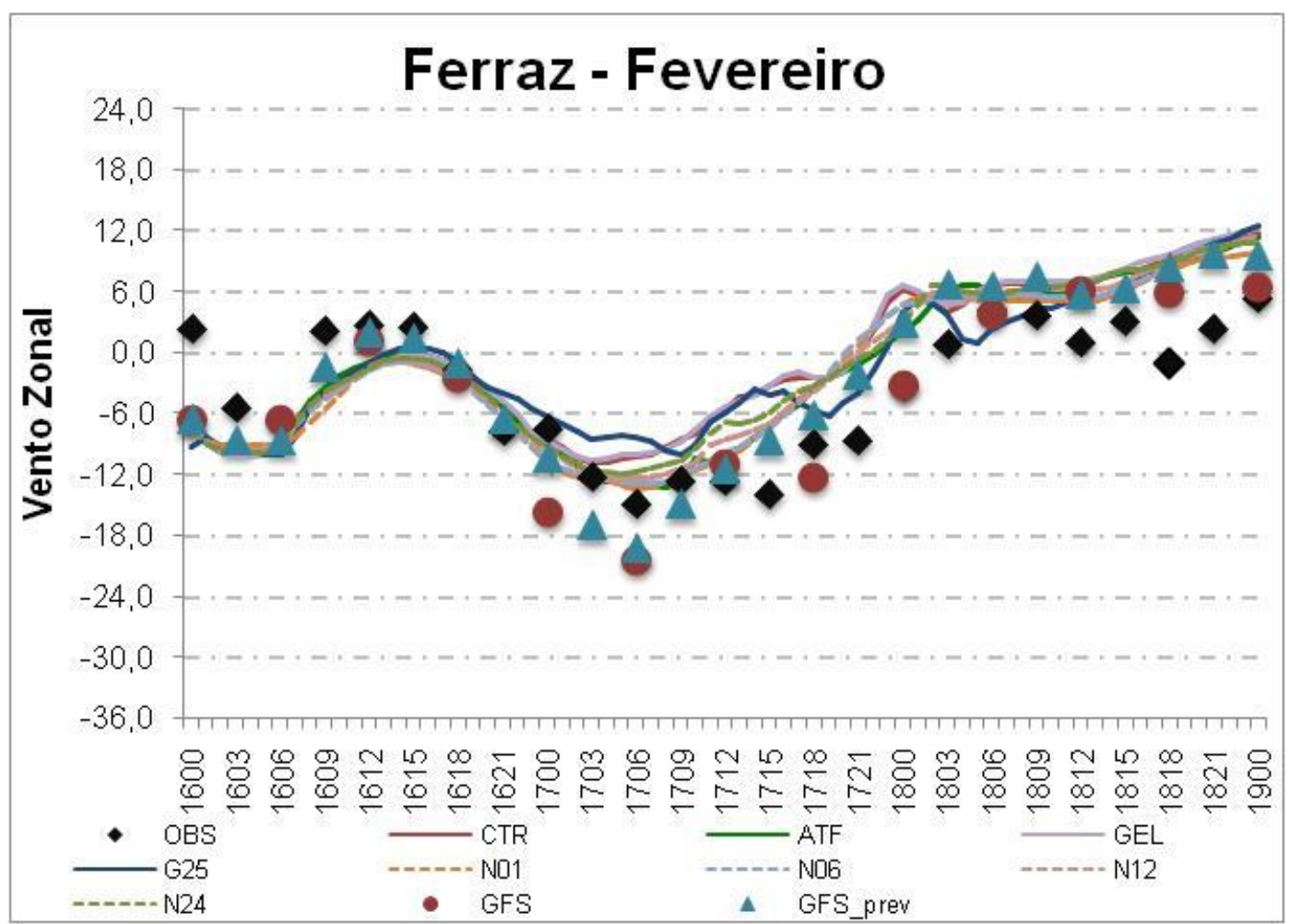

Figura 3.2-21: Série temporal da componente zonal do vento para a EACF no evento de fevereiro

A figura 3.2-23 mostra as mudanças de direção do vento zonal na estação Jubany. Fica bastante evidente a predominância da componente meridional do vento nesta estação ao longo do período analisado, apesar de que em alguns momentos é registrado um fraco vento de oeste. 
Para esta estação (Jubany) o modelo numérico simulou ventos de leste, não observados in situ, acompanhando tanto as análises e previsões do modelo GFS. Além disso, após a passagem do ciclone, o modelo simula uma componente de oeste. O vento zonal da rodada G25, mesmo seguindo o padrão principal de oscilação do BRAMS, apresentou mais variações de magnitude em relação aos demais experimentos, possivelmente devido a maior resolução horizontal utilizada nesta simulação.

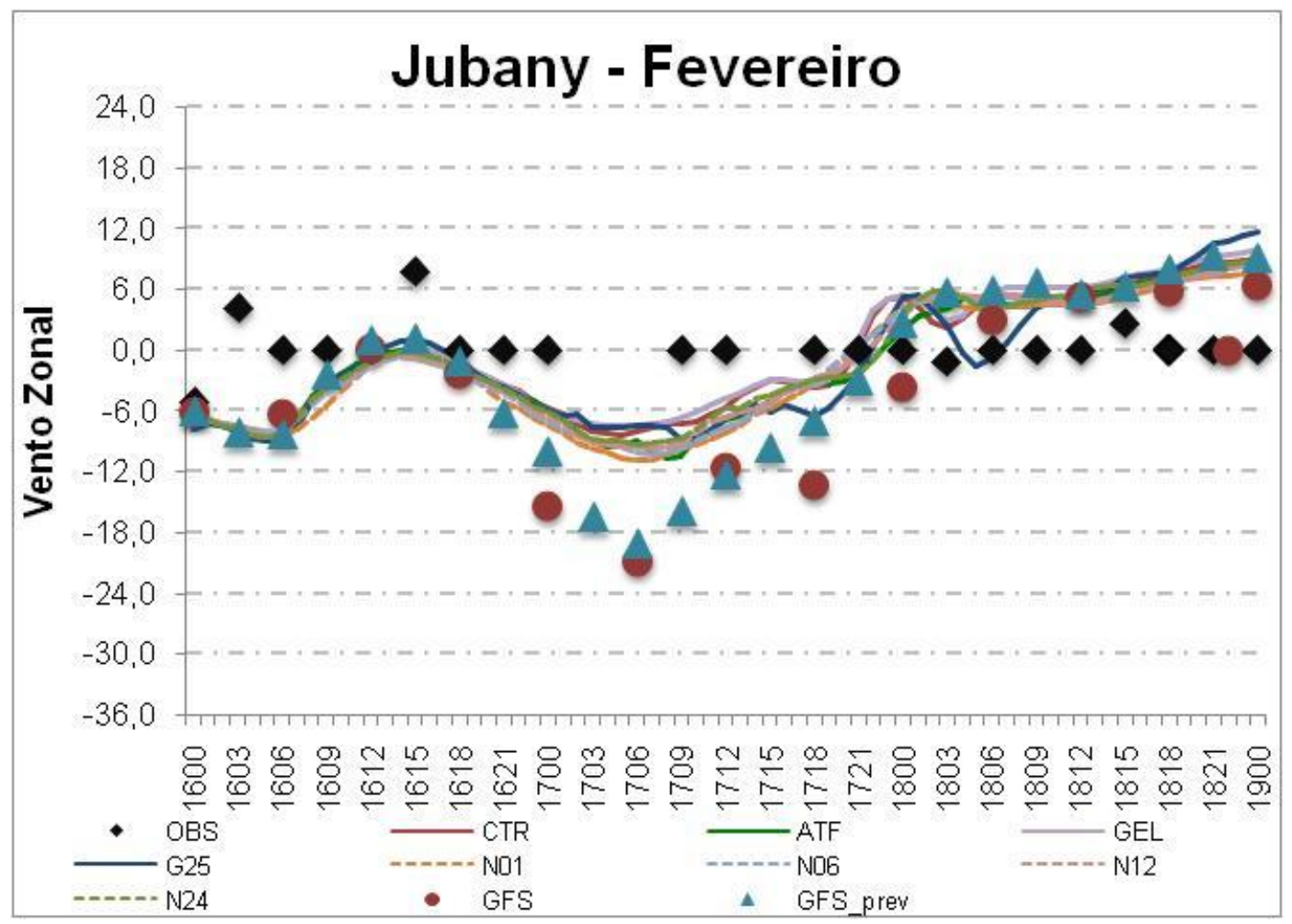

Figura 3.2-22: Série temporal da componente zonal do vento para Jubany no evento de fevereiro 


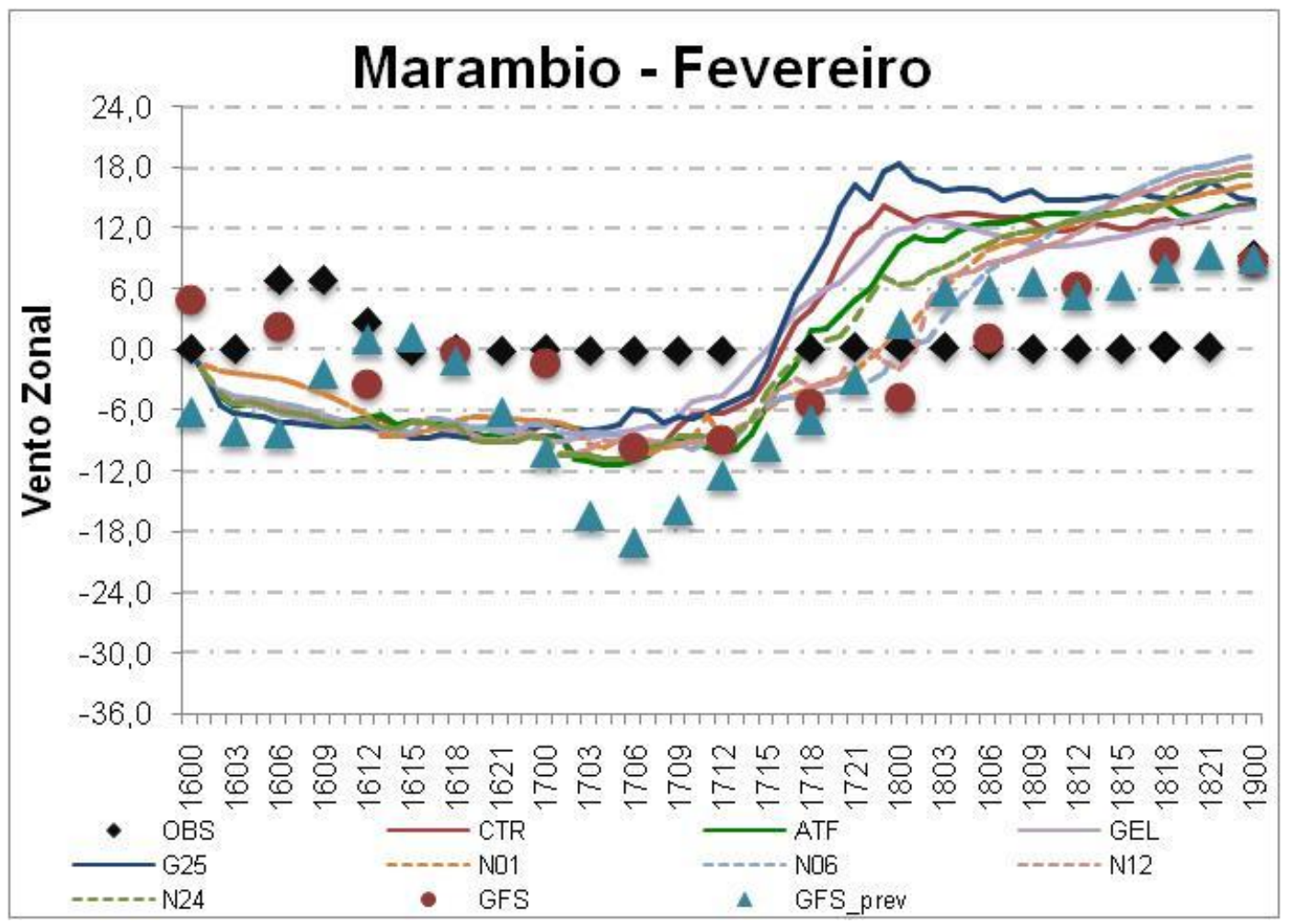

Figura 3.2-23: Série temporal da componente zonal do vento para Marambio no evento de fevereiro

Entre os dias 16 e 19 de fevereiro, na estação Marambio (fig. 3.2-24), predominou um escoamento praticamente meridional. Apenas entre 06 UTC e às 12 UTC das primeiras 24 horas analisadas, observou-se uma fraca componente de oeste.

Diferente do simulado nas duas estações anteriores, em Marambio antes da passagem do ciclone pela PA o BRAMS não acompanha as previsões do GFS. O modelo regional simula uma componente de leste antes da passagem do ciclone. Porém a partir das 15 UTC do dia 17 de fevereiro ocorre um enfraquecimento dos ventos de leste que passam a soprar de oeste nas últimas 24 horas simuladas, condição prevista também pelo modelo GFS.

Em Pratt, figura 3.2-25, é possível observar que em grande parte do período em análise o vento zonal permaneceu soprando de leste e somente a partir das 00 UTC do dia 18 de fevereiro ocorre a diminuição destes ventos, que nas últimas 18 horas passam a soprar de oeste. Nota-se que o modelo BRAMS acompanha as principais variações do vento zonal, apesar de subestimar sua magnitude. Os experimentos ATF e os que envolviam NDC foram os que mais se aproximaram do máximo do vento de leste que ocorreu às 06 UTC do dia 17 de fevereiro, sendo que 
para as rodadas N01, N06, N12 e N24 isto já era esperado, pois as previsões do GFS já indicavam esta intensificação dos ventos de leste.

Fortes ventos de leste foram observados na estação de Frei como mostra a figura 3.2-26. Os ventos mais intensos foram registrados antes da passagem do ciclone pela PA, sendo que às 06 UTC do dia 17 de fevereiro o vento chegou a atingir mais de $30 \mathrm{~m} / \mathrm{s}$. Fica evidente que o modelo BRAMS subestimou os intensos ventos de leste que foram registrados na estação. Além disso, os experimentos não simularam a brusca mudança de direção do vento que ocorreu entre 00 UTC e 06 UTC do dia 18 de fevereiro.

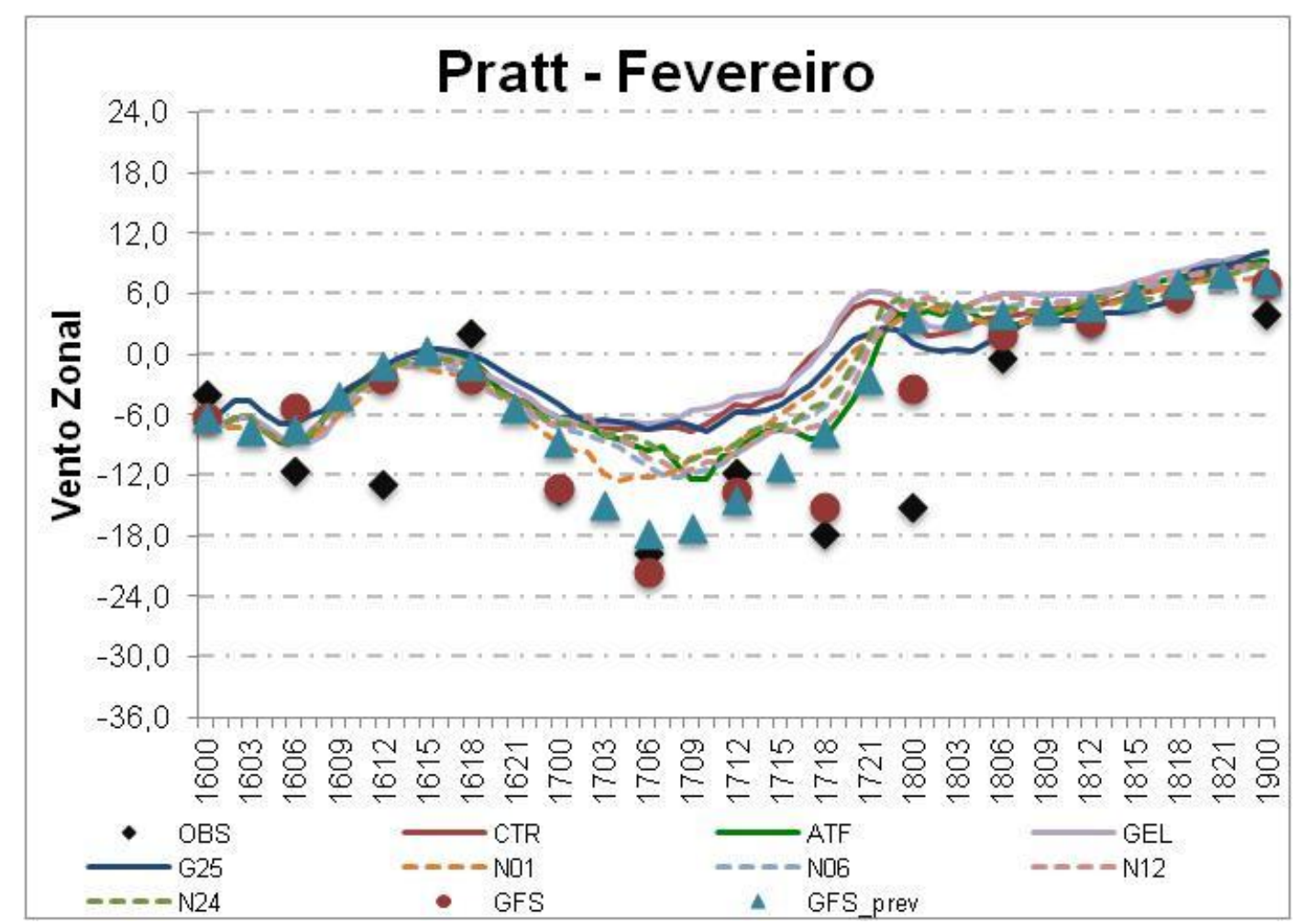

Figura 3.2-24: Série temporal da componente zonal do vento para Pratt no evento de fevereiro 


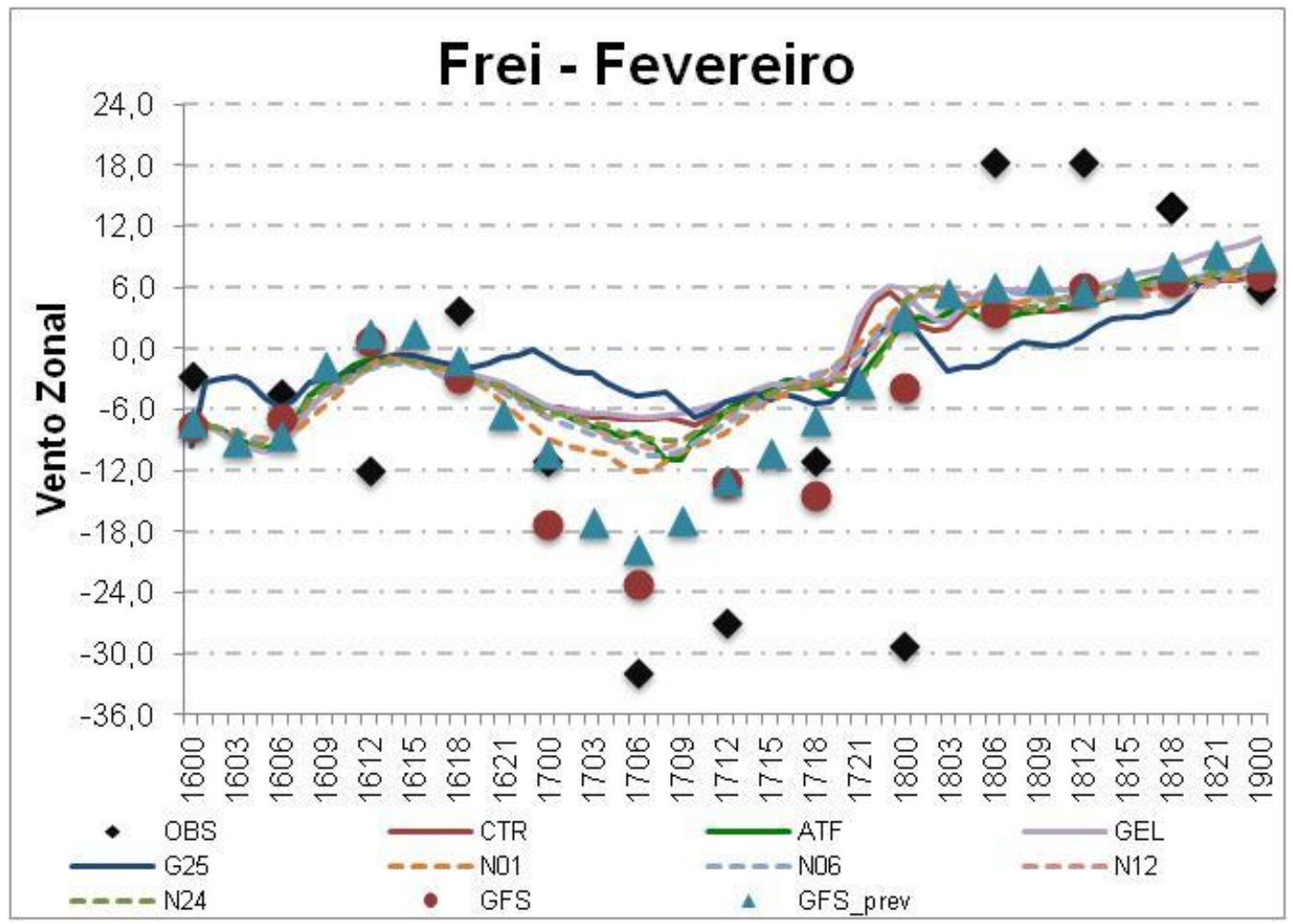

Figura 3.2-25: Série temporal da componente zonal do vento para Frei no evento de fevereiro

Em O'higgins predominaram os ventos de leste durante grande parte do período em análise, como mostram as observações na figura 3.2-27. O modelo BRAMS não apresentou um bom desempenho em simular o escoamento zonal. Desde o inicio das simulações as previsões do BRAMS não condiziam com o que era registrado na estação e ao longo das 72 horas não conseguiu prever as variações nem de direção nem de intensidade do vento. 


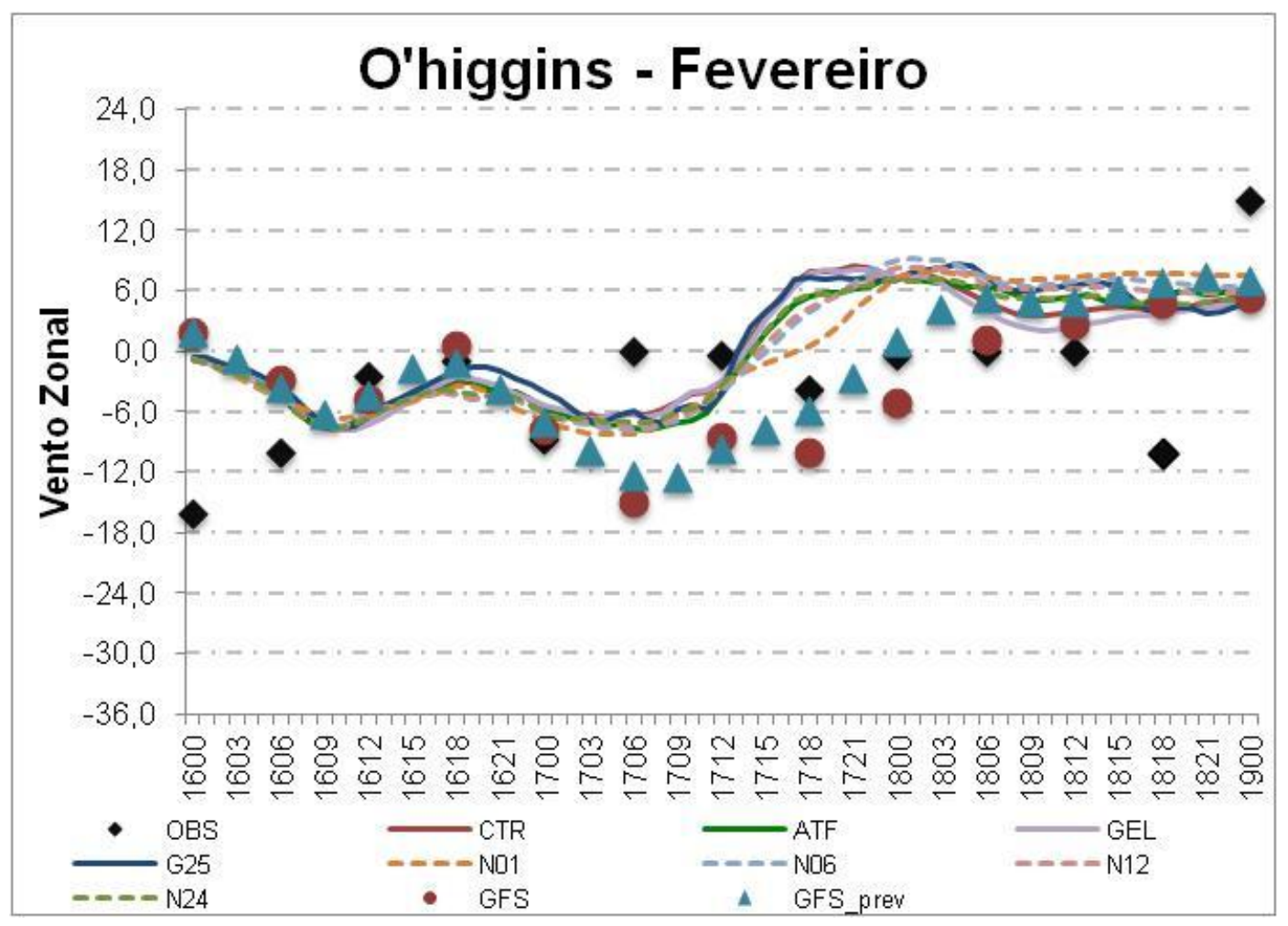

Figura 3.2-26: Série temporal da componente zonal do vento para O'higgins no evento de fevereiro

\subsubsection{JULHO}

$\mathrm{Na}$ EACF no caso de inverno (Fig. 3.2-28) as observações mostram num primeiro momento um enfraquecimento dos ventos de oeste, que passam a soprar de leste a partir das 09 UTC do dia 10 de julho. Posteriormente, os ventos permaneceram soprando de leste na maior parte do período. Observa-se que o modelo regional já parte de uma condição de ventos de oeste mais intensos que o observado, mas que, apesar disso, consegue simular esta mudança no sentido do vento zonal que ocorre nas primeiras 24 horas.

Entretanto, após a passagem do ciclone extratropical pela PA, o que ocorrer por volta das 03 UTC do dia 11 de julho, os ventos simulados pelo BRAMS mudam bruscamente de direção e passam a soprar de oeste. Nas últimas 71 horas simuladas, os experimentos N01, N06 e N12, que envolvem NDC, acompanharam a previsão do GFS que mantinha os ventos predominando de leste. Já a rodada GEL, mesmo mantendo os ventos soprando de oeste, consegue prever uma diminuição da magnitude entre às 12 UTC do dia 11 de Julho e às 00 UTC do dia 12, o que 
acompanha as observações, que no mesmo intervalo mostra uma intensificação dos ventos de leste.

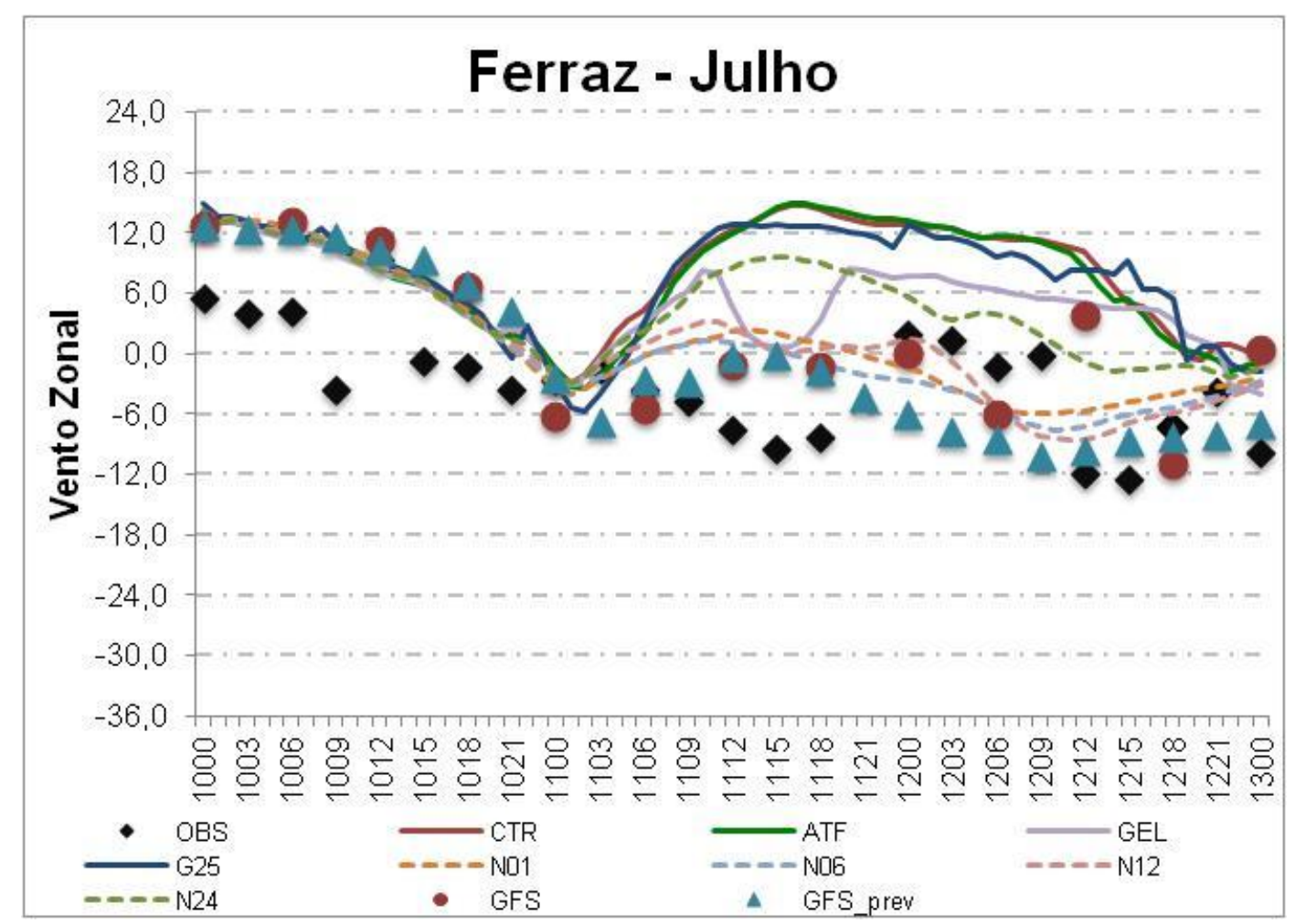

Figura 3.2-27: Série temporal da componente zonal do vento para EACF no evento de julho

$\mathrm{Na}$ estação Jubany (fig. 3.2-29) tanto o vento zonal observado quanto o simulado pelo BRAMS apresentaram um comportamento bem semelhante àqueles vistos na EACF. As observações mostravam um gradual enfraquecimento dos ventos de oeste e posterior predominância de leste e já o modelo regional previa intensos ventos de oeste após a passagem do sistema sinótico pela PA. 


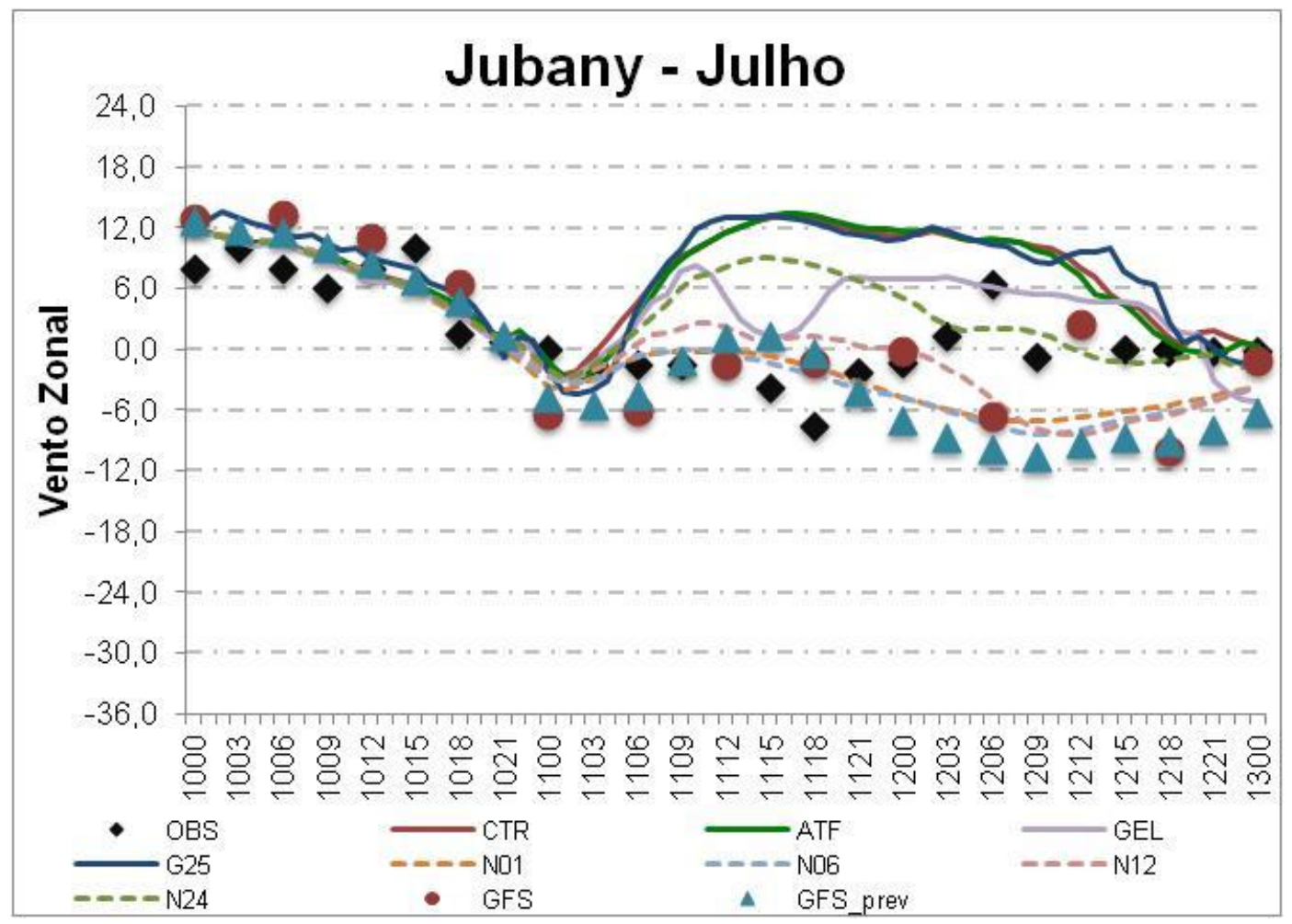

Figura 3.2-28: Série temporal da componente zonal do vento para Jubany no evento de julho

$\mathrm{Na}$ estação Marambio ventos de oeste com magnitude menor de $6 \mathrm{~m} / \mathrm{s}$ foram observados em grande parte do período analisado, como mostra a figura 3.2-30. Entretanto, é possível observar que as simulações do BRAMS, até às 00 UTC do dia 12 de julho, mostravam um comportamento parecido e uma predominância dos ventos de leste. Entretanto a partir das 15 UTC até as 21 UTC do dia 11 de julho estes ventos de leste simulados pelos experimentos CTR, GEL e ATF ganharam intensidade, enquanto as observações indicavam fracos ventos de oeste. $O$ vento destes experimentos passa a soprar de oeste nas últimas 18 horas de simulação e com maior intensidade do que foi realmente registrado. Já os experimentos que envolviam N24, N12 e GEL apresentaram um comportamento bem parecido com as previsões do GFS a partir das 12 UTC do dia 11 de julho. Por outro lado os experimentos N01 e N06 permaneceram com ventos de oeste com fraca intensidade nas últimas 36 horas simuladas. 


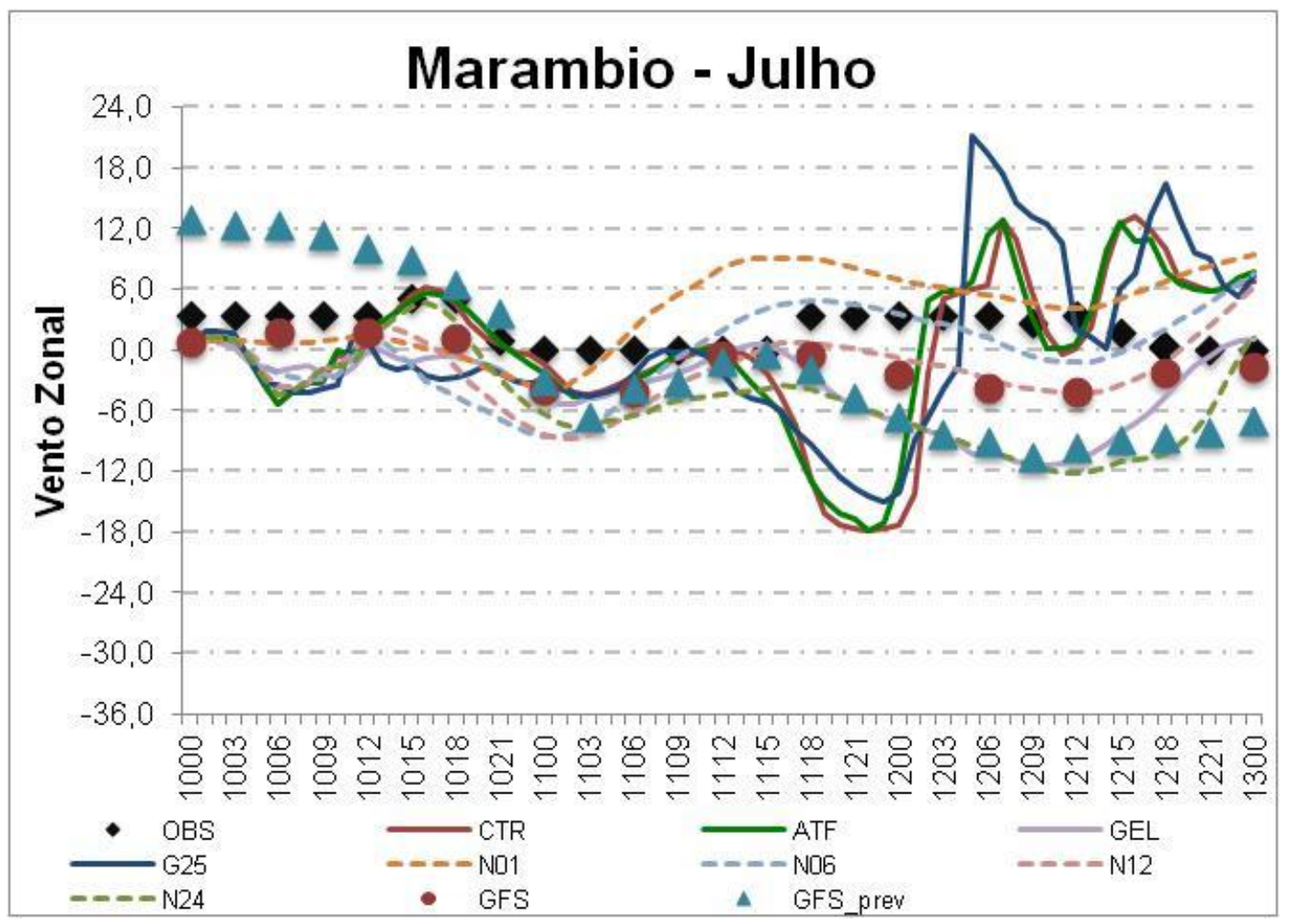

Figura 3.2-29: Série temporal da componente zonal do vento para Marambio no evento de julho

\subsubsection{VENTO MERIDIONAL}

\subsubsection{FEVEREIRO}

A figura 3.2-31 mostra o comportamento do vento meridional na EACF durante a passagem do sistema ciclônico no mês de fevereiro. Até às 18 UTC do dia 17 de fevereiro, fracos ventos predominavam do quadrante norte. Porém conforme o ciclone avança pela PA, além dos ventos ganharem intensidade, a componente meridional muda de direção, adquirindo uma componente de sul. Já o modelo BRAMS não conseguiu simular adequadamente 0 comportamento do vento meridional na estação EACF, pois entre às 21 UTC do dia 16 de fevereiro e 03 UTC do dia 18 de fevereiro o modelo previu uma forte componente de sul, no período em que o ciclone extratropical se aproximava e avançava sobre a PA. O observado foi justamente o contrário, com ventos de norte predominando. De modo geral as rodadas com o modelo regional seguiram as previsões do GFS. 
Analisando a Figura 3.2-32, que mostra o comportamento vento meridional para a na estação de Jubany, é possível notar que conforme o ciclone se aproxima da PA os ventos de norte vão gradualmente perdendo intensidade, comportamento previsto pelo modelo regional. Entretanto, O BRAMS força ventos de sul, enquanto o que foi observado na estação é um vento praticamente nulo entre às 03 UTC do dia 17 e às 03 UTC do dia 18. Já nas últimas horas da simulação BRAMS previu um comportamento oposto ao registrado, que foi o vento meridional passando a soprar de sul. Outro fato a ser observado é que apesar das simulações regionais apresentarem magnitudes diferentes para o vento meridional, todas mostram o mesmo comportamento em relação à direção do escoamento.

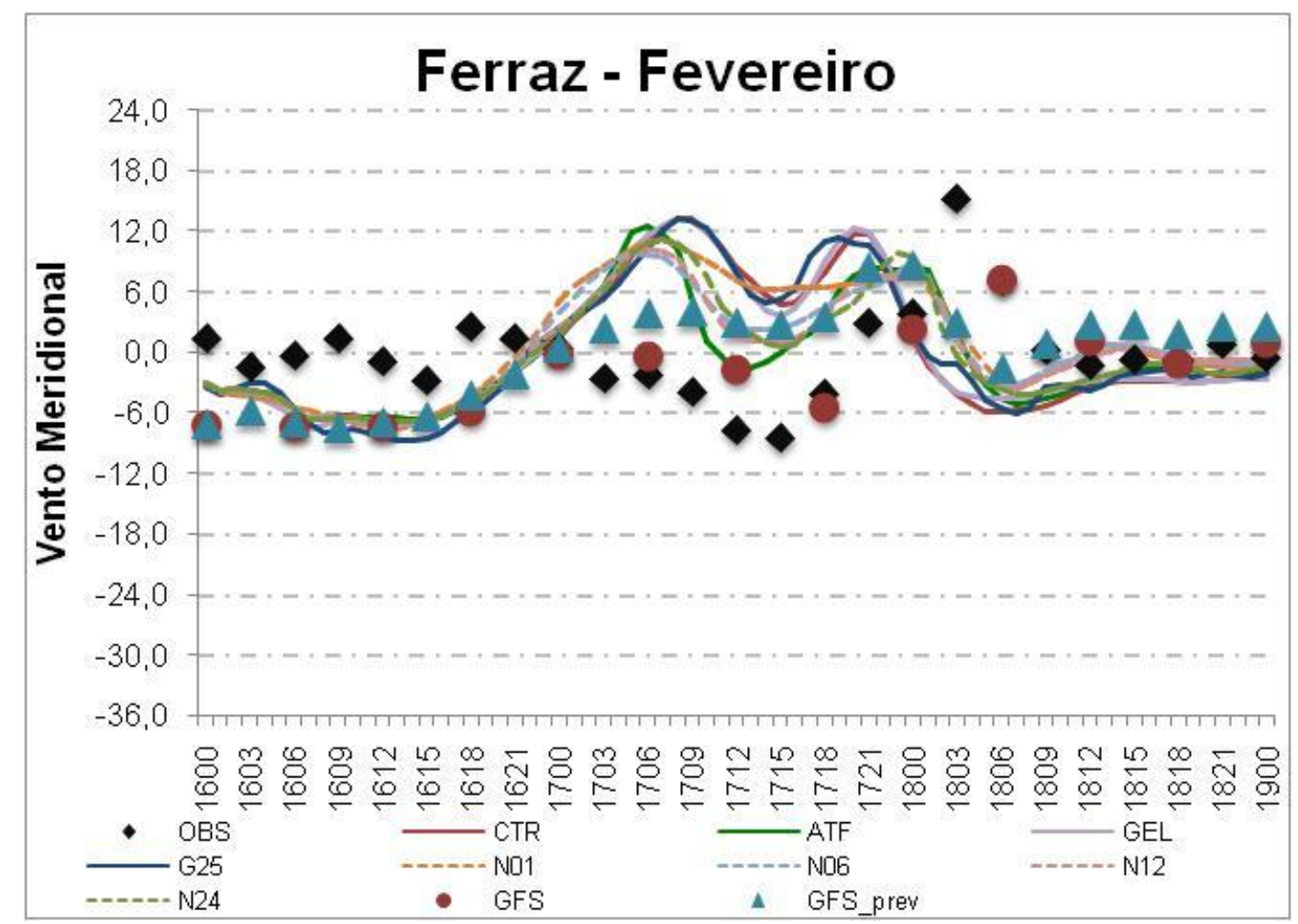

Figura 3.2-30: Série temporal da componente meridional do vento para EACF no evento de fevereiro 


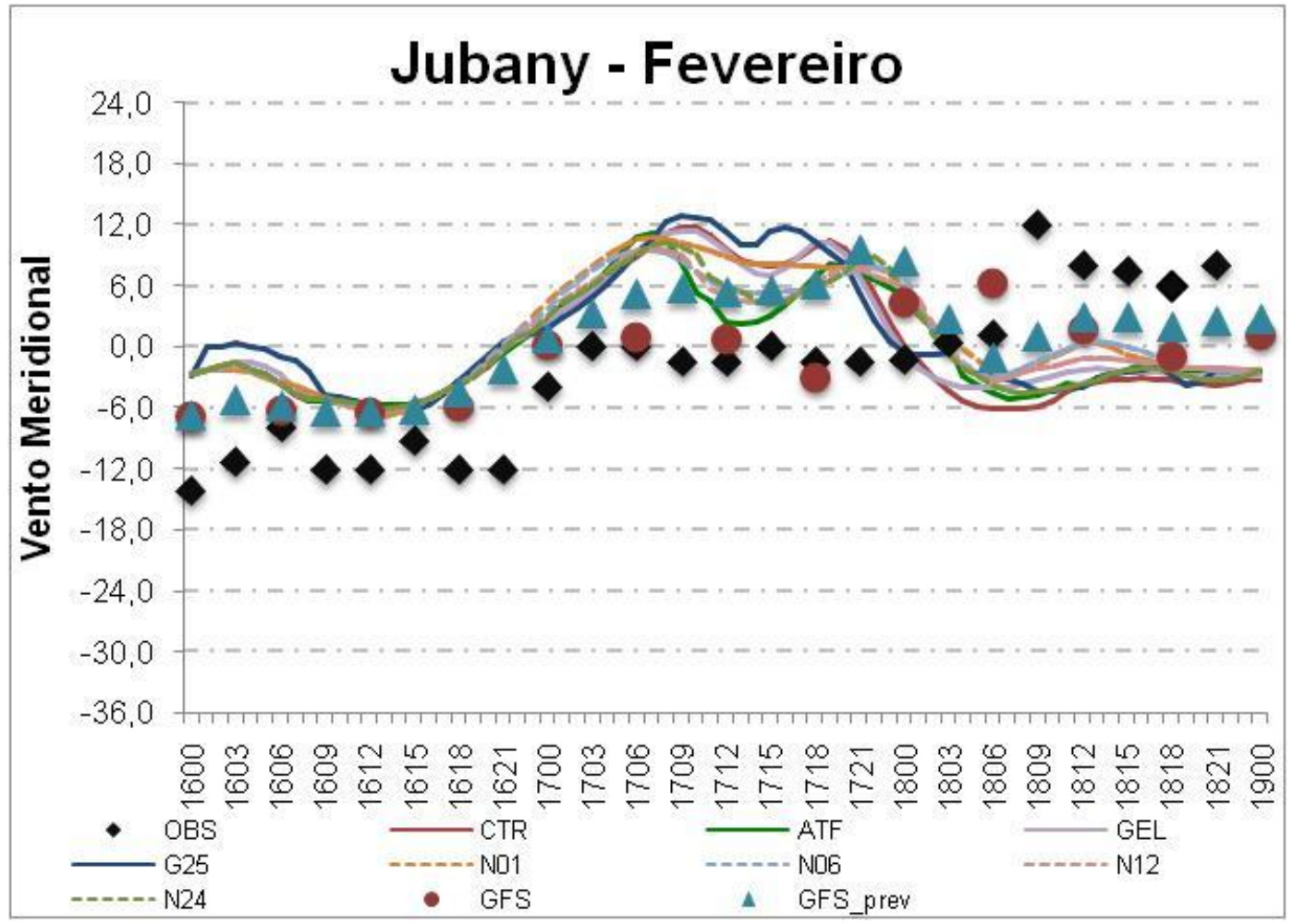

Figura 3.2-31: Série temporal da componente meridional para Jubany no evento de fevereiro

Nas primeiras horas do dia 16 de fevereiro de 2009, Marambio (Figura 3.2-33) registrava intensos ventos de norte, porém entre às 09 UTC e 15 UTC deste mesmo dia observa-se uma brusca desintensificação do vento norte, ficando praticamente nulo nas horas que seguem. O BRAMS, de modo geral, previu o comportamento do vento meridional, porém erra na magnitude.

Para a estação Pratt (Figura 3.2-34) o modelo conseguiu captar as mudanças de direção do vento meridional, como a mudança para norte que ocorreu às 18 UTC do dia 16 de fevereiro. Porém, entre o dia 17 e 18 ele intensifica os ventos do quadrante sul, bem como ocorre em outras estações meteorológicas. Além disso, durante o período são observados dois máximos de vento sul, mas as previsões feitas com o BRAMS simulam apenas um grande máximo. 


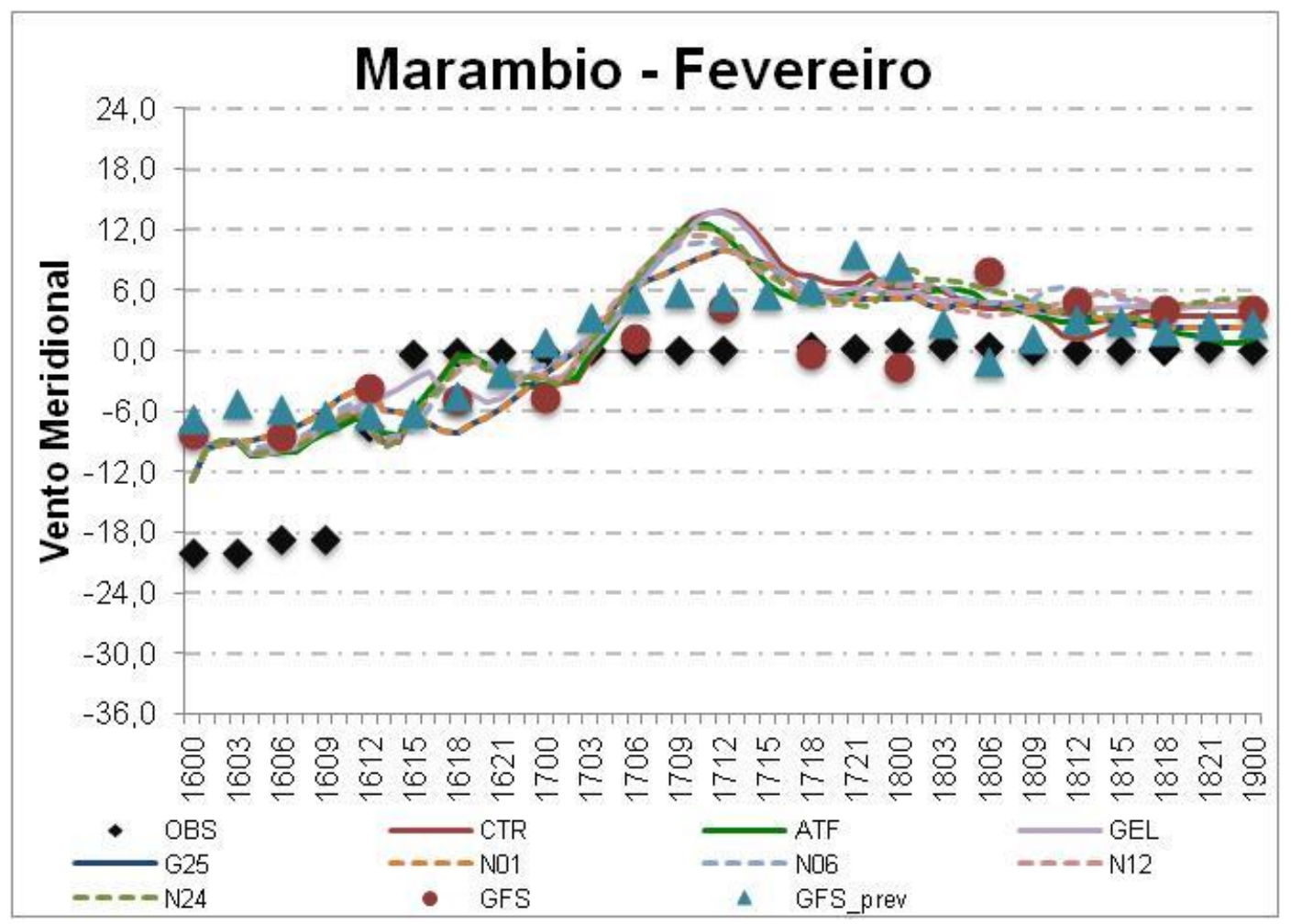

Figura 3.2-32: Série temporal da componente meridional para Marambio no evento de fevereiro

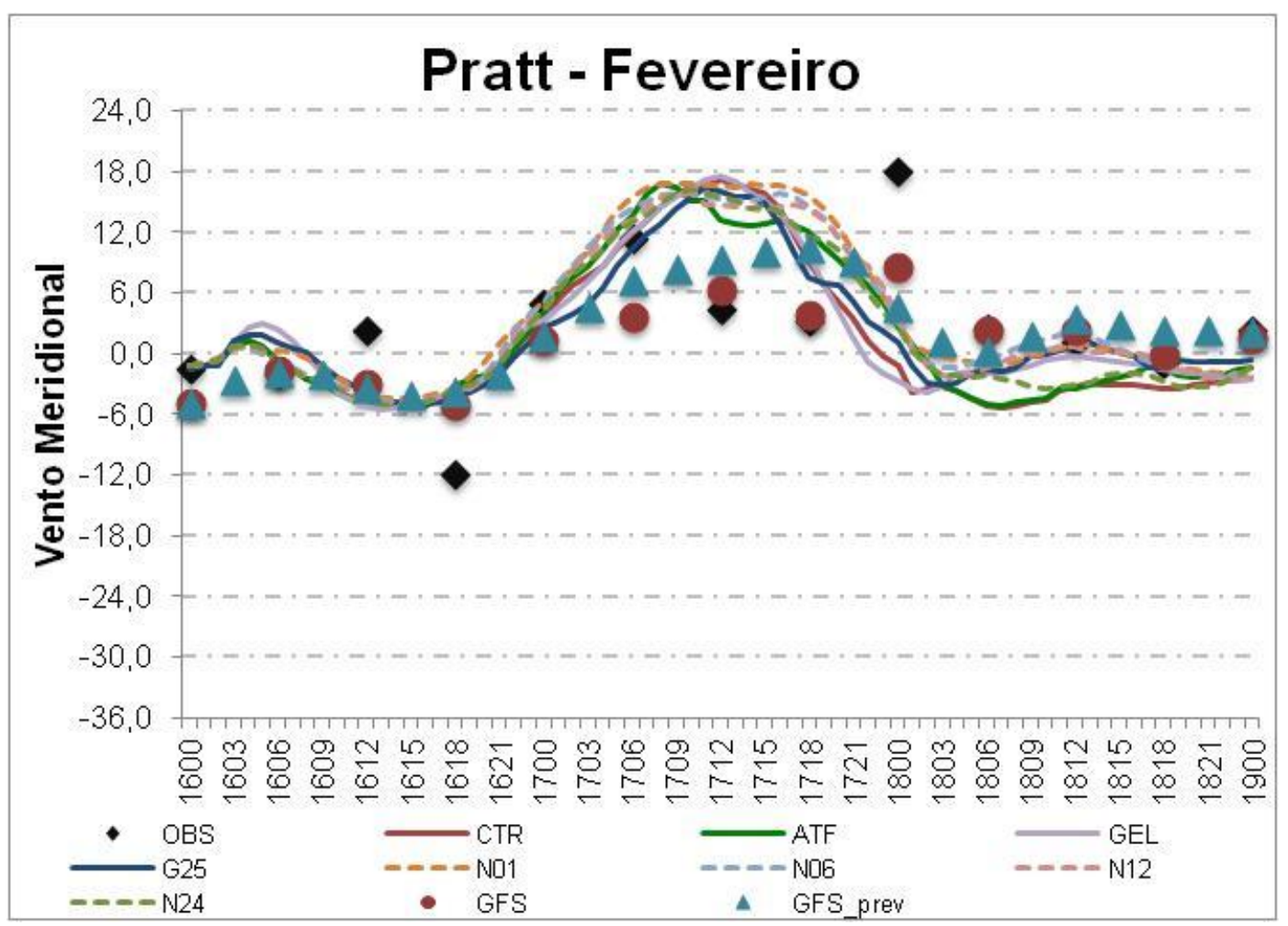

Figura 3.2-33: Série temporal da componente meridional para Pratt no evento de fevereiro

Uma brusca intensificação do vento meridional de norte foi observada na estação Frei ainda nas primeiras 18 horas do período analisado, como pode ser visto 
na figura 3.2-35. Nas últimas 6 horas do dia 16 de fevereiro os ventos de norte começam a perder intensidade e acabam virando para sul e assim permanecem pelo menos até as 12 horas do dia 18, quando mudam novamente para norte. Nesta estação, as simulações com o BRAMS apresentaram variações que seguiram o mesmo comportamento das condições dadas como input ao modelo, as previsões do GFS. Interessante notar que o primeiro pico na intensidade dos ventos de sul observado na estação às 06 UTC do dia 17 foi previsto por todas as simulações do BRAMS, mesmo não sendo visto nas previsões do modelo GFS. Os experimentos N06, N12 e ATF mostraram um enfraquecimento do vento um pouco mais significativo, em relação aos demais. Este enfraquecimento do vento meridional entre as 06 e 18 UTC foi registrado na estação, mas se deu de forma mais intensa do que previu o BRAMS. Ainda, um segundo máximo de vento sul foi observado 06 UTC do dia 18, não representado pelas simulações regionais, que neste momento já mostram ventos de norte.

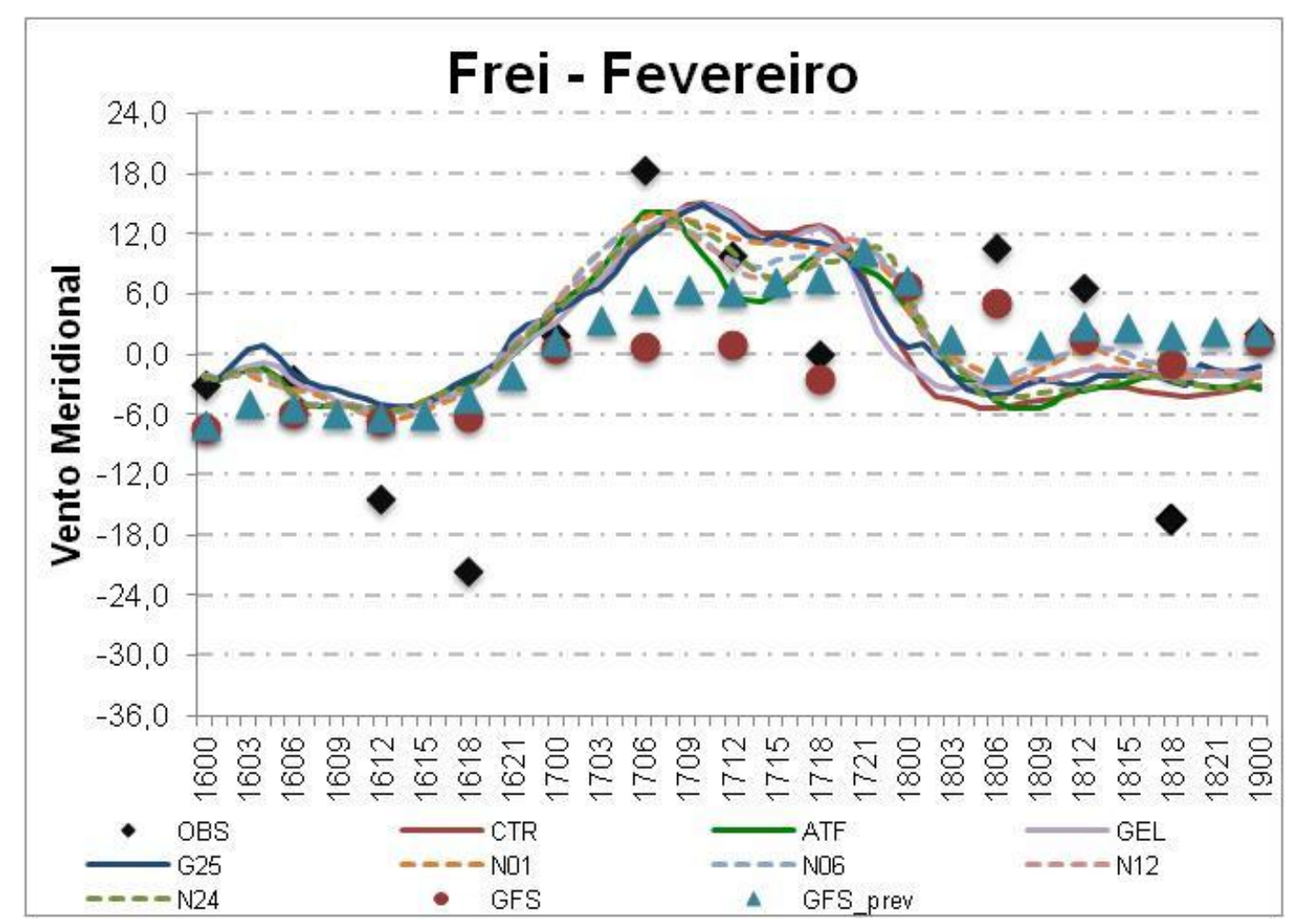

Figura 3.2-34: Série temporal da componente meridional para Frei no evento de fevereiro

Em O'higgins (Figura 3.2-36), o dia 16 de fevereiro inicia com fortes ventos de sul que gradualmente vão perdendo intensidade até que passam a soprar do quadrante sul até às 12 UTC do dia 17 de fevereiro e predominando de sul nas 
horas seguinte. Antes da passagem do ciclone extratropical os experimentos G25 e GEL apresentavam vento meridional praticamente nulo, assemelhando-se muito ao registrado na estação. Durante a passagem do ciclone, assim como em outras estações, houve uma superestimativa dos ventos de sul simulados pelo BRAMS.

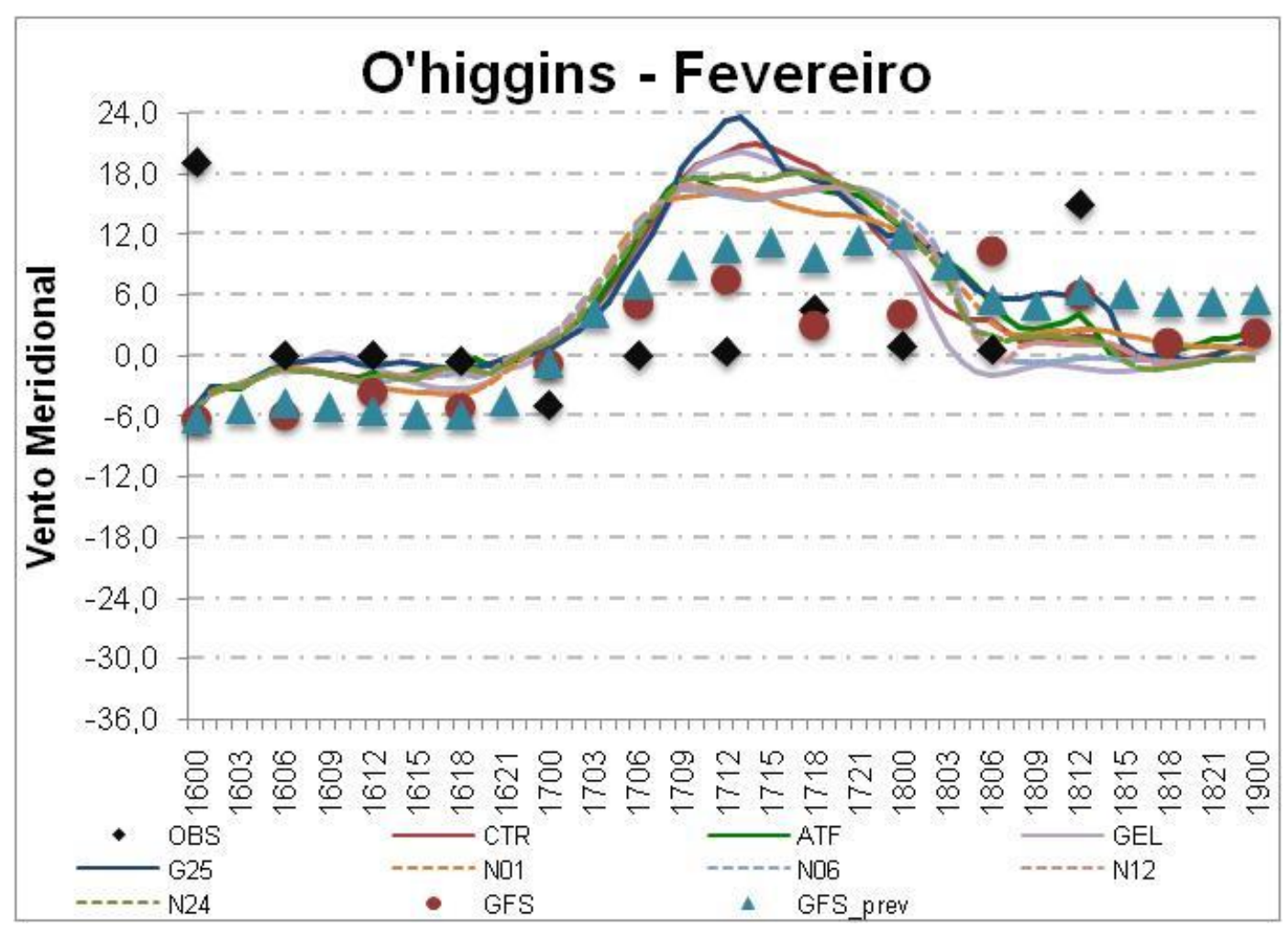

Figura 3.2-35: Série temporal da componente meridional para O'higgins no evento de fevereiro

\subsubsection{JULHO}

Durante o dia 10 de julho na estação EACF (figura 3.2-37) observa-se uma intensificação dos ventos de norte até às 21 UTC quando atinge $12 \mathrm{~m} / \mathrm{s}$. Fica claro que o BRAMS previu as variações do vento meridional. Todas as simulações conseguiram prever ventos do quadrante norte antes da passagem do ciclone extratropical e, também, a mudança de direção do vento meridional após a passagem do mesmo. Por outro lado, após a passagem do sistema os ventos meridionais observados na estação ficam praticamente nulos, enquanto que a maioria das simulações volta a indicar ventos de norte a partir das 00 UTC do dia 12 . Este fato contribuiu para aumentar a temperatura do ar nesta estação, já que os ventos do quadrante norte são responsáveis pelo transporte de ar relativamente mais quente. 
Em Jubany (Figura 3.2-38) o BRAMS mostrou o mesmo comportamento obtido na EACF. Porém, nesta estação o escoamento meridional era praticamente nulo, com ventos fracos de norte durante a passagem do sistema ciclônico pela PA.

O modelo foi bastante ineficiente na simulação do vento meridional para a estação de Marambio (Figura 3.2-39). Na maior parte do período em análise os ventos meridionais observados nesta estação predominaram de norte. Porém o modelo regional, seguindo as previsões do GFS, inicia a simulações sob uma condição de ventos do quadrante norte, que só é revertida após a passagem do ciclone pela região da PA. Um pouco diferente do que ocorre nas outras duas estações, EACF e Jubany, apenas os experimentos CTR, ATF e G25 voltam a mostrar ventos do quadrante norte entre às 00 UTC e 15 UTC do dia 12 de julho.

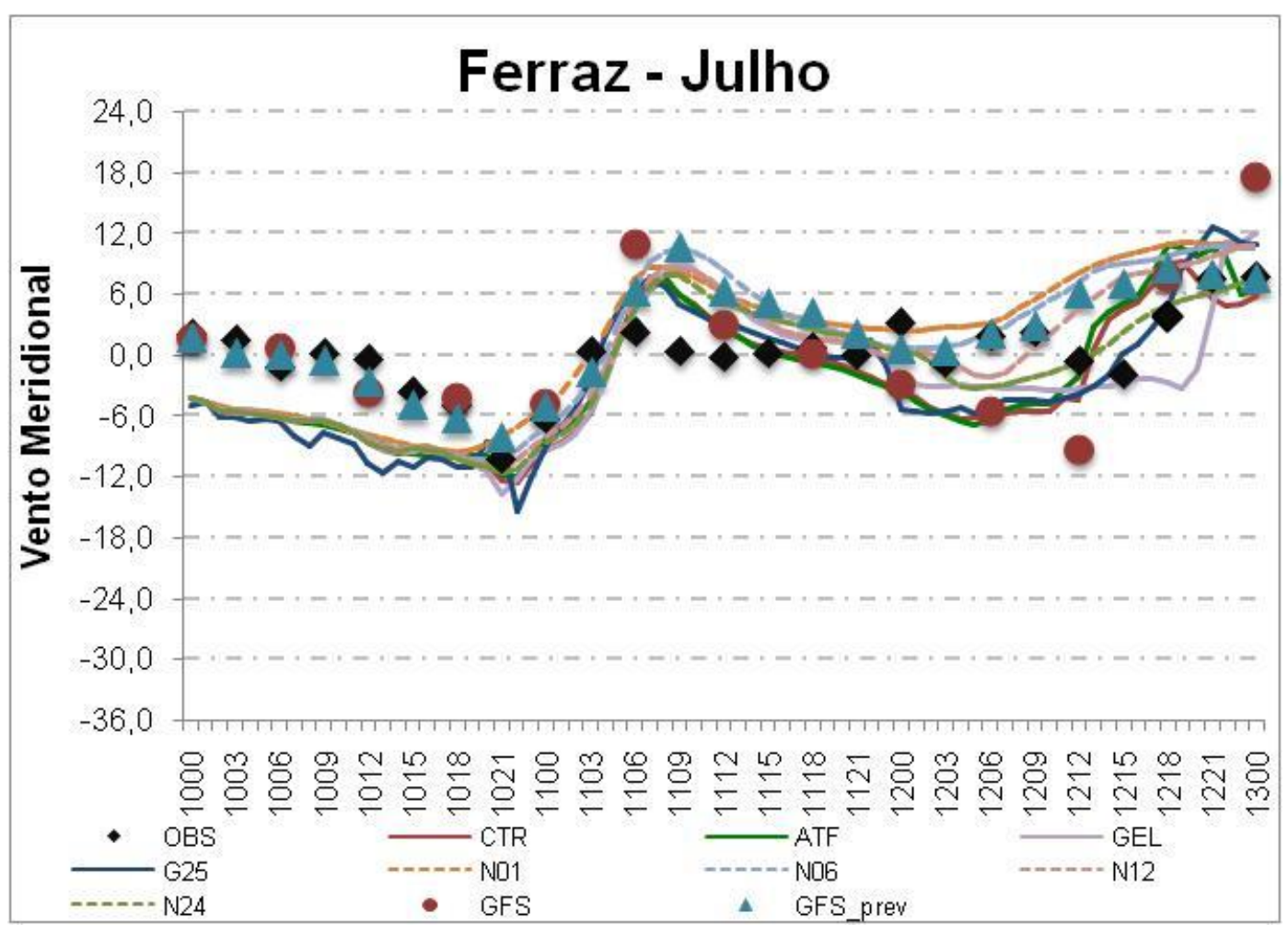

Figura 3.2-36: Série temporal da componente meridional do vento para EACF no evento de julho 


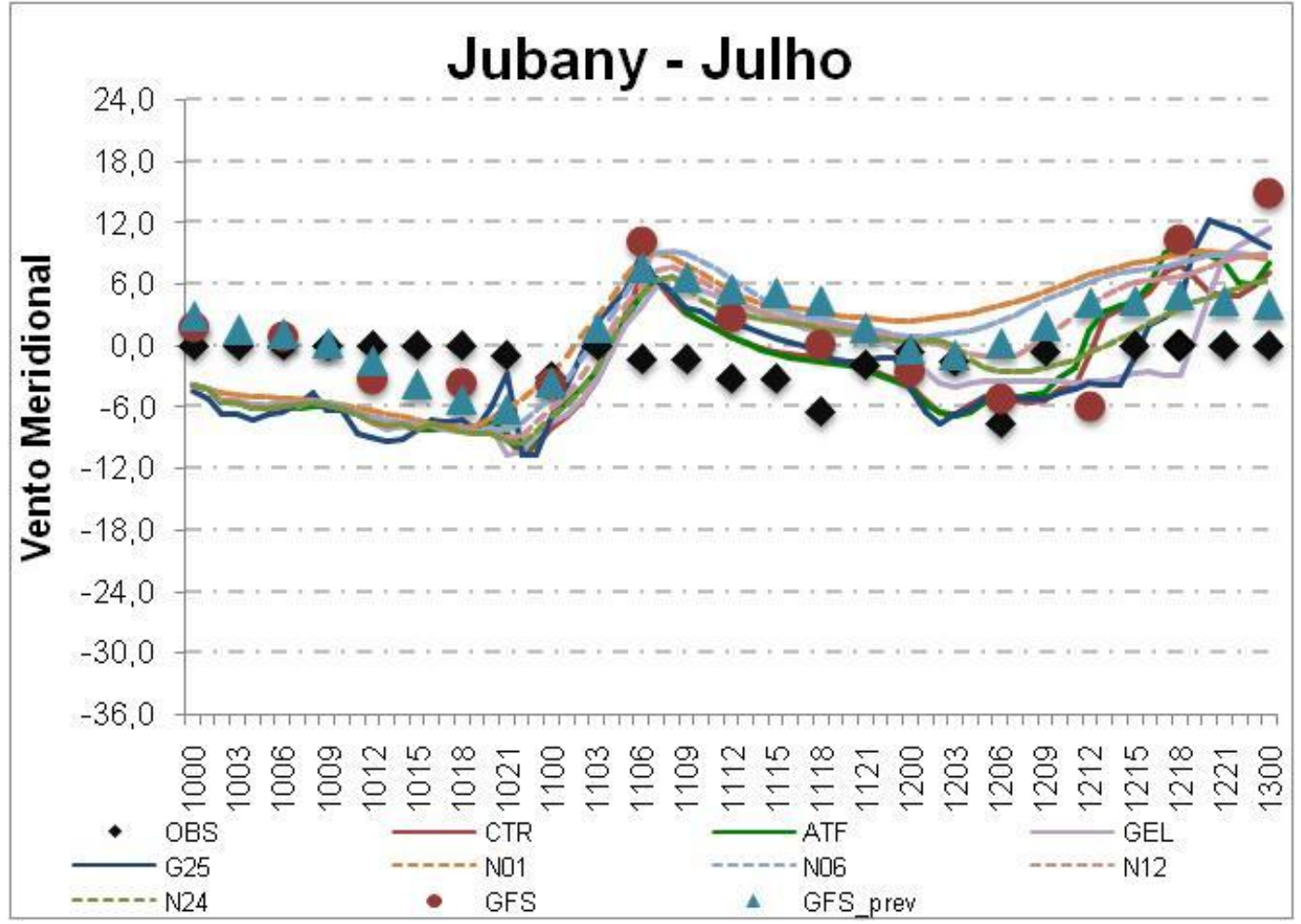

Figura 3.2-37: Série temporal da componente meridional do vento para Jubany no evento de julho

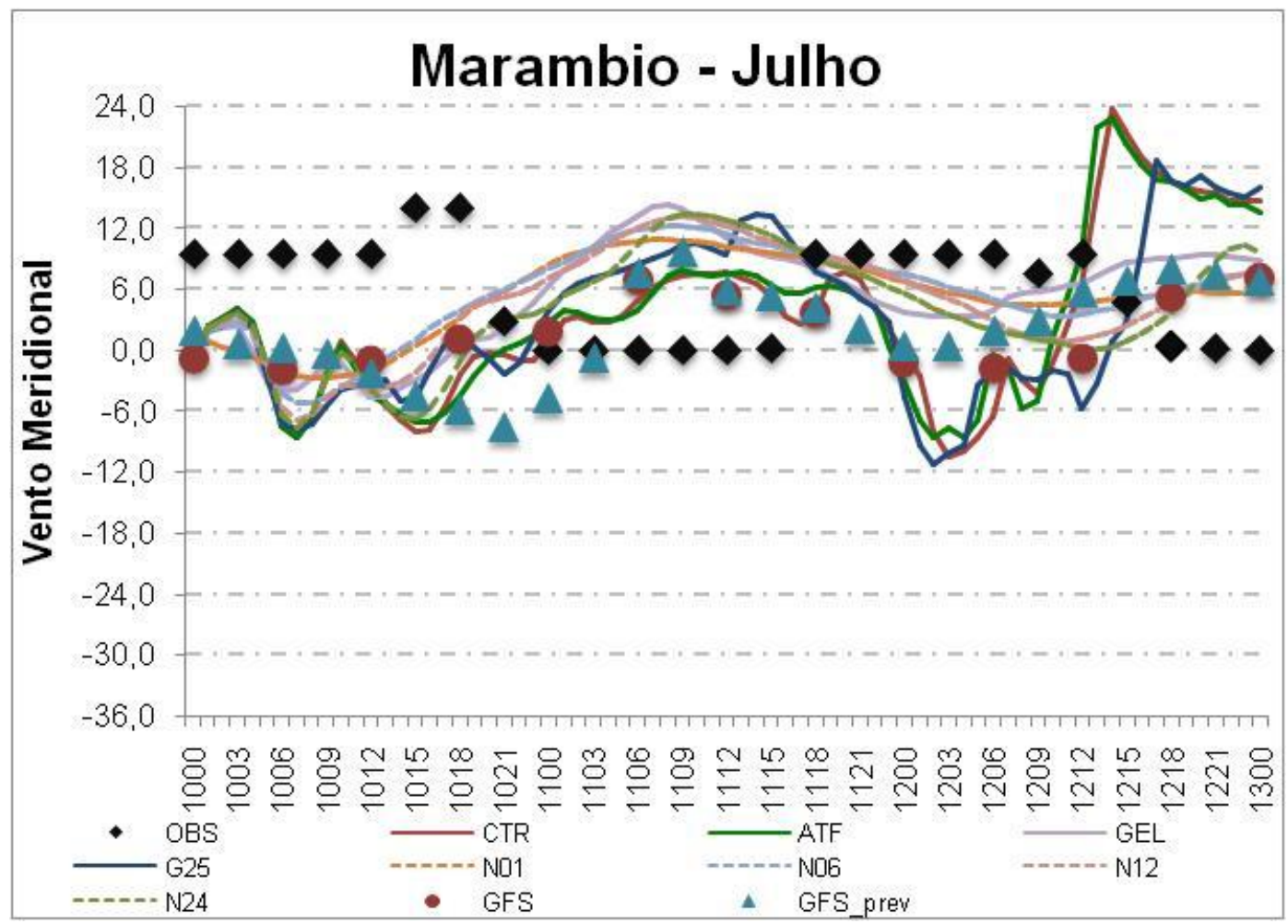

Figura 3.2-38: Série temporal da componente meridional do vento para Marambio no evento de julho 


\subsection{ANÁLISE DE SENSIBILIDADE DAS SIMULAÇÕES}

Para avaliar estatisticamente as saídas do modelo regional foram calculados diversos índices, são eles: média das observações e das saídas do modelo, desvio padrão das observações e saídas, coeficiente de correlação, bias, raiz do erro médio quadrático (RMSE) e a raiz do erro médio quadrático normalizado pelos desvios

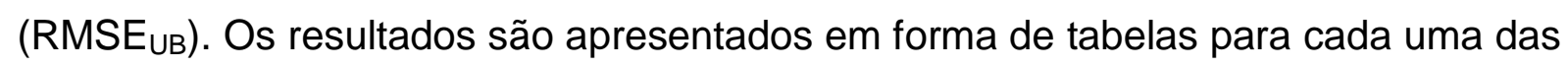
variáveis e estações meteorológicas e são referidos como análise de skill. Para determinar a habilidade do modelo na simulação, deve-se atender aos seguintes critérios propostos por Pielke (2002):

- Desvio das observações $\approx$ desvio das simulações;

- RMSE < desvio das observações;

- $\mathrm{RMSE}_{\mathrm{UB}}<$ desvio das observações;

\subsubsection{TEMPERATURA DO AR}

Observando a tabela 3.3-1, que mostra a análise de skill para a temperatura do ar para a EACF, nota-se que em fevereiro o experimento de maior erro foi ATF e o de menor N01, já em julho o de maior erro foi GEL. As médias das simulações em fevereiro é cerca de $1^{\circ} \mathrm{C}$ mais quente que as observações. A média observada em julho é de $-11^{\circ} \mathrm{C}$ e das simulações é $-3,5^{\circ} \mathrm{C}$, ou seja, as simulações são $6,5^{\circ} \mathrm{C}$ mais quentes. Para fevereiro a única simulação que pode ser considerada com uma boa acurácia é G25, porém em julho a única que passa nos critérios é N01. As correlações no caso de julho são mais altas que as do caso de fevereiro.

Em Jubany, conforme se observa na tabela 3.3-2, em fevereiro os menores valores de erro ficam por conta dos experimentos GEL e G25, enquanto que em julho estes cabem aos experimentos com NDC. Para os experimentos de fevereiro as correlações em Jubany aumentam quando comparadas a EACF, já em julho este valor gira em torno de $79 \%$. Todas as simulações feitas para a passagem do ciclone em fevereiro possuem uma boa acurácia. Em julho o bom desempenho do modelo fica restrito as simulações N01 e N06. 
Tabela 3.3-1: Análise de skill para a temperatura do ar para a EACF.

\begin{tabular}{|c|c|c|c|c|c|c|c|c|}
\hline Simulação & Mobs & Msimul & oobs & osimul & $\mathbf{R}_{\text {so }}$ & BIAS & RMSE & RMSE $_{\mathrm{UB}}$ \\
\hline \multicolumn{9}{|c|}{ Fevereiro } \\
\hline ANT & 1,49 & 4,12 & 1,96 & 1,95 & 0,46 & 2,63 & 3,33 & 2,05 \\
\hline CTR & 2,42 & 3,44 & 1,51 & 0,92 & 0,45 & 1,02 & 1,68 & 1,34 \\
\hline ATF & 2,42 & 3,77 & 1,51 & 0,96 & 0,54 & 1,35 & 1,84 & 1,25 \\
\hline GEL & 2,42 & 3,17 & 1,51 & 0,81 & 0,52 & 0,75 & 1,47 & 1,27 \\
\hline G25 & 2,42 & 2,82 & 1,51 & 1,04 & 0,40 & 0,40 & 1,47 & 1,42 \\
\hline N01 & 2,42 & 2,91 & 1,51 & 0,97 & 0,39 & 0,49 & 1,48 & 1,38 \\
\hline N06 & 2,42 & 3,12 & 1,51 & 0,87 & 0,41 & 0,70 & 1,54 & 1,36 \\
\hline N12 & 2,42 & 3,30 & 1,51 & 0,85 & 0,40 & 0,88 & 1,63 & 1,37 \\
\hline N24 & 2,42 & 3,31 & 1,51 & 0,86 & 0,43 & 0,89 & 1,62 & 1,35 \\
\hline \multicolumn{9}{|c|}{ Julho } \\
\hline ANT & $-7,52$ & $-2,00$ & 6,54 & 1,15 & 0,79 & 5,52 & 7,84 & 5,57 \\
\hline CTR & $-11,78$ & $-2,28$ & 7,97 & 1,92 & 0,81 & 9,50 & 11,45 & 6,39 \\
\hline ATF & $-11,78$ & $-2,18$ & 7,97 & 1,97 & 0,80 & 9,60 & 11,53 & 6,38 \\
\hline GEL & $-11,78$ & $-2,25$ & 7,97 & 2,12 & 0,68 & 9,53 & 11,58 & 6,57 \\
\hline G25 & $-11,78$ & $-2,84$ & 7,97 & 2,09 & 0,81 & 8,94 & 10,91 & 6,27 \\
\hline N01 & $-11,78$ & $-7,86$ & 7,97 & 6,97 & 0,83 & 3,92 & 5,87 & 4,37 \\
\hline N06 & $-11,78$ & $-5,68$ & 7,97 & 5,19 & 0,81 & 6,10 & 7,75 & 4,77 \\
\hline N12 & $-11,78$ & $-4,10$ & 7,97 & 4,01 & 0,77 & 7,68 & 9,40 & 5,43 \\
\hline N24 & $-11,78$ & $-2,92$ & 7,97 & 2,74 & 0,79 & 8,86 & 10,66 & 5,92 \\
\hline
\end{tabular}

Tabela 3.3-2: Análise de skill para a temperatura do ar para Jubany

\begin{tabular}{|c|c|c|c|c|c|c|c|c|}
\hline Simulação & Mobs & Msimul & oobs & osimul & $\mathbf{R}_{\text {so }}$ & BIAS & RMSE & RMSE $_{\text {UB }}$ \\
\hline \multicolumn{9}{|c|}{ Fevereiro } \\
\hline ANT & 1,38 & 3,45 & 1,80 & 1,95 & 0,56 & 2,07 & 2,70 & 1,73 \\
\hline CTR & 2,17 & 2,66 & 1,34 & 0,94 & 0,64 & 0,49 & 1,12 & 1,01 \\
\hline ATF & 2,17 & 2,84 & 1,34 & 0,91 & 0,66 & 0,62 & 1,12 & 0,95 \\
\hline GEL & 2,17 & 2,47 & 1,34 & 0,94 & 0,71 & 0,30 & 0,97 & 0,93 \\
\hline G25 & 2,17 & 2,30 & 1,34 & 1,16 & 0,71 & 0,12 & 0,96 & 0,95 \\
\hline N01 & 2,17 & 2,31 & 1,34 & 0,92 & 0,61 & 0,13 & 1,05 & 1,04 \\
\hline N06 & 2,17 & 2,43 & 1,34 & 0,86 & 0,64 & 0,25 & 1,04 & 1,01 \\
\hline N12 & 2,17 & 2,25 & 1,34 & 0,84 & 0,66 & 0,37 & 1,05 & 0,99 \\
\hline N24 & 2,17 & 2,58 & 1,34 & 0,86 & 0,66 & 0,41 & 1,07 & 0,99 \\
\hline \multicolumn{9}{|c|}{ Julho } \\
\hline ANT & $-7,34$ & $-0,85$ & 6,37 & 0,99 & 0,30 & 6,48 & 3,60 & 3,11 \\
\hline CTR & $-11,56$ & $-2,67$ & 7,84 & 1,82 & 0,84 & 8,89 & 10,88 & 6,27 \\
\hline ATF & $-11,56$ & $-2,66$ & 7,84 & 1,85 & 0,80 & 8,91 & 10,93 & 6,34 \\
\hline GEL & $-11,56$ & $-2,72$ & 7,84 & 2,06 & 0,72 & 8,84 & 10,91 & 6,39 \\
\hline G25 & $-11,56$ & $-3,05$ & 7,84 & 1,96 & 0,82 & 8,52 & 10,55 & 6,22 \\
\hline N01 & $-11,56$ & $-8,26$ & 7,84 & 6,77 & 0,82 & 3,30 & 5,50 & 4,40 \\
\hline N06 & $-11,56$ & $-6,19$ & 7,84 & 5,15 & 0,81 & 5,37 & 7,14 & 4,70 \\
\hline N12 & $-11,56$ & $-4,58$ & 7,84 & 3,92 & 0,76 & 6,98 & 8,80 & 5,36 \\
\hline N24 & $-11,56$ & $-3,44$ & 7,84 & 2,64 & 0,81 & 8,12 & 9,97 & 5,79 \\
\hline
\end{tabular}


No caso de julho nenhum dos experimentos tiveram um bom desempenho para a estação de Marambio (Tabela 3.3-3), porém dentre eles deve se destacar a simulação GEL que foi a que apresentou os menores valores de erro, com um bias de $10^{\circ} \mathrm{C}$ e correlação de $64 \%$. Os maiores erros do modelo em julho foram no experimento ATF. As correlações negativas em CTR, ATF e G25 mostram que enquanto ocorria uma queda de temperatura na estação o modelo simulava um aquecimento. Em fevereiro apenas a simulação com N01 foi consideradas acuradas.

Tabela 3.3-3: Análise de skill para a temperatura do ar para Marambio

\begin{tabular}{|c|c|c|c|c|c|c|c|c|}
\hline Simulação & Mobs & Msimul & oobs & osimul & $\mathbf{R}_{\mathrm{so}}$ & BIAS & RMSE & RMSE $_{\text {UB }}$ \\
\hline \multicolumn{9}{|c|}{ Fevereiro } \\
\hline ANT & $-2,54$ & $-1,53$ & 1,58 & 0,80 & 0,57 & 1,01 & 1,63 & 1,28 \\
\hline CTR & $-2,31$ & $-1,04$ & 1,38 & 0,57 & $-0,10$ & 1,27 & 1,97 & 1,51 \\
\hline ATF & $-2,31$ & $-1,11$ & 1,38 & 0,54 & $-0,06$ & 1,19 & 1,90 & 1,48 \\
\hline GEL & $-2,31$ & $-1,29$ & 1,38 & 0,59 & 0,30 & 1,02 & 1,65 & 1,30 \\
\hline G25 & $-2,31$ & $-1,28$ & 1,38 & 0,46 & $-0,08$ & 1,02 & 1,78 & 1,45 \\
\hline N01 & $-2,31$ & $-1,49$ & 1,38 & 0,76 & 0,82 & 0,82 & 1,18 & 0,85 \\
\hline N06 & $-2,31$ & $-1,38$ & 1,38 & 0,56 & 0,53 & 0,93 & 1,48 & 1,16 \\
\hline N12 & $-2,31$ & $-1,27$ & 1,38 & 0,51 & 0,30 & 1,04 & 1,66 & 1,29 \\
\hline N24 & $-2,31$ & $-1,27$ & 1,38 & 0,50 & 0,34 & 1,04 & 1,64 & 1,27 \\
\hline \multicolumn{9}{|c|}{ Julho } \\
\hline ANT & $-24,11$ & $-4,11$ & 9,04 & 2,11 & 0,23 & 20,00 & 21,78 & 8,63 \\
\hline CTR & $-26,83$ & $-4,56$ & 10,01 & 2,55 & $-0,15$ & 22,27 & 24,61 & 10,49 \\
\hline ATF & $-26,83$ & $-4,55$ & 10,01 & 2,56 & $-0,15$ & 22,28 & 24,63 & 10,49 \\
\hline GEL & $-26,83$ & $-16,44$ & 10,01 & 6,15 & 0,64 & 10,39 & 12,83 & 7,53 \\
\hline G25 & $-26,83$ & $-5,02$ & 10,01 & 2,25 & $-0,16$ & 21,81 & 24,15 & 10,38 \\
\hline N01 & $-26,83$ & $-11,83$ & 10,01 & 4,43 & 0,73 & 15,00 & 16,66 & 7,26 \\
\hline N06 & $-26,83$ & $-9,14$ & 10,01 & 3,44 & 0,57 & 17,69 & 19,57 & 8,36 \\
\hline N12 & $-26,83$ & $-7,81$ & 10,01 & 3,21 & 0,47 & 19,01 & 20,94 & 8,78 \\
\hline N24 & $-26,83$ & $-6,53$ & 10,01 & 2,68 & 0,29 & 20,30 & 22,37 & 9,40 \\
\hline
\end{tabular}

Em Pratt (tabela 3.3-4), o experimento com bom desempenho na previsão da temperatura foi GEL. Os maiores erros ficaram com as simulações ANT e G25 e os menores com GEL que apresentou correlação de 55\%. Já em Frei (Tabela 3.3-5) a simulação que mais ficou mais distante das observações foi CTR com RMSE de $1,595^{\circ} \mathrm{C}$. Segundo os critérios de Pielke as simulações com melhor desempenho foram N01, N06, N12 e N24. 
Tabela 3.3-4: Análise de skill para a temperatura do ar para Pratt

\begin{tabular}{|lcccccccc|}
\hline Simulação & Mobs & Msimul & oobs & osimul & R $_{\text {so }}$ & BIAS & RMSE & RMSE $_{\text {UB }}$ \\
\hline \hline & & & & Fevereiro & & & & \\
ANT & 0,63 & 2,93 & 1,20 & 1,49 & 0,38 & 2,29 & 2,72 & 1,46 \\
CTR & 1,74 & 2,38 & 1,13 & 0,96 & 0,43 & 0,64 & 1,26 & 1,09 \\
ATF & 1,74 & 2,67 & 1,13 & 0,97 & 0,54 & 0,93 & 1,35 & 0,98 \\
GEL & 1,74 & 2,20 & 1,13 & 0,88 & 0,55 & 0,46 & 1,05 & 0,94 \\
G25 & 1,74 & 2,91 & 1,13 & 1,08 & 0,42 & 1,17 & 1,64 & 1,15 \\
N01 & 1,74 & 2,04 & 1,13 & 0,74 & 0,17 & 0,30 & 1,23 & 1,19 \\
N06 & 1,74 & 2,09 & 1,13 & 0,74 & 0,32 & 0,35 & 1,14 & 1,09 \\
N12 & 1,74 & 2,25 & 1,13 & 0,79 & 0,43 & 0,51 & 1,14 & 1,02 \\
N24 & 1,74 & 2,31 & 1,13 & 0,84 & 0,43 & 0,57 & 1,18 & 1,04 \\
\hline
\end{tabular}

Tabela 3.3-5: Análise de skill para a temperatura do ar para Frei

\begin{tabular}{|c|c|c|c|c|c|c|c|c|}
\hline Simulação & Mobs & Msimul & oobs & osimul & $\mathbf{R}_{\text {so }}$ & BIAS & RMSE & RMSE $_{\text {UB }}$ \\
\hline \multicolumn{9}{|c|}{ Fevereiro } \\
\hline ANT & 0,70 & 2,97 & 1,45 & 1,50 & 0,35 & 2,27 & 2,78 & 1,62 \\
\hline CTR & 1,42 & 2,49 & 1,02 & 0,87 & 0,16 & 1,07 & 1,60 & 1,18 \\
\hline ATF & 1,42 & 2,66 & 1,02 & 0,84 & 0,46 & 1,24 & 1,56 & 0,94 \\
\hline GEL & 1,42 & 2,35 & 1,02 & 0,86 & 0,20 & 0,94 & 1,48 & 1,15 \\
\hline G25 & 1,42 & 1,98 & 1,02 & 0,84 & 0,20 & 0,57 & 1,27 & 1,14 \\
\hline N01 & 1,42 & 2,27 & 1,02 & 0,88 & 0,59 & 0,86 & 1,20 & 0,84 \\
\hline N06 & 1,42 & 2,30 & 1,02 & 0,77 & 0,54 & 0,89 & 1,23 & 0,86 \\
\hline N12 & 1,42 & 2,37 & 1,02 & 0,76 & 0,38 & 0,96 & 1,37 & 0,98 \\
\hline N24 & 1,42 & 2,37 & 1,02 & 0,78 & 0,40 & 0,95 & 1,36 & 0,97 \\
\hline
\end{tabular}

$\mathrm{Na}$ estação meteorológica de O’higgins (Tabela 3.3-6) nenhuma das simulações apresentou um bom desempenho. Os experimentos apresentaram bias positivo de cerca 1,90 , sendo que G25, N01 e N06 mostraram os menores erros com correlações em acima de $47 \%$. Os maiores erros podem ser notados no experimento ANT.

Tabela 3.3-6: Análise de skill para a temperatura do ar para O'higgins

\begin{tabular}{|c|c|c|c|c|c|c|c|c|}
\hline Simulação & Mobs & Msimul & oobs & $\sigma$ simul & $\mathbf{R}_{\text {so }}$ & BIAS & RMSE & RMSE $_{\text {UB }}$ \\
\hline \multicolumn{9}{|c|}{ Fevereiro } \\
\hline ANT & $-0,39$ & 2,21 & 1,15 & 1,24 & 0,52 & 2,60 & 2,83 & 2,12 \\
\hline CTR & 0,30 & 2,34 & 1,11 & 1,21 & 0,73 & 2,04 & 2,18 & 0,76 \\
\hline ATF & 0,30 & 2,58 & 1,11 & 1,09 & 0,66 & 2,28 & 2,44 & 0,87 \\
\hline GEL & 0,30 & 2,18 & 1,11 & 0,93 & 0,62 & 1,88 & 2,07 & 0,87 \\
\hline G25 & 0,30 & 1,92 & 1,11 & 0,89 & 0,58 & 1,62 & 1,85 & 0,90 \\
\hline N01 & 0,30 & 1,79 & 1,11 & 0,87 & 0,47 & 1,49 & 1,80 & 1,00 \\
\hline N06 & 0,30 & 1,99 & 1,11 & 0,86 & 0,53 & 1,69 & 1,93 & 0,94 \\
\hline N12 & 0,30 & 2,13 & 1,11 & 0,91 & 0,59 & 1,83 & 2,04 & 0,90 \\
\hline N24 & 0,30 & 2,20 & 1,11 & 0,94 & 0,60 & 1,90 & 2,10 & 0,89 \\
\hline
\end{tabular}




\subsubsection{PRESSÃO ATMOSFÉRICA}

Na EACF (tabela 3.3-7) é possível ver que tanto no caso de fevereiro quanto no de julho a média das simulações foi menor que a média das observações, gerando assim um bias negativo, exceto no experimento ANT de fevereiro que apresenta um bias positivo de $0,8 \mathrm{hPa}$. O experimento N06 foi o que apresentou os menores erros em fevereiro, já em julho os que menos erraram foram N01 e N06. Ainda um julho os maiores valores de RMSE e bias foram do experimento G25, o mesmo é visto em fevereiro, mas acompanhado da simulação ATF. Em todas as simulações os valores dos desvios padrão das observações e simulações foram suficientemente próximos. Em fevereiro a correlação foi superior a $98 \%$ em todas as simulações, já em julho este valor cai para $87 \%$. Como todas as simulações atendem os critérios de Pielke, em fevereiro o modelo mostrou uma boa acurácia em prever a pressão ao nível médio do mar. Em julho os experimentos CTR, ATF e G25 não atenderam os critérios, pois os valores de RMSE são maiores que os valores do desvio das observações.

Tabela 3.3-7: Análise de skill para a pressão ao nível médio do mar para EACF

\begin{tabular}{|c|c|c|c|c|c|c|c|c|}
\hline Simulação & Mobs & Msimul & бobs & $\sigma$ simul & $\mathbf{R}_{\mathrm{so}}$ & BIAS & RMSE & RMSE $_{U B}$ \\
\hline \multicolumn{9}{|c|}{ Fevereiro } \\
\hline ANT & 981,42 & 982,23 & 19,11 & 16,22 & 1,00 & 0,81 & 3,22 & 3,12 \\
\hline CTR & 972,59 & 969,65 & 17,50 & 18,44 & 0,98 & $-2,93$ & 4,60 & 3,55 \\
\hline ATF & 972,59 & 968,85 & 17,50 & 19,23 & 0,99 & $-3,74$ & 5,12 & 3,50 \\
\hline GEL & 972,59 & 969,70 & 17,50 & 18,36 & 0,98 & $-2,89$ & 4,46 & 3,40 \\
\hline G25 & 972,59 & 969,37 & 17,50 & 18,01 & 0,98 & $-3,22$ & 5,04 & 3,87 \\
\hline N01 & 972,59 & 969,38 & 17,50 & 17,10 & 0,99 & $-3,21$ & 4,05 & 2,34 \\
\hline N06 & 972,59 & 969,47 & 17,50 & 18,35 & 1,00 & $-3,12$ & 3,66 & 1,91 \\
\hline N12 & 972,59 & 969,39 & 17,50 & 18,58 & 0,99 & $-3,20$ & 3,90 & 2,22 \\
\hline N24 & 972,59 & 969,35 & 17,50 & 18,70 & 0,99 & $-3,24$ & 4,19 & 2,66 \\
\hline \multicolumn{9}{|c|}{ Julho } \\
\hline ANT & 982,26 & 976,95 & 14,68 & 16,97 & 0,95 & $-5,67$ & 7,76 & 5,30 \\
\hline CTR & 975,10 & 965,44 & 10,48 & 13,70 & 0,88 & $-9,67$ & 11,73 & 6,64 \\
\hline ATF & 975,10 & 965,65 & 10,48 & 13,69 & 0,87 & $-9,46$ & 11,58 & 6,68 \\
\hline GEL & 975,10 & 967,18 & 10,48 & 13,06 & 0,90 & $-7,93$ & 9,74 & 5,67 \\
\hline G25 & 975,10 & 963,82 & 10,48 & 13,37 & 0,90 & $-11,83$ & 12,78 & 6,00 \\
\hline N01 & 975,10 & 972,93 & 10,48 & 11,78 & 0,89 & $-2,17$ & 5,68 & 5,25 \\
\hline N06 & 975,10 & 971,06 & 10,48 & 12,48 & 0,90 & $-4,05$ & 6,82 & 5,49 \\
\hline N12 & 975,10 & 969,75 & 10,48 & 12,88 & 0,89 & $-5,36$ & 7,90 & 5,80 \\
\hline N24 & 975,10 & 968,27 & 10,48 & 13,02 & 0,89 & $-6,84$ & 8,99 & 5,83 \\
\hline
\end{tabular}


Tabela 3.3-8: Análise de skill para a pressão ao nível médio do mar para Jubany

\begin{tabular}{|c|c|c|c|c|c|c|c|c|}
\hline Simulação & Mobs & Msimul & oobs & osimul & $\mathbf{R}_{\text {so }}$ & BIAS & RMSE & RMSE $_{U B}$ \\
\hline \multicolumn{9}{|c|}{ Fevereiro } \\
\hline ANT & 982,96 & 982,58 & 18,30 & 15,94 & 0,99 & $-0,38$ & 3,53 & 3,51 \\
\hline CTR & 974,06 & 970,06 & 17,26 & 18,22 & 0,98 & $-3,99$ & 5,50 & 3,79 \\
\hline ATF & 974,06 & 968,46 & 17,26 & 18,53 & 0,94 & $-5,60$ & 8,09 & 6,19 \\
\hline GEL & 974,06 & 970,18 & 17,26 & 18,19 & 0,98 & $-3,88$ & 5,34 & 3,67 \\
\hline G25 & 974,06 & 969,66 & 17,26 & 17,89 & 0,98 & $-4,40$ & 5,89 & 3,91 \\
\hline N01 & 974,06 & 970,26 & 17,26 & 17,10 & 0,98 & $-3,79$ & 5,18 & 3,52 \\
\hline N06 & 974,06 & 969,92 & 17,26 & 18,13 & 0,98 & $-4,14$ & 5,38 & 3,44 \\
\hline N12 & 974,06 & 969,80 & 17,26 & 18,38 & 0,98 & $-4,25$ & 5,44 & 3,40 \\
\hline \multirow[t]{2}{*}{ N24 } & 974,06 & 969,78 & 17,26 & 18,47 & 0,98 & $-4,27$ & 5,49 & 3,44 \\
\hline & & & & Julho & & & & \\
\hline ANT & 982,24 & 993,92 & 14,69 & 1,07 & $-0,30$ & 11,68 & 3,62 & 15,11 \\
\hline CTR & 975,05 & 965,00 & 10,35 & 13,56 & 0,88 & $-10,05$ & 11,94 & 6,45 \\
\hline ATF & 975,05 & 965,23 & 10,35 & 13,54 & 0,88 & $-9,82$ & 11,77 & 6,49 \\
\hline GEL & 975,05 & 966,79 & 10,35 & 12,82 & 0,92 & $-8,26$ & 9,78 & 5,23 \\
\hline G25 & 975,05 & 963,55 & 10,35 & 13,18 & 0,90 & $-11,51$ & 12,89 & 5,81 \\
\hline N01 & 975,05 & 973,13 & 10,35 & 11,68 & 0,88 & $-1,92$ & 5,69 & 5,35 \\
\hline N06 & 975,05 & 971,03 & 10,35 & 12,32 & 0,90 & $-4,02$ & 6,74 & 5,40 \\
\hline N12 & 975,05 & 969,61 & 10,35 & 12,71 & 0,90 & $-5,44$ & 7,83 & 5,62 \\
\hline N24 & 975,05 & 968,00 & 10,35 & 12,83 & 0,90 & $-7,06$ & 8,97 & 5,54 \\
\hline
\end{tabular}

Para a estação de Jubany (Tabela 3.3-8) os maiores valores de erro em fevereiro são observados na simulação ATF e os menores verificados em N01. No evento de julho o experimento ANT chama a atenção em virtude de seu valor de correlação negativo de $-30 \%$, indicando um comportamento oposto entre observação e simulação. Outros experimentos que não apresentam uma boa acurácia são o CTR e o G25, onde o BIAS e o RMSE são bastante elevados. Já a simulação N06 apresenta os menores erros para o caso de julho. As demais simulações obtiveram um bom desempenho. Todas as simulações de pressão para esta estação mostraram correlação superior a 88\% com valores de desvios bastante próximos.

Dentre todas as estações meteorológicas, Marambio (Tabela 3.3-9) no mês de julho foi aquela na qual os maiores valores de erros puderam ser vistos, da ordem de $20 \mathrm{hPa}$ nas simulações que não envolviam NDC, sendo G25 a pior delas. É interessante notar que apesar dos altos valores de erro quando comparada a N01, N06, N12 e N24, o experimentos GEL foi o que mostrou os menores valores entre as outras simulações. Em fevereiro a simulação que apresentou os maiores erros foi ATF e a com os menores foi N01, indicando uma boa qualidade das condições 
iniciais de pressão. Durante o caso de fevereiro a correlação é em torno de $99 \%$, enquanto que em julho é $77 \%$. Todas as simulações de fevereiro apresentaram um bom desempenho durante a passagem do ciclone. Por outro lado, nenhuma das simulações atendeu aos critérios de Pielke durante a passagem de julho, e muito disso por não preverem o aumento de pressão que ocorria após atingir os mínimos.

Tabela 3.3-9: Análise de skill para a pressão ao nível médio do mar para Marambio

\begin{tabular}{|c|c|c|c|c|c|c|c|c|}
\hline Simulação & Mobs & Msimul & oobs & osimul & $\mathbf{R}_{\text {so }}$ & BIAS & RMSE & RMSE $_{\mathrm{UB}}$ \\
\hline \multicolumn{9}{|c|}{ Fevereiro } \\
\hline ANT & 986,97 & 983,30 & 13,84 & 16,07 & 0,99 & $-3,67$ & 4,59 & 2,75 \\
\hline CTR & 976,94 & 971,70 & 15,69 & 18,83 & 0,99 & $-5,25$ & 6,34 & 3,56 \\
\hline ATF & 976,94 & 971,49 & 15,69 & 19,69 & 1,00 & $-5,45$ & 6,62 & 3,75 \\
\hline GEL & 976,94 & 971,80 & 15,69 & 18,69 & 1,00 & $-5,14$ & 6,23 & 3,52 \\
\hline G25 & 976,94 & 971,30 & 15,69 & 18,25 & 0,99 & $-5,65$ & 6,46 & 3,14 \\
\hline N01 & 976,94 & 973,05 & 15,69 & 17,13 & 1,00 & $-3,89$ & 4,31 & 1,85 \\
\hline N06 & 976,94 & 972,22 & 15,69 & 18,19 & 1,00 & $-4,73$ & 5,48 & 2,77 \\
\hline N12 & 976,94 & 971,94 & 15,69 & 18,51 & 1,00 & $-5,00$ & 5,85 & 3,04 \\
\hline N24 & 976,94 & 971,91 & 15,69 & 18,58 & 1,00 & $-5,03$ & 5,94 & 3,16 \\
\hline \multicolumn{9}{|c|}{ Julho } \\
\hline ANT & 982,61 & 972,29 & 11,04 & 15,64 & 0,87 & $-10,32$ & 13,01 & 7,92 \\
\hline CTR & 979,60 & 959,62 & 7,68 & 13,10 & 0,50 & $-19,98$ & 22,88 & 11,15 \\
\hline ATF & 979,60 & 959,82 & 7,68 & 13,33 & 0,53 & $-19,78$ & 22,70 & 11,14 \\
\hline GEL & 979,60 & 968,18 & 7,68 & 10,12 & 0,86 & $-11,42$ & 12,52 & 5,14 \\
\hline G25 & 979,60 & 959,27 & 7,68 & 11,82 & 0,48 & $-20,33$ & 22,83 & 10,39 \\
\hline N01 & 979,60 & 975,98 & 7,68 & 9,37 & 0,97 & $-3,62$ & 4,42 & 2,54 \\
\hline N06 & 979,60 & 972,25 & 7,68 & 10,18 & 0,95 & $-7,35$ & 8,26 & 3,76 \\
\hline N12 & 979,60 & 970,25 & 7,68 & 10,76 & 0,93 & $-9,35$ & 10,41 & 4,58 \\
\hline N24 & 979,60 & 967,30 & 7,68 & 10,74 & 0,86 & $-12,30$ & 13,52 & 5,61 \\
\hline
\end{tabular}

Para Pratt (tabela 3.3-10) as médias das simulações foram cerca de $3 \mathrm{hPa}$ mais baixas que as médias das observações. Os maiores erros ficaram por conta do experimento G25 e os menores foram de N01, com destaque para GEL que dentre as que não possuem NDC apresentou os menores valores. Em todas as simulações a correlação é de aproximadamente $98 \%$. Todas as simulações obtiveram um bom desempenho, visando os critérios de Pielke. 
Tabela 3.3-10: Análise de skill para a pressão ao nível médio do mar Pratt

\begin{tabular}{|lllllllll|}
\hline Simulação & Mobs & Msimul & oobs & osimul & R $_{\text {so }}$ & BIAS & RMSE & RMSEUB \\
\hline \hline & & & & Fevereiro & & & & \\
ANT & 981,62 & 982,34 & 18,83 & 15,78 & 1,00 & 0,71 & 3,35 & 3,28 \\
CTR & 973,45 & 970,85 & 17,53 & 18,11 & 0,99 & $-2,61$ & 4,01 & 3,05 \\
ATF & 973,45 & 970,05 & 17,53 & 18,93 & 0,99 & $-3,41$ & 4,46 & 2,88 \\
GEL & 973,45 & 971,07 & 17,53 & 18,04 & 0,99 & $-2,39$ & 3,75 & 2,89 \\
G25 & 973,45 & 970,35 & 17,53 & 17,86 & 0,98 & $-3,10$ & 4,51 & 3,28 \\
N01 & 973,45 & 971,39 & 17,53 & 16,86 & 1,00 & $-2,07$ & 2,56 & 1,51 \\
N06 & 973,45 & 971,00 & 17,53 & 17,83 & 1,00 & $-2,46$ & 2,74 & 1,21 \\
N12 & 973,45 & 970,81 & 17,53 & 18,12 & 1,00 & $-2,65$ & 3,06 & 1,54 \\
N24 & 973,45 & 970,73 & 17,53 & 18,22 & 0,99 & $-2,72$ & 3,39 & 2,02 \\
\hline
\end{tabular}

Analisando a tabela 3.3-11 para Frei e a tabela 3.3-12 que mostra os valores para O’higgins, observa-se que ambas satisfizeram os critérios de Pielke. O BIAS é sempre negativo e não superior a $4,5 \mathrm{hPa}$ considerando as duas estações. Os maiores erros são observados na simulação G25, os menores ficaram com N01 e N06. Os valores de correlação são maiores a 97\%.

Tabela 3.3-11: Análise de skill para a pressão ao nível médio do mar para Frei

\begin{tabular}{|c|c|c|c|c|c|c|c|c|}
\hline Simulação & Mobs & Msimul & oobs & osimul & $\mathbf{R}_{\text {so }}$ & BIAS & RMSE & RMSE $_{\mathrm{UB}}$ \\
\hline \multicolumn{9}{|c|}{ Fevereiro } \\
\hline ANT & 980,02 & 982,08 & 19,70 & 16,24 & 1,00 & 2,06 & 4,17 & 3,63 \\
\hline CTR & 972,25 & 970,51 & 17,80 & 18,46 & 0,98 & $-1,74$ & 4,24 & 3,87 \\
\hline ATF & 972,25 & 969,68 & 17,80 & 19,25 & 0,98 & $-2,57$ & 4,49 & 3,69 \\
\hline GEL & 972,25 & 970,66 & 17,80 & 18,46 & 0,98 & $-1,59$ & 4,10 & 3,78 \\
\hline G25 & 972,25 & 970,14 & 17,80 & 18,23 & 0,97 & $-2,11$ & 4,71 & 4,21 \\
\hline N01 & 972,25 & 970,69 & 17,80 & 17,55 & 0,99 & $-1,55$ & 2,66 & 2,16 \\
\hline N06 & 972,25 & 970,43 & 17,80 & 18,46 & 0,99 & $-1,82$ & 2,86 & 2,20 \\
\hline N12 & 972,25 & 970,30 & 17,80 & 18,69 & 0,99 & $-1,95$ & 3,13 & 2,45 \\
\hline N24 & 972,25 & 970,26 & 17,80 & 18,73 & 0,99 & $-1,98$ & 3,51 & 2,90 \\
\hline
\end{tabular}

Tabela 3.3-12: Análise de skill para a pressão ao nível médio do mar para O’higgins

\begin{tabular}{|c|c|c|c|c|c|c|c|c|}
\hline Simulação & Mobs & Msimul & oobs & osimul & $\mathbf{R}_{\text {so }}$ & BIAS & RMSE & RMSE $_{U B}$ \\
\hline \multicolumn{9}{|c|}{ Fevereiro } \\
\hline ANT & 983,45 & 982,41 & 17,08 & 17,58 & 1,00 & $-1,05$ & 1,71 & 1,35 \\
\hline CTR & 974,79 & 971,24 & 17,41 & 19,53 & 0,99 & $-3,55$ & 4,59 & 2,92 \\
\hline ATF & 974,79 & 970,91 & 17,41 & 19,90 & 0,99 & $-3,87$ & 4,95 & 3,08 \\
\hline GEL & 974,79 & 971,38 & 17,41 & 19,51 & 0,99 & $-3,41$ & 4,43 & 2,83 \\
\hline G25 & 974,79 & 970,57 & 17,41 & 19,49 & 0,99 & $-4,22$ & 5,20 & 3,05 \\
\hline N01 & 974,79 & 972,31 & 17,41 & 17,79 & 1,00 & $-2,74$ & 2,74 & 1,18 \\
\hline N06 & 974,79 & 971,73 & 17,41 & 18,82 & 1,00 & $-3,05$ & 3,57 & 1,84 \\
\hline N12 & 974,79 & 971,48 & 17,41 & 19,19 & 1,00 & $-3,31$ & 3,94 & 2,13 \\
\hline N24 & 974,79 & 971,28 & 17,41 & 19,47 & 1,00 & $-3,51$ & 4,29 & 2,48 \\
\hline
\end{tabular}




\subsubsection{VENTO ZONAL}

Na EACF (tabela 3.3-13) é possível ver que tanto nos caso de fevereiro quanto no de julho a média das simulações foi maior que a média das observações, gerando assim BIAS positivos. O experimento GEL foi o que apresentou os maiores erros em fevereiro, já em julho os que mais erraram foram CTR, ATF e G25. Por outro lado o experimento G25 foi aquele que apresentou os menores erros e o que mais se enquadrou nas condições para "bom" desempenho propostas por Pielke no caso de fevereiro. Já durante o caso de inverno a simulação que se mostrou mais eficiente prever a componente zonal do vento foi a N12, que apresentou um coeficiente de correlação de cerca de $64 \%$.

Tabela 3.3-13: Análise de skill para a componente zonal do vento para EACF

\begin{tabular}{|c|c|c|c|c|c|c|c|c|}
\hline Simulação & Mobs & Msimul & oobs & osimul & $\mathbf{R}_{\text {so }}$ & BIAS & RMSE & RMSE $_{\text {UB }}$ \\
\hline \multicolumn{9}{|c|}{ Fevereiro } \\
\hline ANT & $-5,40$ & $-1,08$ & 5,33 & 4,57 & $-0,11$ & 4,32 & 8,42 & 7,23 \\
\hline CTR & $-3,44$ & $-0,71$ & 6,60 & 7,30 & 0,70 & 2,73 & 5,97 & 5,31 \\
\hline ATF & $-3,44$ & $-1,70$ & 6,60 & 7,74 & 0,79 & 1,75 & 5,02 & 4,71 \\
\hline GEL & $-3,44$ & $-0,62$ & 6,60 & 7,49 & 0,69 & 2,83 & 6,20 & 5,52 \\
\hline G25 & $-3,44$ & $-1,35$ & 6,60 & 6,80 & 0,70 & 2,09 & 5,54 & 5,13 \\
\hline N01 & $-3,44$ & $-1,81$ & 6,60 & 7,57 & 0,76 & 1,63 & 4,82 & 4,71 \\
\hline N06 & $-3,44$ & $-1,86$ & 6,60 & 7,75 & 0,75 & 1,59 & 5,31 & 5,07 \\
\hline N12 & $-3,44$ & $-1,64$ & 6,60 & 7,65 & 0,76 & 1,80 & 5,26 & 4,94 \\
\hline N24 & $-3,44$ & $-1,35$ & 6,60 & 7,49 & 0,75 & 2,09 & 5,42 & 5,00 \\
\hline \multicolumn{9}{|c|}{ Julho } \\
\hline ANT & 0,25 & 7,55 & 4,85 & 4,10 & 0,29 & 7,29 & 8,99 & 5,26 \\
\hline CTR & $-2,73$ & 8,03 & 5,48 & 5,27 & 0,29 & 10,76 & 12,56 & 6,49 \\
\hline ATF & $-2,73$ & 7,70 & 5,48 & 5,69 & 0,26 & 10,43 & 12,37 & 6,66 \\
\hline GEL & $-2,73$ & 5,12 & 5,48 & 4,40 & 0,61 & 7,85 & 9,00 & 4,41 \\
\hline G25 & $-2,73$ & 7,70 & 5,48 & 5,61 & 0,22 & 10,43 & 12,44 & 6,79 \\
\hline N01 & $-2,73$ & 1,38 & 5,48 & 6,29 & 0,57 & 4,11 & 6,79 & 5,40 \\
\hline N06 & $-2,73$ & 0,73 & 5,48 & 6,45 & 0,59 & 3,46 & 6,36 & 5,33 \\
\hline N12 & $-2,73$ & 1,21 & 5,48 & 6,47 & 0,64 & 3,94 & 6,41 & 5,05 \\
\hline N24 & $-2,73$ & 4,64 & 5,48 & 5,04 & 0,50 & 7,37 & 9,00 & 5,18 \\
\hline
\end{tabular}

Os maiores valores de erro em fevereiro são observados na série ATF, para a estação de Jubany (tabela 3.3-14). No evento de julho os experimentos CTR e G25 não apresentaram uma boa acurácia, onde os erros e o BIAS são bastante elevados. As simulações, apesar de não atenderem os critérios de Pielke, obtiveram um desempenho satisfatório no caso de julho, principalmente o N12. O experimento 
N06 foi aquele que apresentou o maior coeficiente de correlação, cerca de $69 \%$ em julho.

Tabela 3.3-14: Análise de skill para a componente zonal do vento para Jubany

\begin{tabular}{|c|c|c|c|c|c|c|c|c|}
\hline Simulação & Mobs & Msimul & oobs & $\sigma$ simul & $\mathbf{R}_{\text {so }}$ & BIAS & RMSE & RMSE $_{\text {UB }}$ \\
\hline \multicolumn{9}{|c|}{ Fevereiro } \\
\hline ANT & 1,25 & $-1,19$ & 3,00 & 3,87 & 0,09 & $-2,44$ & 4,62 & 3,14 \\
\hline CTR & 0,38 & $-0,79$ & 2,27 & 5,85 & 0,17 & $-1,17$ & 5,27 & 4,90 \\
\hline ATF & 0,38 & $-2,03$ & 2,27 & 6,23 & 0,22 & $-2,41$ & 5,94 & 4,75 \\
\hline GEL & 0,38 & $-0,41$ & 2,27 & 6,07 & 0,15 & $-0,79$ & 5,31 & 5,09 \\
\hline G25 & 0,38 & $-1,25$ & 2,27 & 6,42 & 0,18 & $-1,63$ & 5,63 & 5,01 \\
\hline N01 & 0,38 & $-1,78$ & 2,27 & 6,17 & 0,15 & $-2,16$ & 6,08 & 5,32 \\
\hline N06 & 0,38 & $-1,38$ & 2,27 & 6,20 & 0,15 & $-1,76$ & 5,89 & 5,30 \\
\hline N12 & 0,38 & $-1,29$ & 2,27 & 6,09 & 0,15 & $-1,67$ & 5,76 & 5,21 \\
\hline N24 & 0,38 & $-1,14$ & 2,27 & 6,04 & 0,14 & $-1,52$ & 5,64 & 5,14 \\
\hline \multicolumn{9}{|c|}{ Julho } \\
\hline ANT & 3,64 & 6,37 & 5,61 & 1,42 & $-0,41$ & 2,73 & 4,44 & 5,91 \\
\hline CTR & 1,58 & 7,18 & 4,58 & 4,70 & 0,07 & 5,60 & 8,37 & 6,07 \\
\hline ATF & 1,58 & 6,96 & 4,58 & 5,02 & 0,08 & 5,38 & 8,36 & 6,26 \\
\hline GEL & 1,58 & 4,44 & 4,58 & 4,30 & 0,55 & 2,86 & 5,07 & 3,96 \\
\hline G25 & 1,58 & 7,45 & 4,58 & 5,39 & 0,18 & 5,87 & 8,61 & 6,08 \\
\hline N01 & 1,58 & $-0,24$ & 4,58 & 6,12 & 0,69 & $-1,83$ & 4,64 & 4,34 \\
\hline N06 & 1,58 & $-0,51$ & 4,58 & 6,33 & 0,69 & $-2,09$ & 4,87 & 4,48 \\
\hline N12 & 1,58 & 0,64 & 4,58 & 5,95 & 0,60 & $-0,94$ & 4,77 & 4,72 \\
\hline N24 & 1,58 & 4,11 & 4,58 & 4,44 & 0,37 & 2,53 & 5,57 & 4,89 \\
\hline
\end{tabular}

A estação meteorológica de Marambio (Tabela 3.3-16) apresentou altos valores de erros, tanto para o mês de julho quanto para fevereiro. No caso de fevereiro o experimento G25 foi quem apresentou os maiores valores de erros. Outro fato que chama a atenção são os valores negativos de correlação encontrados nas simulações G25 e ANT para fevereiro e CTR, ATF, GEL, G25 e N01 em julho, indicando tendências opostas entre tais simulações e as observações. Para Marambio nenhuma das simulações obteve bom desempenho. Mas N12 no verão e N06 no inverno foram aquelas que apresentaram os menores erros. De modo geral a intensidade do vento foi subestimada nesta estação. 
Tabela 3.3-15: de skill para a componente zonal do vento para Marambio

\begin{tabular}{|c|c|c|c|c|c|c|c|c|}
\hline Simulação & Mobs & Msimul & oobs & $\sigma$ simul & $\mathbf{R}_{\text {so }}$ & BIAS & RMSE & RMSE \\
\hline \multicolumn{9}{|c|}{ Fevereiro } \\
\hline ANT & 1,37 & $-2,81$ & 2,52 & 7,26 & $-0,16$ & $-4,18$ & 7,62 & 5,38 \\
\hline CTR & 1,12 & 1,46 & 2,64 & 9,91 & 0,02 & 0,34 & 9,65 & 9,67 \\
\hline ATF & 1,12 & 0,76 & 2,64 & 9,99 & 0,05 & $-0,36$ & 9,64 & 9,61 \\
\hline GEL & 1,12 & 1,32 & 2,64 & 9,14 & 0,02 & 0,20 & 8,90 & 8,91 \\
\hline G25 & 1,12 & 3,02 & 2,64 & 11,19 & $-0,01$ & 1,90 & 11,10 & 11,02 \\
\hline N01 & 1,12 & 0,28 & 2,64 & 9,11 & 0,19 & $-0,84$ & 8,34 & 8,23 \\
\hline N06 & 1,12 & $-0,06$ & 2,64 & 9,83 & 0,19 & $-1,18$ & 8,91 & 8,73 \\
\hline N12 & 1,12 & $-0,04$ & 2,64 & 9,69 & 0,17 & $-1,16$ & 8,87 & 8,70 \\
\hline N24 & 1,12 & 0,57 & 2,64 & 9,80 & 0,12 & $-0,55$ & 9,11 & 9,06 \\
\hline \multicolumn{9}{|c|}{ Julho } \\
\hline ANT & 2,26 & 0,12 & 1,81 & 4,46 & 0,51 & $-2,14$ & 4,35 & 3,79 \\
\hline CTR & 2,16 & $-0,15$ & 1,79 & 7,46 & $-0,16$ & $-2,30$ & 8,11 & 7,77 \\
\hline ATF & 2,16 & 0,01 & 1,79 & 7,23 & $-0,08$ & $-2,15$ & 7,73 & 7,43 \\
\hline GEL & 2,16 & $-3,69$ & 1,79 & 3,79 & $-0,18$ & $-5,84$ & 7,30 & 4,38 \\
\hline G25 & 2,16 & 0,11 & 1,79 & 1,79 & $-0,19$ & $-2,05$ & 8,75 & 8,51 \\
\hline N01 & 2,16 & 3,72 & 1,79 & 4,03 & $-0,18$ & 1,57 & 4,86 & 4,60 \\
\hline N06 & 2,16 & $-0,15$ & 1,79 & 4,11 & 0,04 & $-2,30$ & 4,90 & 4,33 \\
\hline N12 & 2,16 & $-1,86$ & 1,79 & 3,37 & 0,23 & $-4,02$ & 5,25 & 3,37 \\
\hline N24 & 2,16 & $-4,78$ & 1,79 & 4,59 & 0,30 & $-6,93$ & 8,17 & 4,32 \\
\hline
\end{tabular}

Tabela 3.3-16: Análise de skill para a componente zonal do vento para Pratt

\begin{tabular}{|c|c|c|c|c|c|c|c|c|}
\hline Simulação & Mobs & Msimul & oobs & osimul & $\mathbf{R}_{\text {so }}$ & BIAS & RMSE & RMSE $_{\text {UB }}$ \\
\hline \multicolumn{9}{|c|}{ Fevereiro } \\
\hline ANT & $-9,27$ & $-1,51$ & 6,69 & 4,84 & $-0,40$ & 7,76 & 12,12 & 9,31 \\
\hline CTR & $-7,07$ & $-0,73$ & 9,09 & 5,98 & 0,62 & 6,33 & 9,33 & 6,86 \\
\hline ATF & $-7,07$ & $-1,82$ & 9,09 & 6,99 & 0,73 & 5,24 & 7,95 & 5,98 \\
\hline GEL & $-7,07$ & $-0,15$ & 9,09 & 6,50 & 0,62 & 6,91 & 9,75 & 6,88 \\
\hline G25 & $-7,07$ & $-0,90$ & 9,09 & 5,41 & 0,72 & 6,16 & 8,73 & 6,19 \\
\hline N01 & $-7,07$ & $-2,14$ & 9,09 & 6,78 & 0,67 & 4,93 & 8,15 & 6,49 \\
\hline N06 & $-7,07$ & $-1,75$ & 9,09 & 7,16 & 0,68 & 5,32 & 8,40 & 6,50 \\
\hline N12 & $-7,07$ & $-1,67$ & 9,09 & 7,23 & 0,70 & 5,40 & 8,28 & 6,28 \\
\hline N24 & $-7,07$ & $-1,43$ & 9,09 & 6,72 & 0,68 & 5,64 & 8,57 & 6,45 \\
\hline
\end{tabular}

Para Pratt (Tabela 3.3-16) as simulações ATF, G25, N01, N06, N12 e N24 apresentaram valores de erros menores que o desvio padrão das observações. Por outro lado, aquela que melhor atendeu o primeiro critério de Pielke foi a ATF, pois o desvio padrão das simulações foi mais próximo do desvio padrão das simulações. 0 
experimento G25 foi quem obteve o melhor coeficiente de correlação, em torno de $71 \%$. A simulação que obteve os maiores erros foi GEL.

Analisando a tabela 3.3-17 para Frei nota-se que nenhuma das simulações atendeu ao primeiro critério de Pielke, pois o desvio padrão das observações é muito maior do que o das simulações, evidenciando a grande variação da série. $A$ simulação G25 obteve o pior desempenho em prever o comportamento do vento zonal. Já os experimentos N01 e N06 apresentaram as maiores correlações com as observações, próximo dos 59\%, e, também, os menores erros.

Tabela 3.3-17: Análise de skill para a componente zonal do vento para Frei

\begin{tabular}{|c|c|c|c|c|c|c|c|c|}
\hline Simulação & Mobs & Msimul & oobs & osimul & $\mathbf{R}_{\text {so }}$ & BIAS & RMSE & RMSE $_{U B}$ \\
\hline \multicolumn{9}{|c|}{ Fevereiro } \\
\hline ANT & $-10,85$ & $-1,41$ & 11,38 & 4,01 & $-0,40$ & 9,44 & 16,04 & 12,97 \\
\hline CTR & $-5,27$ & $-1,41$ & 17,22 & 6,01 & 0,51 & 3,86 & 15,00 & 14,49 \\
\hline ATF & $-5,27$ & $-1,70$ & 17,22 & 5,89 & 0,56 & 3,57 & 14,63 & 14,19 \\
\hline GEL & $-5,27$ & $-0,56$ & 17,22 & 6,97 & 0,49 & 4,71 & 15,21 & 14,46 \\
\hline G25 & $-5,27$ & $-1,57$ & 17,22 & 4,69 & 0,32 & 3,70 & 16,13 & 15,70 \\
\hline N01 & $-5,27$ & $-2,04$ & 17,22 & 6,88 & 0,59 & 3,23 & 14,09 & 13,72 \\
\hline N06 & $-5,27$ & $-1,62$ & 17,22 & 6,54 & 0,59 & 3,65 & 14,30 & 13,83 \\
\hline N12 & $-5,27$ & $-1,69$ & 17,22 & 6,33 & 0,57 & 3,61 & 14,47 & 14,02 \\
\hline N24 & $-5,27$ & $-1,60$ & 17,22 & 6,22 & 0,52 & 3,67 & 14,83 & 14,36 \\
\hline
\end{tabular}

Tabela 3.3-18: Análise de skill para a componente zonal do vento para O’higgins

\begin{tabular}{|lcccccccc|}
\hline Simulação & Mobs & Msimul & oobs & osimul & R $_{\text {so }}$ & BIAS & RMSE & RMSEUB \\
\hline \hline & & & & Fevereiro & & & & \\
ANT & $-5,99$ & $-0,06$ & 6,61 & 5,61 & $-0,08$ & 5,92 & 10,47 & 8,64 \\
CTR & $-2,92$ & 0,25 & 7,50 & 5,42 & 0,32 & 3,17 & 8,08 & 7,44 \\
ATF & $-2,92$ & 0,30 & 7,50 & 5,74 & 0,28 & 3,22 & 8,37 & 7,73 \\
GEL & $-2,92$ & $-0,01$ & 7,50 & 5,27 & 0,29 & 2,91 & 8,08 & 7,54 \\
G25 & $-2,92$ & 0,78 & 7,50 & 5,47 & 0,27 & 3,70 & 8,53 & 7,68 \\
N01 & $-2,92$ & 0,26 & 7,50 & 6,34 & 0,32 & 3,18 & 8,43 & 7,81 \\
N06 & $-2,92$ & 0,47 & 7,50 & 6,27 & 0,29 & 3,39 & 8,66 & 7,97 \\
N12 & $-2,92$ & 0,26 & 7,50 & 5,95 & 0,28 & 3,18 & 8,45 & 7,83 \\
N24 & $-2,92$ & 0,05 & 7,50 & 5,51 & 0,29 & 2,97 & 8,17 & 7,61 \\
\hline
\end{tabular}

Analisando os resultados estatísticos encontrados para a estação de O'higgins (Tabela 3.3-18), observa-se que o vento zonal foi superestimado em todas as simulações. O experimento N06 apresentou os maiores valores de erros. Em contrapartida, N24 e GEL apresentaram os menores erros. Apesar disso, nenhuma das simulações obteve "bom" desempenho, já que o RMSE foi maior que o desvio 
padrão das observações. Interessante observar o valor negativo de correlação encontrado para a série ANT, indicando o desacordo entre observação e simulação.

\subsubsection{VENTO MERIDIONAL}

Analisando a tabela 3.3-19, que apresenta os resultados estatísticos do vento meridional para a EACF, é possível observar que os erros foram menores para o evento de inverno do que para o caso de verão, isto devido à maior variabilidade desta componente durante fevereiro, onde os valores de desvio padrão são, também, mais elevados. Em julho a série GEL foi aquela que apresentou os maiores erros, já em julho isto ficou com o experimento N01. Para ambos os eventos, nenhuma das simulações teve boa acurácia em prever o comportamento do veto meridional. Os menores valores de erros ocorreram nos experimentos N12 e N24, para fevereiro e julho, respectivamente. No evento de julho todas as simulações apresentaram tendência oposta às observações. A correlação da maioria das simulações é da ordem de $65 \%$.

Tabela 3.3-19: Análise de skill para a componente meridional do vento para EACF

\begin{tabular}{|c|c|c|c|c|c|c|c|c|}
\hline Simulação & Mobs & Msimul & oobs & $\sigma$ simul & $\mathbf{R}_{\text {so }}$ & BIAS & RMSE & RMSE $_{U B}$ \\
\hline \multicolumn{9}{|c|}{ Fevereiro } \\
\hline ANT & $-0,68$ & 0,80 & 3,20 & 6,00 & $-0,65$ & 1,48 & 8,39 & 8,26 \\
\hline CTR & 0,01 & $-0,03$ & 4,56 & 6,30 & $-0,41$ & $-0,04$ & 8,97 & 8,97 \\
\hline ATF & 0,01 & $-0,46$ & 4,56 & 5,23 & 0,00 & $-0,45$ & 6,82 & 6,80 \\
\hline GEL & 0,01 & 0,04 & 4,56 & 6,39 & $-0,37$ & 0,04 & 8,93 & 8,93 \\
\hline G25 & 0,01 & 0,12 & 4,56 & 6,46 & $-0,34$ & 0,11 & 8,90 & 8,90 \\
\hline N01 & 0,01 & 0,89 & 4,56 & 2,62 & $-0,23$ & 0,88 & 7,82 & 7,77 \\
\hline N06 & 0,01 & 0,37 & 4,56 & 5,06 & $-0,13$ & 0,36 & 7,11 & 7,10 \\
\hline N12 & 0,01 & 0,06 & 4,56 & 4,90 & $-0,10$ & 0,05 & 6,89 & 6,89 \\
\hline N24 & 0,01 & $-0,13$ & 4,56 & 5,26 & $-0,15$ & $-0,13$ & 7,31 & 7,30 \\
\hline \multicolumn{9}{|c|}{ Julho } \\
\hline ANT & $-0,49$ & $-2,05$ & 3,07 & 4,52 & 0,27 & $-1,56$ & 4,90 & 4,65 \\
\hline CTR & 0,17 & $-2,63$ & 3,81 & 6,00 & 0,67 & $-2,80$ & 5,19 & 4,37 \\
\hline ATF & 0,17 & $-2,18$ & 3,81 & 6,42 & 0,68 & $-2,35$ & 5,19 & 4,63 \\
\hline GEL & 0,17 & $-2,31$ & 3,81 & 6,26 & 0,70 & $-2,48$ & 5,05 & 4,40 \\
\hline G25 & 0,17 & $-2,32$ & 3,81 & 6,62 & 0,69 & $-2,49$ & 5,37 & 4,76 \\
\hline N01 & 0,17 & 1,39 & 3,81 & 6,96 & 0,64 & 1,22 & 5,43 & 5,29 \\
\hline N06 & 0,17 & 0,82 & 3,81 & 7,25 & 0,65 & 0,65 & 5,52 & 5,48 \\
\hline N12 & 0,17 & $-0,35$ & 3,81 & 6,81 & 0,68 & $-0,52$ & 4,99 & 4,96 \\
\hline N24 & 0,17 & $-1,52$ & 3,81 & 5,93 & 0,69 & $-1,69$ & 4,53 & 4,21 \\
\hline
\end{tabular}


Tabela 3.3-20: Análise de skill para a componente meridional do vento para Jubany

\begin{tabular}{|c|c|c|c|c|c|c|c|c|}
\hline Simulação & Mobs & Msimul & oobs & osimul & $\mathbf{R}_{\text {so }}$ & BIAS & RMSE & RMSE $_{\mathrm{UB}}$ \\
\hline \multicolumn{9}{|c|}{ Fevereiro } \\
\hline ANT & $-7,65$ & 0,62 & 4,81 & 4,65 & 0,66 & 8,26 & 7,43 & 3,30 \\
\hline CTR & $-2,12$ & 0,04 & 8,42 & 5,93 & 0,09 & 2,16 & 9,50 & 9,18 \\
\hline ATF & $-2,12$ & 0,84 & 8,42 & 5,52 & 0,39 & 2,96 & 7,94 & 7,22 \\
\hline GEL & $-2,12$ & 0,37 & 8,42 & 5,55 & 0,15 & 2,49 & 9,11 & 8,69 \\
\hline G25 & $-2,12$ & 0,87 & 8,42 & 5,89 & 0,12 & 2,99 & 9,54 & 8,99 \\
\hline N01 & $-2,12$ & 1,24 & 8,42 & 5,51 & 0,37 & 3,36 & 8,36 & 7,56 \\
\hline N06 & $-2,12$ & 0,83 & 8,42 & 4,90 & 0,41 & 2,95 & 7,84 & 7,19 \\
\hline N12 & $-2,12$ & 0,52 & 8,42 & 4,83 & 0,35 & 2,64 & 7,99 & 7,48 \\
\hline N24 & $-2,12$ & 0,24 & 8,42 & 5,07 & 0,26 & 2,36 & 8,39 & 7,99 \\
\hline \multicolumn{9}{|c|}{ Julho } \\
\hline ANT & 1,20 & $-1,36$ & 4,60 & 1,97 & $-0,58$ & $-2,56$ & 9,78 & 7,66 \\
\hline CTR & $-1,32$ & $-2,34$ & 2,08 & 5,26 & 0,00 & $-1,02$ & 5,35 & 5,19 \\
\hline ATF & $-1,32$ & $-1,95$ & 2,08 & 5,61 & 0,05 & $-0,63$ & 5,48 & 5,40 \\
\hline GEL & $-1,32$ & $-1,94$ & 2,08 & 5,57 & $-0,24$ & $-0,62$ & 5,67 & 5,58 \\
\hline G25 & $-1,32$ & $-1,77$ & 2,08 & 5,81 & $-0,04$ & $-0,45$ & 5,71 & 5,66 \\
\hline N01 & $-1,32$ & 1,59 & 2,08 & 5,91 & $-0,21$ & 2,91 & 6,85 & 6,36 \\
\hline N06 & $-1,32$ & 0,92 & 2,08 & 6,13 & $-0,20$ & 2,24 & 6,74 & 6,49 \\
\hline N12 & $-1,32$ & $-0,14$ & 2,08 & 5,73 & $-0,14$ & 1,18 & 5,96 & 5,92 \\
\hline N24 & $-1,32$ & $-1,35$ & 2,08 & 4,89 & $-0,21$ & $-0,03$ & 5,32 & 5,32 \\
\hline
\end{tabular}

Em Jubany (Tabela 3.3-20) o primeiro critério de Pielke não foi atendido em nenhuma das simulações para o caso de fevereiro, exceto ANT. Já no caso de julho o RMSE foi maior que o desvio padrão em todas as simulações, não obtendo, assim, um bom desempenho. Em fevereiro os maiores erros são visíveis em G25 e o experimento que obteve o melhor desempenho foi N06, sendo este que este obteve uma correlação de $41 \%$ com as observações. Já no caso de julho, os menores erros foram encontrados para N12 e os maiores em N01 e ANT. Além disso, no caso de julho a diversos experimentos mostraram tendência oposta às observações, evidente pelos valores negativos de correlação.

Em Marambio, (tabela 3.3-21) para a passagem do ciclone de fevereiro, excetuando os experimentos ANT e CTR, todos os demais apresentaram bom desempenho em simular a componente meridional do vento, sendo que 0 experimento GEL foi quem mais se adequou aos critérios de Pielke. A simulação CTR foi a que apresentou os maiores valores de erros. Por outro lado, no caso de julho todas as simulações apresentaram tendência oposta às observações. Além disso, em Marambio foram encontrados os maiores valores de erros dentre as três estações (EACF, Jubany e Marambio). Em julho, apesar de nenhum dos 
experimentos obterem bom desempenho, a simulação N06, foi a que se saiu melhor. Já CTR, ATF e G25 foram as que se saíram pior e mostraram os maiores erros.

Tabela 3.3-21: Análise de skill para a componente meridional do vento para Marambio

\begin{tabular}{|c|c|c|c|c|c|c|c|c|}
\hline Simulação & Mobs & Msimul & Gobs & osimul & $\mathbf{R}_{\text {so }}$ & BIAS & RMSE & RMSE $_{U B}$ \\
\hline \multicolumn{9}{|c|}{ Fevereiro } \\
\hline ANT & $-2,93$ & 0,71 & 9,88 & 7,58 & 0,49 & 3,63 & 8,93 & 8,51 \\
\hline CTR & $-3,32$ & 1,24 & 7,55 & 7,06 & 0,76 & 4,56 & 6,57 & 4,91 \\
\hline ATF & $-3,32$ & 0,77 & 7,55 & 6,60 & 0,78 & 4,10 & 6,13 & 4,65 \\
\hline GEL & $-3,32$ & 1,38 & 7,55 & 6,82 & 0,78 & 4,70 & 6,47 & 4,67 \\
\hline G25 & $-3,32$ & 0,53 & 7,55 & 6,61 & 0,79 & 3,89 & 5,83 & 4,48 \\
\hline N01 & $-3,32$ & 0,60 & 7,55 & 6,33 & 0,71 & 3,92 & 6,43 & 5,21 \\
\hline N06 & $-3,32$ & 1,42 & 7,55 & 6,74 & 0,79 & 4,75 & 6,42 & 4,56 \\
\hline N12 & $-3,32$ & 1,25 & 7,55 & 6,71 & 0,79 & 4,57 & 6,25 & 4,51 \\
\hline N24 & $-3,32$ & 1,43 & 7,55 & 6,92 & 0,78 & 4,75 & 6,45 & 4,62 \\
\hline \multicolumn{9}{|c|}{ Julho } \\
\hline ANT & 6,21 & 1,26 & 4,96 & 4,35 & $-0,34$ & $-4,95$ & 8,98 & 7,49 \\
\hline CTR & 5,92 & 2,81 & 4,91 & 8,19 & $-0,61$ & $-3,11$ & 12,01 & 11,60 \\
\hline ATF & 5,92 & 3,16 & 4,91 & 7,82 & $-0,62$ & $-2,76$ & 11,63 & 11,30 \\
\hline GEL & 5,92 & 5,14 & 4,91 & 5,24 & $-0,77$ & $-0,78$ & 9,38 & 9,35 \\
\hline G25 & 5,92 & 2,87 & 4,91 & 7,86 & $-0,74$ & $-3,05$ & 12,11 & 11,72 \\
\hline N01 & 5,92 & 5,05 & 4,91 & 4,22 & $-0,65$ & $-0,88$ & 8,18 & 8,13 \\
\hline N06 & 5,92 & 5,40 & 4,91 & 4,74 & $-0,64$ & $-0,52$ & 8,58 & 8,57 \\
\hline N12 & 5,92 & 4,62 & 4,91 & 5,36 & $-0,66$ & $-1,30$ & 9,25 & 9,16 \\
\hline N24 & 5,92 & 3,82 & 4,91 & 5,69 & $-0,71$ & $-2,11$ & 9,85 & 9,62 \\
\hline
\end{tabular}

Tabela 3.3-22: Análise de skill para a componente meridional do vento para Pratt

\begin{tabular}{|c|c|c|c|c|c|c|c|c|}
\hline Simulação & Mobs & Msimul & oobs & $\sigma$ osimul & $\mathbf{R}_{\text {so }}$ & BIAS & RMSE & RMSE $_{\text {UB }}$ \\
\hline \multicolumn{9}{|c|}{ Fevereiro } \\
\hline ANT & 1,64 & 0,20 & 7,32 & 4,90 & 0,44 & $-1,44$ & 6,65 & 6,50 \\
\hline CTR & 2,58 & 1,15 & 7,01 & 7,12 & 0,35 & $-1,43$ & 7,89 & 7,76 \\
\hline ATF & 2,58 & 1,82 & 7,01 & 6,85 & 0,47 & $-0,76$ & 6,91 & 6,87 \\
\hline GEL & 2,58 & 1,98 & 7,01 & 6,97 & 0,29 & $-0,60$ & 8,05 & 8,03 \\
\hline G25 & 2,58 & 1,96 & 7,01 & 5,95 & 0,43 & $-0,62$ & 6,71 & 6,68 \\
\hline N01 & 2,58 & 3,36 & 7,01 & 7,56 & 0,46 & 0,77 & 7,35 & 7,31 \\
\hline N06 & 2,58 & 3,06 & 7,01 & 7,11 & 0,49 & 0,48 & 6,90 & 6,88 \\
\hline N12 & 2,58 & 2,75 & 7,01 & 6,91 & 0,49 & 0,17 & 6,78 & 6,78 \\
\hline N24 & 2,58 & 2,10 & 7,01 & 6,88 & 0,48 & $-0,49$ & 6,85 & 6,84 \\
\hline
\end{tabular}

Em Pratt (tabela 3.3-22) os experimentos com bom desempenho na previsão componente meridional foram N06, N012 e N24. Os maiores erros ficaram com a simulação GEL, que apresentou correlação de apenas 28\%. Já em Frei (tabela 3.323) a simulação que ficou mais distante das observações foi GEL com RMSE e 
RMSE $_{U B}$ de $11,66 \mathrm{~m} / \mathrm{s}$. Mesmo com todos os experimentos apresentando erros atendendo os critérios de Pielke, o modelo não obteve bom desempenho, já que os desvios padrão de simulação foram muito menores que os das observações.

Tabela 3.3-23: Análise de skill para componente meridional do vento para Frei

\begin{tabular}{|c|c|c|c|c|c|c|c|c|}
\hline Simulação & Mobs & Msimul & oobs & osimul & $\mathbf{R}_{\text {so }}$ & BIAS & RMSE & RMSE $_{\text {UB }}$ \\
\hline \multicolumn{9}{|c|}{ Fevereiro } \\
\hline ANT & 0,89 & 0,52 & 12,01 & 5,27 & 0,47 & $-0,37$ & 10,23 & 10,22 \\
\hline CTR & 1,24 & 0,91 & 13,35 & 7,29 & 0,41 & $-0,32$ & 11,83 & 11,82 \\
\hline ATF & 1,24 & 0,86 & 13,35 & 6,29 & 0,53 & $-0,37$ & 10,94 & 10,93 \\
\hline GEL & 1,24 & 1,34 & 13,35 & 6,90 & 0,43 & 0,11 & 11,66 & 11,66 \\
\hline G25 & 1,24 & 1,37 & 13,35 & 6,40 & 0,44 & 0,13 & 11,51 & 11,51 \\
\hline N01 & 1,24 & 1,83 & 13,35 & 6,60 & 0,60 & 0,60 & 10,34 & 10,32 \\
\hline N06 & 1,24 & 1,71 & 13,35 & 6,10 & 0,64 & 0,48 & 10,17 & 10,16 \\
\hline N12 & 1,24 & 1,37 & 13,35 & 6,14 & 0,64 & 0,14 & 10,16 & 10,16 \\
\hline N24 & 1,24 & 1,04 & 13,35 & 6,33 & 0,58 & $-0,20$ & 10,52 & 10,52 \\
\hline
\end{tabular}

$\mathrm{Na}$ estação meteorológica de O’higgins (Tabela 3.3-24) nenhuma das simulações apresentou um bom desempenho, exceto ANT. Os maiores erros podem ser notados no experimento GEL. Quase todas as simulações apresentaram coeficiente de correlação negativo. Além disso, em todos os experimentos a velocidade do vento meridional foi subestimada.

Tabela 3.3-24: Análise de skill para componente meridional do vento para O’higgins

\begin{tabular}{|lcccccccc|}
\hline Simulação & Mobs & Msimul & oobs & osimul & R $_{\text {so }}$ & BIAS & RMSE & RMSEUB \\
\hline \hline & & & & Fevereiro & & & & \\
ANT & 4,11 & 2,37 & 9,89 & 7,61 & 0,71 & $-1,74$ & 6,89 & 6,67 \\
CTR & 6,87 & 4,40 & 11,16 & 7,92 & $-0,32$ & $-2,47$ & 15,18 & 14,98 \\
ATF & 6,87 & 4,69 & 11,16 & 7,24 & $-0,30$ & $-2,18$ & 14,61 & 14,45 \\
GEL & 6,87 & 3,31 & 11,16 & 8,26 & $-0,31$ & $-3,56$ & 15,60 & 15,19 \\
G25 & 6,87 & 5,23 & 11,16 & 8,29 & $-0,30$ & $-1,64$ & 15,25 & 15,16 \\
N01 & 6,87 & 3,98 & 11,16 & 7,39 & $-0,29$ & $-2,89$ & 14,79 & 14,50 \\
N06 & 6,87 & 3,80 & 11,16 & 7,88 & $-0,37$ & $-3,07$ & 15,55 & 15,25 \\
N12 & 6,87 & 3,80 & 11,16 & 7,78 & $-0,36$ & $-3,07$ & 15,42 & 15,11 \\
N24 & 6,87 & 4,13 & 11,16 & 7,97 & $-0,37$ & $-2,74$ & 15,54 & 15,30 \\
\hline
\end{tabular}




\section{Conclusões e sugestões}

O objetivo deste trabalho foi avaliar o desempenho do modelo numérico BRAMS durante a passagem de dois ciclones extratropicais pela região da Península Antártica. Isto foi realizado através de comparações das previsões numéricas do BRAMS com dados observados nas estações EACF, Jubany, Marambio, Pratt, Frei e O'higgins, todas localizadas na região da PA.

A partir da analise qualitativa das simulações pode-se observar que 0 desempenho do modelo BRAMS esteve altamente dependente das condições iniciais dadas pelas previsões do GFS, principalmente quando se trata de temperatura e ventos. Muitas vezes as condições iniciais não conduziam com o observado nas estações, acarretando em erros altíssimos na saída do BRAMS.

Por meio de uma análise qualitativa e de sensibilidade das simulações numéricas fornecidas pelo modelo regional, ficou claro o ótimo desempenho do BRAMS em prever as variações de pressão ao nível médio do mar.

O modelo demonstrou maior acurácia para o caso de fevereiro com correlações acima de 94\% e uma faixa de RMSE entre 2 e $6 \mathrm{hPa}$. A estação Marambio foi a que apresentou os maiores erros, passando de $6 \mathrm{hPa}$ em mais de uma das simulações. Já a estação de Pratt apresentou os menores RMSE e RMSE $E_{\text {UB }}$ e correlação acima de $98 \%$.

Durante o caso de julho, apesar do modelo ter representado adequadamente as variações de pressão, não previu um rápido aumento da pressão que ocorreu logo após a passagem do ciclone extratropical. Além disso, nas três estações avaliadas no caso de julho (EACF, Jubany e Marambio) o experimento com maior resolução horizontal (G25) foi quem apresentou os maiores erros. Já os maiores valores de erros foram verificados em Marambio, pois o BRAMS previu a formação de um vórtice ciclônico a sotavento da PA, que ajudou a manter a pressão mais baixa por mais tempo nesta estação, resultando em um RMSE de até $22 \mathrm{hPa}$ e a correlação de $48 \%$.

Em todas as estações registraram pequeno BIAS negativo que está pode estar associado à deficiência do modelo em representar adequadamente a topografia. 
Bromwich et al.(2004) encontrou um BIAS negativo de pressão em estações costeiras e relacionou à suavização da topografia, uma vez que o modelo numérico situa estas estação mais para o interior do que elas realmente estão.

Já com relação à temperatura do ar durante a passagem do sistema sinótico no mês de fevereiro o que se pode concluir é que o BRAMS não consegue prever adequadamente o comportamento variações de temperatura de forma adequada para a maioria das estações. Apesar disso, Jubany durante a passagem do sistema no mês de fevereiro apresentou skill satisfatório para quase todos os experimentos realizados, com valores baixos de erro e correlações entre 60-70\%.

No caso de julho ficou clara a deficiência do BRAMS em prever a temperatura do ar para a região costeira da Antártica. Nem mesmo o experimento GEL que possui gelo marinho conseguiu simular as bruscas quedas de temperatura que ocorreram após a passagem do ciclone extratropical pela região da PA. Isto em grande parte devido à baixa concentração ou ausência do gelo marinho, no BRAMS, onde as observações mostravam que ele estava presente. A ausência de gelo marinho nestas localidades contribui para a intensificação dos fluxos de calor sensível do oceano para atmosfera adjacente, resultando em um aumento da temperatura do ar.

Além disso, os experimentos realizados com o BRAMS, para todas as estações em ambos os casos, simularam temperaturas mais elevadas que aquelas registradas, resultando assim em um BIAS positivo de temperatura do ar. Os experimentos de fevereiro apresentaram um BIAS máximo de $2,63^{\circ} \mathrm{C}$, já a para as rodadas realizadas para o caso de julho o BIAS máximo verificado é de $22,28^{\circ} \mathrm{C}$. Além da cobertura de gelo, outro fator que pode ter contribuído para que as temperaturas simuladas pelo BRAMS fossem mais elevadas é a nebulosidade. Diversos modelos atmosféricos de globais e de mesoescala prevêem a fração de nuvens em excesso, o que acaba ajudando a deixar a superfície mais aquecida através de um aumento de radiação de onda longa descendente.

O modelo BRAMS, de forma geral, não obteve bom desempenho na simulação do vento, principalmente em relação às variações de direção. Em se tratando de do vento zonal o que se observou foi que o BRAMS, no caso de fevereiro, impõem um forte escoamento de leste antes da passagem do ciclone extratropical pela PA nas estações de Jubany e Marambio, que registravam vento zonal praticamente nulo, o que demonstra uma forte dependência das condições iniciais, uma vez que as 
previsões do GFS também mostravam este forte vento de leste. Já no caso de julho ficou muito claro que modelo simula intensos ventos de oeste logo após a passagem do sistema pela região, o que difere do observado na EACF e em Jubany. Já para Marambio, primeiro o modelo intensifica os ventos de leste e logo em seguida o vento zonal muda de direção. Com relação ao vento meridional o que se observou que tanto em fevereiro quanto em julho o modelo intensifica ou em algumas estações força um escoamento de sul durante e também após, no caso de julho, a passagem do ciclone pela PA. Os ventos previstos pelo BRMAS, de forma geral foram mais intensos que aqueles observados.

\section{Sugestões para Trabalhos Futuros}

- Melhorar a representatividade da cobertura de gelo Marinho;

- Utilização de dados topográficos mais refinados e, consequentemente, maior resolução de grades;

- Melhorar a parametrização da camada limite planetária e avaliar o comportamento do vento;

- Testar novas parametrizações para melhorar nebulosidade; 


\section{Referências bibliográficas}

ASTAPENKO, P.D. Atmospheric Processes in the High Latitudes of Southern Hemisphere. Section II of the IGY Programme (meteorology) $N^{\circ} 3$. Israel Program for Scientific Translations, Jerusalem, Oldourne Press, London, 286pp, 1964.

BOIASKI, N. T. Extremos intra-sazonais de temperatura na Península Antártica e mecanismos atmosféricos associados, 2007. Dissertação de mestrado, Departamento de Ciências Atmosféricas do Instituto de Astronomia, Geofísica e Ciências Atmosféricas da Universidade de São Paulo.

BROMWICH, D. H. Introduction to special section: synoptic and mesoscale weather system in the polar regions. Journal of Geophysics Research, v. 102, n. 13, p. 727- 14,028, 1997.

BROMWICH, D. H.; Parish, T. R. Meteorology of the Southern Hemisphere. In: Karoly, D. J ; Vincent, D. G. ed. Meteorology of the Antarctic. Boston: AMS, Cap. 4, p. 175-200, 1999.

BROMWICH, D.H.; CASSANA, J.J.; KLEIN, T.; HEINEMANN, G.; HINES, K.M.; STEFFEN, K. and BO,J.E., 2001: Mesoescale Modeling of katabatic winds over Greenland with the Polar MM5. Mon Wea. Rev., 129, 2290-2309.

BROMWICH D.H., MONAGHAN, A.J., MANNING, K.W., POWERS, J.G.; 2005: RealTime Forecasting for the Antarctic: An Evaluation of the Antarctic Mesoscale Prediction System (AMPS). Mon. Wea. Rev., 133, 579-603.

CARLETON, A. M.; FITCH, M. Synoptic aspects of Antarctic mesocyclones, Journal of Geophysical Research, v. 98, n.D7, p. 12, 997-13,018, jul. 1993.

CARPENEDO, C. B. Interações entre os ciclones extratropicais e a variabilidade extrema do gelo marinho nos mares de Bellingshausen-Amundsen e no mar de Weddell - Antártica. 2012. 181 f. Dissertação (Mestrado em Meteorologia) Instituto de Astronomia, Geofísica e Ciências Atmosféricas, Universidade de São Paulo, São Paulo, 2012.

CARRASCO, J. F.; BROMWICH, D. H. A study of mesoscale cyclone activity near the Antarctic peninsula. Serie Cientifica, INACH, n. 46, p.83-101,1996. 
CARRASCO, J.; BROMWICH, D.H.; LIU, Z. 1997. Mesoscale cyclone activity over Antarctica during 1991. Part 2: Near the Antarctic Peninsula. Journal of Geophysical Research, 102 (D12),.13939 - 13954.

CARVALHO L.M.V., GANDU, A.W., JONES C., FREITAS, E.D., SILVA DIAS, P.L., 2008: BRAMS simulation of extreme intraseasonal anomalies in the Antartic Peninsula. XV Congresso Brasileiro de Meteorologia. SBMET, São Paulo.

CLARK, T. L.; FARLEY, R. D. Severe downslope windstorm calculations in two three spatial dimensions using anelastic interactive grid nesting: A possible Mechanism for gustiness. J. Atmos. Sci., 41, 329-350, 1984.

CLARK, T. L; HALL, W. D. Multi-domain simulations of the time dependent NavierStokes equations: Benchmarck error analysis of some nesting procedures. J. Compt. Phys.

FREITAS, E. D. Circulações Locais em São Paulo e sua Influência Sobre a Dispersão de Poluentes, Ano de Obtenção: 2003. Tese de Doutorado. Departamento de Ciências Atmosféricas do Instituto de Astronomia, Geofísica e Ciências Atmosféricas da Universidade de São Paulo.

GUO, Z.; D. H. BROWMWICH, CASSANO, J.J.; 2003: Evaluation of Polar MM5 simulations of Antartic atmospheric circulations Mon Wea. Rev., 131,384-411.

KING, J.C.; TURNER, J. Antarctic meteorology and climatology. Cambridge: Atmospheric and Space Science Series, England, 1997. cap. 1, 4, 5 e 6.

MARTINS, T. R.; GANDU, A. W. ; CARVALHO, Leila Maria Véspoli de ; MOREIRA, D.S. ; SILVA DIAS, P. L. . Avaliação inicial de previsões operacionais de tempo por diversos modelos atmosféricos na Península Antártica. In: XVII Simpósio Brasileiro sobre pesquisa Antártica, 2009, São Paulo, v. 1. p. 44.

MESSINGER, C. J. G.; ARAKAWA, A. Numerical methods using in atmospheric models. GARP Publications Series. N¹7, WMO/ICSU Joint Organizing Committee, 64 pp, 1976.

MONAGHAN, A. J.; D. H. BROMWICH; H. WEI; A. M. CAYETTE; J. G. POWERS; Y. H. KUO; M. LAZZARA, 2003: Performance of weather forecast models on the rescue of Dr. Ronald Shemenski from South Pole in April 2001. Wea. Forecasting, 18, 142-160.

PIELKE, R. A. SR. Mesoescale Meteorological Modeling. Second Edition. International Geophysics Series, vol 78. Academic Press. 2002. 676p. 
SCHWERDTFEGER, W. 1984. Weather and Climate of the Antarctic. Developments in Atmospheric Sciences, 15. Amsterdam: Elsevier, 261p.

TRIPOLI, G.J., and W.R. COTTON, 1982: The Colorado State University threedimencional cloud/mesoscale model - 1982. Part I: General Theoretical framework and sensitivity experiments. J. de Rech. Atmos., 16, 185-220.

TURNER, J.; THOMAS, A. L.; THOMAS, J. P. A comparison of Arctic and Antarctic mesoscale vortices. Journal of Geophysical Research, v. 98, n. D7 p. 13, 019-13, 034, july, 1993.

WALKO, R.L., BAND, L.E., BARON, J., KITTEL, T.G.F, LAMMERS,R., ET AL.: Coupled atmosphere-biophysics-hydrology models for environmental modeling, J. Appl. Meteor., 39,932-944.

WALKO, R. L.; TREMBACK, C. J. Regional Atmopheric Modeling System (RAMS) version4.3/4.4 - Model Input Namelist Parameters, 2000. In http://www.atmet.com

WILKS, D. S. Statistical Methods in the Atmospheric Sciences. Second Edition. International Geophysics Series, vol 91. Academic Press, San Diego, 1995,467p. 